\title{
Anfípodos bentónicos (Amphilochidea y Senticaudata) en el centro norte de la plata- forma continental del Perú
}

\section{Benthic amphipods (Amphilochidea and Senticaudata) in the northern central peruvian conti- nental shelf}

\section{Analí Jiménez*, Robert Marquina, Luis Quipúzcoa}

Instituto del Mar del Perú. IMARPE. Dirección General de Investigaciones Oceanográficas y Cambio Climático, Laboratorio de Bentos Marino, Callao, Perú *Autor de correspondencia

Email Analí Jiménez: anali.jimenez.c@upch.pe; analijim@gmail.com

Email Robert Marquina: rmarquina@imarpe.gob.pe

Email Luis Quipúzcoa: Iquipuzcoa@imarpe.gob.pe

\section{Resumen}

En el presente trabajo se reportan las especies de anfípodos bentónicos de los subórdenes Amphilochidea y Senticaudata de la Plataforma Continental Centro Norte del Perú $\left(03^{\circ} 24^{\prime} \mathrm{S}-79^{\circ} 30^{\prime} \mathrm{W}\right.$ a $\left.09^{\circ} 00^{\prime} \mathrm{S}-81^{\circ} 30^{\prime} \mathrm{W}\right)$ colectadas durante la estación de otoño. A partir de 136 puntos de muestreo, distribuidas en entre 22 y 372 $\mathrm{m}$, se determinaron 28 taxa de anfípodos, pertenecientes a 15 familias; 14 especies consideradas como nuevos registros para el mar peruano. La familia Ampeliscidae fue la más diversa, con 11 especies. Se incluye información taxonómica descriptiva y distribución geográfica referenciada.

Palabras claves: anfípodos; plataforma continental; ecosistema de la corriente de Humboldt; biodiversidad; bentos.

\section{Abstract}

In this work, amphipod species of the suborder Amphilochidea and Senticaudata from the North-Central Continental Platform of Peru $\left(03^{\circ} 24^{\prime} \mathrm{S}-79^{\circ} 30^{\prime} \mathrm{W}\right.$ to $\left.09^{\circ} 00^{\prime} \mathrm{S}-81^{\circ} 30^{\prime} \mathrm{W}\right)$ are reported. 136 stations were sampled, range between 22 to $372 \mathrm{~m}$ in depth, all collections were during the autumn. We determined 28 species, belonging to 15 families. Ampeliscidae family was the most diverse with eleven (11) species. Of the total of species, 14 species are new records to Peruvian sea. Indeed, this research includes descriptive taxonomic information and referenced geographical distribution.

Keywords: Amphipod; continental shelf; diversity; Humboldt Current System; benthos.

Citación:

Jiménez A R. Marquina, L. Quipúzcoa. 2018. Anfípodos bentónicos (Amphilochidea y Senticaudata) en el centro norte de la plataforma continental del Perú. Revista peruana de biología 25(4): 371 - 406 (Noviembre 2018). doi: http://dx.doi.org/10.15381/rpb.v25i4.15531

Presentado: $\quad$ 02/08/2017

Aceptado: $\quad 14 / 05 / 2018$

Publicado online: $07 / 12 / 2018$
Información sobre los autores:

AJ: realizó la identificación de las especies, realizó el trabajo de disección y preparación de los especímenes, toma de fotografía y escribió el manuscrito; RM: realizó la colecta de los especímenes, toma y edición de fotografías, contribuyó en la revisión y aprobación del manuscrito LQ: realizó la colecta de los especímenes, contribuyó en la revisión y aprobación del manuscrito.

Los autores declaran que no incurren en conflictos de intereses. 


\section{Introducción}

A nivel mundial, se reconocen alrededor de 10000 especies del orden Amphipoda, la mayor parte de ellas de vida bentónicas, con un $81 \%$ habitando en ambientes marinos y estuarinos, (Lowry \& Myers 2017). Sin embargo, el conocimiento a nivel de especie está limitado por la complejidad taxonómica y la escases de taxónomos especialistas (Coleman com. Pers,). Estos crustáceos se encuentran en casi todos los ecosistemas acuáticos del mundo, mostrando una gran radiación adaptativa, con especies que presentan un alto grado de especificidad al nicho. Algunas especies toleran condiciones físico - químicas del agua y sedimento adversas o extremas y en general tienen poca capacidad de dispersión (Bousfield 1970, Thomas 1993, Macdonald III et al. 2005, Wellborn \& Broughton 2008, Corrigan et al. 2014). A nivel trófico, presentan un rol importante en la alimentación de los consumidores secundarios, como ballenas, peces, aves y crustáceos decápodos (Gallardo 1962, Oliver et al. 1984, Carrasco \& Arcos 1984, Moore et al. 2003).

A pesar de la importancia de los anfípodos, poco se conoce de este grupo de crustáceos en el Perú. Los primeros registros y descripciones de especies marinas en Perú se obtuvieron de expediciones oceanográficas y biológicas (e.g.: Stebbing 1906, Walker 1910, Barnard 1954). Del Solar (1970) realizó la primera lista de crustáceos del Perú, mencionando siete especies de anfípodos marinos. Las investigaciones en Perú sobre anfípodos en general se refieren a estudios del macrobentos, aportando información ecológica de riqueza, abundancia y biomasa, tanto en la franja costera (Paredes et al. 1988, Tarazona 1988) como sobre la plataforma continental (Gutiérrez 1989, Tam 1992, Mayor 1996, Quipúzcoa et al. 1998, Gutiérrez et al. 2005, Yupanqui et al. 2007) donde se observa la dominancia de familia Ampeliscidae. En general para el mar peruano se han reportado un total de 28 especies distribuidas en diferentes hábitats, desde la zona litoral hasta abisal, en la literatura anteriormente mencionada y otra más reciente (Thomas \& Barnard 1986, Barnard \& Karaman 1991, Bousfield \& Chevrier 1996, García-Madrigal 2007).

La presente investigación da a conocer las familias, géneros y especies de anfípodos de fondos blandos en el ecosistema peruano, proporcionando información taxonómica actualizada y comentarios de su distribución geográfica y batimétrica, hábitat y ecología.

\section{Materiales y métodos}

Este estudio se realizó en base a las especies de anfípodos bentónicos determinados en muestras colectadas a profundidades entre 22 y $372 \mathrm{~m}$, usando una draga tipo van Veen de $0.1 \mathrm{~m}^{2}$ de cobertura. Las muestras fueron obtenidas en la Plataforma Continental Centro Norte del Perú $\left(03^{\circ} 24^{\prime} \mathrm{S}\right.$ - $79^{\circ} 30^{\prime} \mathrm{W}$ a $09^{\circ} 00^{\prime} \mathrm{S}$ - 81³0’W), durante los otońos de los años 2004 al 2010 (Fig.

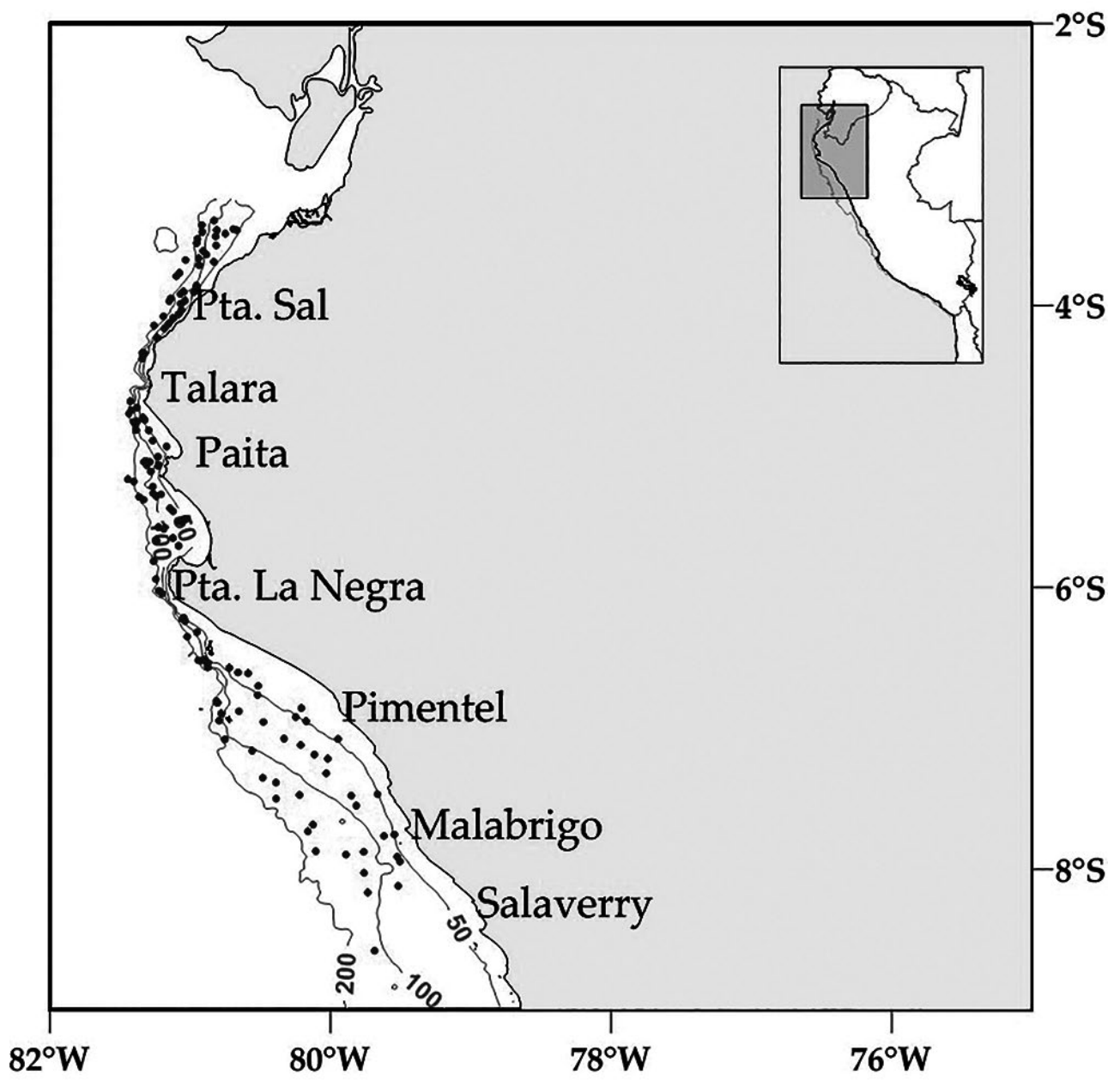

Figura 1. Mapa de distribución de las estaciones de muestreo con presencia de anfípodos bentónicos en la plataforma continental centro norte peruana en los otoños del 2004 al 2010. La localización de las sub-áreas latitudinales evaluadas están delimitadas por las líneas $(\mathrm{n}=136)$. 
1). Para obtener especímenes con artejos más completos en el cuerpo se analizaron algunas estaciones de cruceros de años más recientes (Tabla 3). Este estudio formó parte del programa de Evaluación de Merluza y otros Recursos Demersales del Instituto del Mar del Perú (IMARPE).

Determinación de las especies. - Para la descripción de las especies se tomó en cuenta la morfología externa del cuerpo de un anfípodo, como se observa en la Figura 2. La morfología de los gnatópodos puede ser determinante para la identificación de las especies e importante en la determinación del sexo (Fig. 3). Estas características pueden variar en base a las especializaciones de las especies.

Sistemática de las especies. - La clasificación sistemática de las especies siguió la investigación de Myers y Lowry (2013) y Lowry y Myers (2017). Las superfamilias con amplia distribución geográfica son Eusiroidea, Lysianassoidea y Phoxocephaloidea (Jarret \& Bousfield 1994, Lowry \& Stoddart 1994, Hendrycks \& Bousfield 2004, De Broyer 1984), registradas también en esta publicación. Para la sistemática de la familia Caprellidae siguió lo propuesto por Arimoto (1976) y Myers y Lowry (2003); Phoxocephalidae, con el sistema de subfamilias desarrollado por Barnard y Drummond (1978), con revisión de Jarrett y Bousfield (1994). Pleustidae siguió lo desarrollado por Barnard y Given (1960), con la revisión de Hendrycks y Bousfield (2004). Para la familia Stenothoidae, el reconocimiento de especies siguió lo descrito por Barnard (1962b). Los géneros y especies de la familia Ampeliscidae siguieron lo propuesto por Barnard (1954) y con el estudio sobre el género Ampelisca de Dickinson (1982). Asimismo, para la familia Argissidae se consideró lo propuesto por Bousfield (1973); Megaluropidae, por Thomas y Barnard (1986); Liljeborgiidae, por Barnard (1959); Synopiidae, por Barnard (1972); Eriopsidae, por Barnard (1952); Photidae, por Conlan (1983). Finalmente, la determinación de los géneros y especies de Oedicerotidae siguió la clasificación de Barnard (1962c), Bousfield y Chevrier (1996), y Jansen (2002).

Procesamiento de los especímenes. - Todos los especímenes de anfípodos fueron sumergidos en glicerol para fotografiarlos y diseccionarlos usando un estereoscópico NIKON modelo

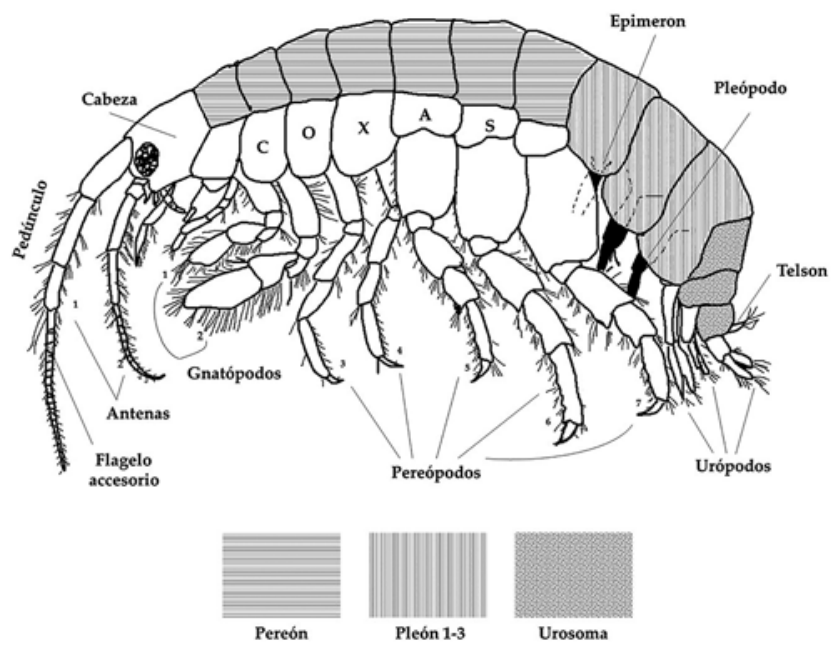

Figura 2. Partes del cuerpo general de un anfípodo: Amphilochidea (tomado de Barnard \& Karaman 1991).
Eclipse R200 con cámara NIKON, modelo DSFI 1C (NIS Element). Los apéndices extraídos fueron vertidos en placas portaobjetos con glicerol, fotografiados usando un microscopio óptico NIKON modelo Eclipse Ti, con la misma marca de cámara. Finalmente, las especies fueron preservadas en solución de alcohol al 70\%, en crioviales. Todos los especímenes fueron depositados en la Colección Científica del Laboratorio de Bentos Marino del Instituto del Mar del Perú.

Las abreviaturas de las figuras fueron: Ca: Cabeza; A1 y A2: Antena 1 y 2; Gn1 y Gn2: gnatópodo 1 y 2; P3 a P7: pereópodo 3 a 7; Ep3: placa epimeral 3; U1 a U3: urópodo 1 a 3; T: telson.

\section{Resultados}

En este estudio se examinaron 2451 especímenes, donde se determinaron 28 taxa de anfípodos de sustrato blando (21 a nivel de especie y 7 a nivel de género), distribuidas en 15 familias y pertenecientes a los subórdenes Amphilochidea (12 familias) y Senticaudata (3 familias) (Tabla 1). Resalta la familia Ampeliscidae con dos géneros: Ampelisca (10 especies) y Byblis (una especie).

Del total de especies, siete especies fueron reportadas en estudios previos: Ampelisca cristoides, A. lobata, A. mexicana, $A$. pugetica, Resupinus coloni, Eudevenopus honduranus, Hartmanodes hartmanae. De los 28 taxa, 13 son nuevos registros a nivel de especies y siete especies a nivel de género (Tabla 2).

A continuación se muestra la clasificación taxonómica de las especies, seguida de la información detallada sobre la descripción taxonómica (con las comparaciones de los trabajos originales), hábitat, distribución geográfica y batimétrica y comentarios, por especie. La Tabla 3 muestra las los datos ubicación de los morfotipos diseccionados para la determinación de las especies; donde algunos ejemplares fueron colectados en cruceros más recientes, debido a una mejor conservación del cuerpo y artejos.

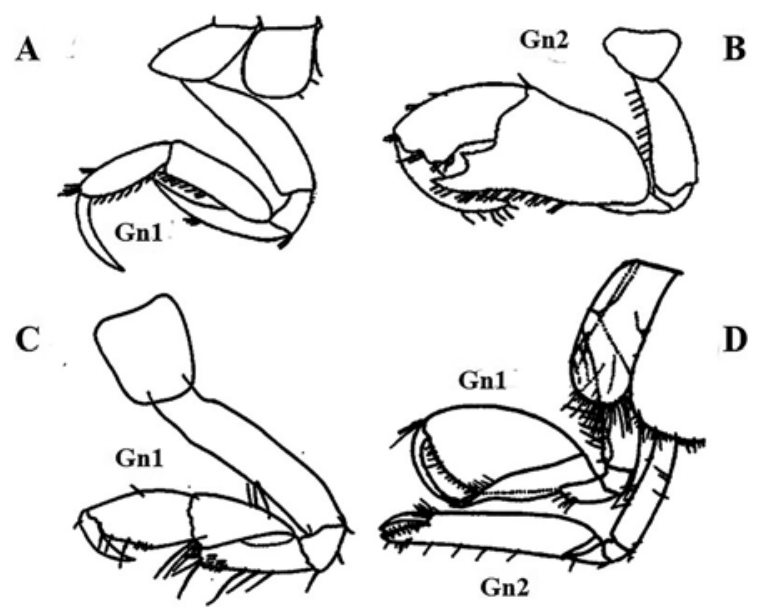

Figura 3. A: gnatópodo 1 (Gn1), meroquelado, Aora typica; B: gnatópodo 2 (Gn2) carpoquelado, Ericthonius punctatus; C, gnatópodo 1 (Gn1) subquelado, Stenothoe penelopae; D, gnatópodo 1(Gn1) transverso, gnatópodo $2(\mathrm{Gn} 2)$ quelado, Americhelidium setosus (figuras modificadas basados en: Barnard \& Karaman 1991, Bousfield \& Chevrier 1996, KrappSchickel 2006). 
Tabla 1. Listado de especie de anfípodos colectados en la Plataforma Continental Centro Norte del Perú $\left(03^{\circ} 24^{\prime} \mathrm{S}-79^{\circ} 30^{\prime} \mathrm{W}\right.$ a $09^{\circ} 00^{\prime} S-81^{\circ} 30^{\prime} \mathrm{W}$ ), a profundidades entre 22 y $372 \mathrm{~m}$, durante los otoños de los años 2004 al 2010.

\begin{tabular}{|c|c|c|c|c|}
\hline Suborden & Superfamilia Familia & Subfamilia & Especie & Autoridad \\
\hline \multicolumn{5}{|c|}{ Amphilochidea Boeck, 1871} \\
\hline \multicolumn{5}{|c|}{ Ampeliscidae Kroyer, 1842} \\
\hline & & & 1. Ampelisca araucana & Gallardo, 1963 \\
\hline & & & 2. Ampelisca brevisimulata & J.L. Barnard, 1954 \\
\hline & & & 3. Ampelisca cristata & Holmes, 1908 \\
\hline & & & 4. Ampelisca cristoides & J.L. Barnard, 1954 \\
\hline & & & 5. Ampelisca hancocki & J.L. Barnard, 1954 \\
\hline & & & 6. Ampelisca lobata & Holmes, 1908 \\
\hline & & & 7. Ampelisca mexicana & J.L. Barnard, 1954 \\
\hline & & & 8. Ampelisca pacifica & Holmes, 1908 \\
\hline & & & 9. Ampelisca pugetica & Stimpson, 1864 \\
\hline & & & 10. Ampelisca & Krøyer, 1842 \\
\hline & & & 11. Byblis cf. millsi & Dickinson, 1983 \\
\hline
\end{tabular}

Argissidae Walker, 1904

12. Argissa hamatipes (Norman, 1869)

Eusiroidea

Eusiridae Stebbing, 1888

13. Rhachotropis $s p$.

Megaluropidae Thomas \& J.L. Barnard 1986

14. Resupinus coloni

Thomas \& Barnard, 1986

Liljeborgioidea

Liljeborgiidae Stebbing, 1899

Idunellinae

15. Idunella diffusa

(J.L. Barnard, 1959)

Lysianassoidea

Tryphosidae Lowry \& Stoddart, 1997

Oedicerotidae Lilljeborg, 1865

16 Orchomenella sp.
17. Hartmanodes hartmanae
(J.L. Barnard, 1962)
18. Americhelidium sp.
19. Westwoodilla tone
Jansen, 2002

Phoxocephalidae G.O. Sars, 1891

Harpiniinae

Platyischnopidae Barnard \& Drummond, 1979

20. Heterophoxus oculatus (Holmes, 1908)

Pleustidae Buchholz, 1874

21. Eudevenopus honduranus

Thomas \& J.L. Barnard, 1983

Stenopleustinae

Stenothoidae Boeck, 1871

22. Gracilipleustes monocuspis (Barnard \& Given, 1960)

23. Metopella aporpis J.L. Barnard, 1962

Synopiidae Dana, 1853

24. Syrrhoe sp.

Senticaudata Lowry \& Myers, 2013

Hadzoidea S. Karaman, 1943 (Bousfield, 1983)

Eriopsidae Lowry \& Myers, 2013

25. Psammogammarus garthi (J.L. Barnard, 1952)

Photoidea Boeck, 1871

Photidae Boeck, 1871

26. Photis $s p$.

27. Gammaropsis sp.

Caprelloidea Leach, 1814

Caprellidae Leach, 1814

Caprellinae Leach, 1814

28. Caprella sp.

Lamarck, 1801 
Tabla 2. Listado de nuevos registros de anfípodos bentónicos de la Plataforma Continental del mar peruano.

\begin{tabular}{|c|c|c|c|}
\hline Especie & Distribución & Prof. (m) & Referencia \\
\hline Ampelisca araucana & Golfo de Arauco, Chile & 60 & Gallardo 1962 \\
\hline Ampelisca brevisimulata & Océano Pacífico, Alaska a Panamá & 20 a 400 & Barnard 1954, Dickinson 1982a \\
\hline Ampelisca cristata & Archipiélago Alexander hasta Costa Rica & 0 a 152 & Barnard 1954, Dickinson 1982a \\
\hline Ampelisca cristoides & Pacífico norte, California hasta Colombia & 3 a 80 & $\begin{array}{l}\text { Barnard 1954, García-Madrigal } \\
2007\end{array}$ \\
\hline Ampelisca hancocki & Columbia British hasta Costa Rica & 9 a 200 & $\begin{array}{l}\text { Barnard 1954, Dickinson 1982a, } \\
\text { Madrigal } 2007\end{array}$ \\
\hline Ampelisca pacifica & Bahía Monterey, California hasta Panamá & 20 a 550 & $\begin{array}{l}\text { Barnard 1954, Dickinson 1982, } \\
\text { Madrigal } 2007\end{array}$ \\
\hline Byblis cf. millsi & Islas de la Reina Charlotte, al sur de California & 0 a 100 & Dickinson $1982 b$ \\
\hline Argissa hamatipes & Norte del Atlántico, Mar de Japón, Pacífico, Golfo de California & 4 a 1096 & Barnard 1967, Nagata 1965 \\
\hline Gracilipleustes monocuspis & Sur de California & 76 & $\begin{array}{l}\text { Barnard \& Given 1960, } \\
\text { Hendrycks \& Bousfield } 2004\end{array}$ \\
\hline Heterophoxus oculatus & Islas de la Reina Charlotte al sur de California & 40 a 600 & Jarrett \& Bousfield 1994 \\
\hline Idunella diffusa & Punta Concepción (México) hasta California & 12 a 172 & Karaman 1980 \\
\hline Metopella aporpis & Sur de California & 46 a 77 & Barnard 1962 \\
\hline Psammogammarus garthi & Costas del Pacífico de Norte América & 0 a 2 & Barnard 1952 \\
\hline Westwoodilla tone & British Columbia (Canada) a California (USA) & 22 a 223 & Jansen 2002 \\
\hline
\end{tabular}

Tabla 3. Lista de los morfotipos de las especies analizadas, con datos de las estaciones, profundidad y año del crucero de colecta.

\begin{tabular}{|c|c|c|c|c|}
\hline ESPECIE & Estación del morfotipo & Ubicación & Prof. (m) & Año \\
\hline Ampelisca araucana & C79 & $07^{\circ} 06^{\prime} \mathrm{S}, 80^{\circ} 48^{\prime} \mathrm{W}$ & 117 & 2005 \\
\hline Ampelisca brevisimulata & $\mathrm{C} 48$ & $06^{\circ} 16.8^{\prime} \mathrm{S}, 81^{\circ} 4.2^{\prime} \mathrm{W}$ & 239 & 2015 \\
\hline Ampelisca cristata & C63 & $04^{\circ} 42^{\prime} \mathrm{S}, 81^{\circ} 24^{\prime} \mathrm{W}$ & 106 & 2004 \\
\hline Ampelisca cristoides & $\mathrm{C} 20$ & $04^{\circ} 49.8^{\prime} \mathrm{S}, 81^{\circ} 18.6^{\prime} \mathrm{W}$ & 38 & 2015 \\
\hline Ampelisca hancocki & $\mathrm{C} 12$ & $03^{\circ} 35.4^{\prime} \mathrm{S}, 81^{\circ} 6.6^{\prime} \mathrm{W}$ & 375 & 2011 \\
\hline Ampelisca lobata & C63 & $04^{\circ} 42^{\prime} \mathrm{S}, 81^{\circ} 24^{\prime} \mathrm{W}$ & 106 & 2004 \\
\hline Ampelisca mexicana & $\mathrm{C} 26$ & $04^{\circ} 42^{\prime} \mathrm{S}, 81^{\circ} 24^{\prime} \mathrm{W}$ & 68 & 2005 \\
\hline Ampelisca pacifica & $\mathrm{C} 1$ & $03^{\circ} 35.4^{\prime} \mathrm{S}, 81^{\circ} 4.8^{\prime} \mathrm{W}$ & 191 & 2016 \\
\hline Ampelisca pugetica & C55 & $06^{\circ} 30^{\prime} \mathrm{S}, 80^{\circ} 54^{\prime} \mathrm{W}$ & 56 & 2007 \\
\hline Ampelisca sp. & $\mathrm{C} 44$ & $06^{\circ} 12^{\prime} \mathrm{S}, 81^{\circ} 00^{\prime} \mathrm{W}$ & 37 & 2006 \\
\hline Byblis cf. millsi & C39 & $05^{\circ} 10.2^{\prime} \mathrm{S}, 81^{\circ} 14.4^{\prime} \mathrm{W}$ & 90 & 2016 \\
\hline Argissa hamatipes & $\mathrm{C} 20$ & $4^{\circ} 49.8^{\prime} \mathrm{S}, 81^{\circ} 18.6^{\prime} \mathrm{W}$ & 38 & 2015 \\
\hline Rhachotropis sp. & EA & $05^{\circ} 24^{\prime} \mathrm{S}, 81^{\circ} 18^{\prime} \mathrm{W}$ & 128 & 2004 \\
\hline Resupinus coloni & E20 & $05^{\circ} 00^{\prime} \mathrm{S}, 81^{\circ} 12^{\prime} \mathrm{W}$ & 24 & 2010 \\
\hline Idunella diffusa & $\mathrm{C} 20$ & $04^{\circ} 49.8^{\prime} \mathrm{S}, 81^{\circ} 18.6^{\prime} \mathrm{W}$ & 38 & 2015 \\
\hline Orchomenella sp. & C94 & $03^{\circ} 24^{\prime} \mathrm{S}, 80^{\circ} 48^{\prime} \mathrm{W}$ & 75 & 2009 \\
\hline Hartmanodes hartmanae & $\mathrm{C} 20$ & $04^{\circ} 49.8^{\prime} \mathrm{S}, 81^{\circ} 18.6^{\prime} \mathrm{W}$ & 38 & 2015 \\
\hline Americhelidium sp. & $\mathrm{C} 14$ & $03^{\circ} 43.8^{\prime} \mathrm{S}, 81^{\circ} 6.6^{\prime} \mathrm{W}$ & 324 & 2015 \\
\hline Westwoodilla tone & $\mathrm{C} 1$ & $03^{\circ} 55.8^{\prime} \mathrm{S}, 81^{\circ} 6.6^{\prime} \mathrm{W}$ & 191 & 2016 \\
\hline Heterophoxus oculatus & $\mathrm{C} 20$ & $04^{\circ} 49.8^{\prime} \mathrm{S}, 81^{\circ} 18.6^{\prime} \mathrm{W}$ & 38 & 2015 \\
\hline Eudevenopus honduranus & C44 & $06^{\circ} 12^{\prime} \mathrm{S}, 81^{\circ} 00^{\prime} \mathrm{W}$ & 37 & 2006 \\
\hline Gracilipleustes monocuspis & E48 & $6^{\circ} 16.8^{\prime} \mathrm{S}, 81^{\circ} 04^{\prime} \mathrm{W}$ & 239 & 2016 \\
\hline Metopella aporpis & $\mathrm{C} 48$ & $05^{\circ} 30^{\prime} \mathrm{S}, 81^{\circ} 00^{\prime} \mathrm{W}$ & 44 & 2004 \\
\hline Syrrhoe sp. & $\mathrm{C} 46$ & $05^{\circ} 18^{\prime} \mathrm{S}, 81^{\circ} 18^{\prime} \mathrm{W}$ & 110 & 2005 \\
\hline Psammogammarus garthi & $\mathrm{C} 22$ & $07^{\circ} 28.8^{\prime} \mathrm{S}, 79^{\circ} 51^{\prime} \mathrm{W}$ & 83 & 2009 \\
\hline Photis sp. & C48 & $05^{\circ} 30^{\prime} \mathrm{S}, 81^{\circ} 00^{\prime} \mathrm{W}$ & 44 & 2004 \\
\hline Gammaropsis sp. & $\mathrm{C} 26$ & $04^{\circ} 42^{\prime} \mathrm{S}, 81^{\circ} 24^{\prime} \mathrm{W}$ & 68 & 2005 \\
\hline Caprella sp. & $\mathrm{C} 39$ & $05^{\circ} 10.2^{\prime} \mathrm{S}, 81^{\circ} 14.4^{\prime} \mathrm{W}$ & 90 & 2016 \\
\hline
\end{tabular}




\section{Taxonomía}

\section{SUBORDEN AMPHILOCHIDEA BOECK, 1871}

FAMILIA AMPELISCIDAE KROYER, 1842

\section{Ampelisca araucana Gallardo, 1963}

Figura $4-6$.

Diagnosis: Cabeza corta, antena 1 más corta que la antena 2 (A2), pero sobrepasa el pedúnculo de la A2. Gnatópodos simples. En el pereópodo 7, el artejo 2 en forma de lóbulo, que se expande en la parte posterior hasta la mitad del artejo 4, éste forma un lóbulo setoso, amplio y lateralmente aplastado, que cubre el artejo 5 (pequeńo); artejo 6 expandido y largo; artejo 7 (dáctilo) largo y con terminación fina. Urópodos birrámeos, donde el tamaño del urópodo 1 sobrepasa al U2. El borde posterior de la placa epimeral 3 con una suave convexidad y una prolongación en forma de diente largo, fuerte y robusto. Telson hendido, cada lóbulo con ápices hendidos y una espina naciendo de cada muesca subterminal; la superficie de cada lóbulo presenta entre 2 a 3 setas (Figs. 4, 5).

Material examinado: se examinaron 1073 especímenes, diseccionando un ejemplar hembra en la estación C79 $\left(07^{\circ} 06^{\prime} \mathrm{S}\right.$, $\left.80^{\circ} 48^{\prime} \mathrm{W}\right)$ a $117 \mathrm{~m}$, del Crucero de Otońo del 2005.

Hábitat: areno - fangoso.

Profundidad: 35 a $179 \mathrm{~m}$.
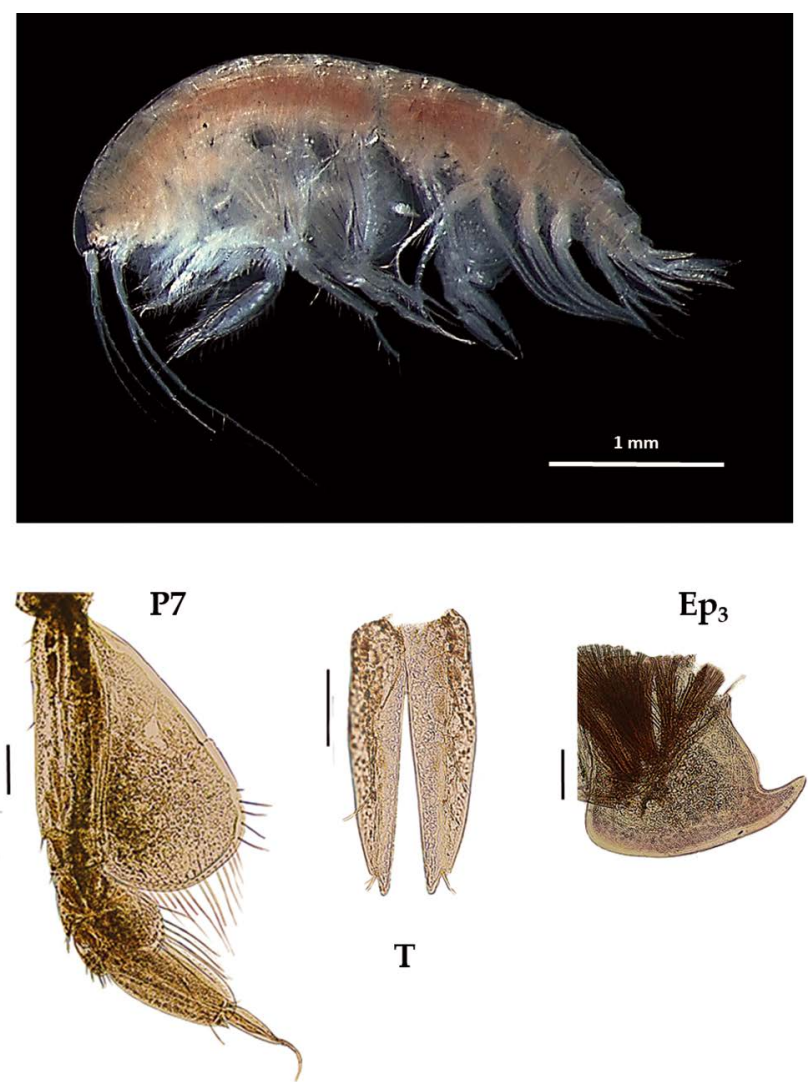

$$
\mathbf{T}
$$

Figura 5. Ampelisca araucana: pereópodo 7 (P7), placa epimeral 3 (Ep3) y telson (T). Escala: P7; 0.2 mm; Ep3: 50 $\mu \mathrm{m} ; \mathrm{T}: 100 \mu \mathrm{m}$.
Localidades en la plataforma centro norte: de Chicama $\left(6^{\circ} \mathrm{S}\right)$ hacia el sur peruano $\left(06^{\circ} 06^{\prime} \mathrm{S}, 81^{\circ} 12 \mathrm{~W}\right.$ a $08^{\circ} 36^{\prime} \mathrm{S}, 79^{\circ} 42^{\prime}$ W; Figura 6), llegando a registrarse hasta Callao (Gutiérrez et al. 2008).

Distribución geográfica en el mundo: Chile (Golfo de Arauco, $37^{\circ} 02^{\prime} \mathrm{S}-73^{\circ} 20^{\prime} \mathrm{W}$, Gallardo 1962).

Observaciones: esta especie presenta una gran similitud con Ampelisca mexicana; aunque no llegan a coexistir, debido a que A. araucana se distribuye en ambientes de masas de agua frías (de surgencia), así como en condiciones de hipoxia (Jiménez 2018).

Referencias: Gallardo 1962 (3 - 11, Lámina I y II), Gutiérrez et al. 2008, Jiménez 2018.

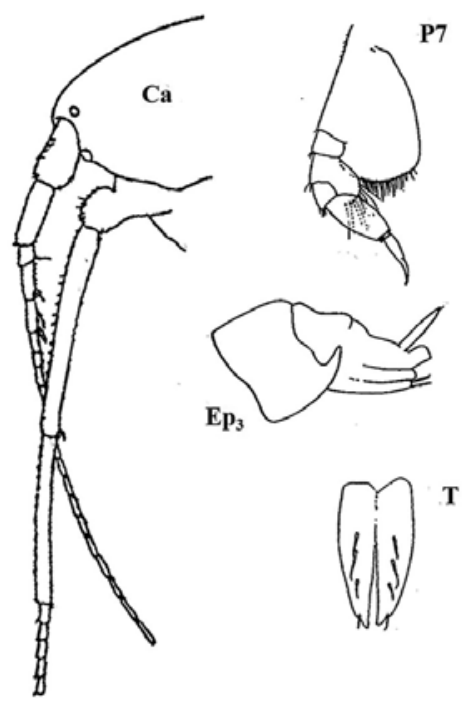

Figura 4. Características taxonómicas de Ampelisca araucana Gallardo, 1963: cabeza (Ca), Pereópodo 7 (P7), placa epimeral 3 (Ep3, sombreado) y telson (T), según Gallardo (1963).

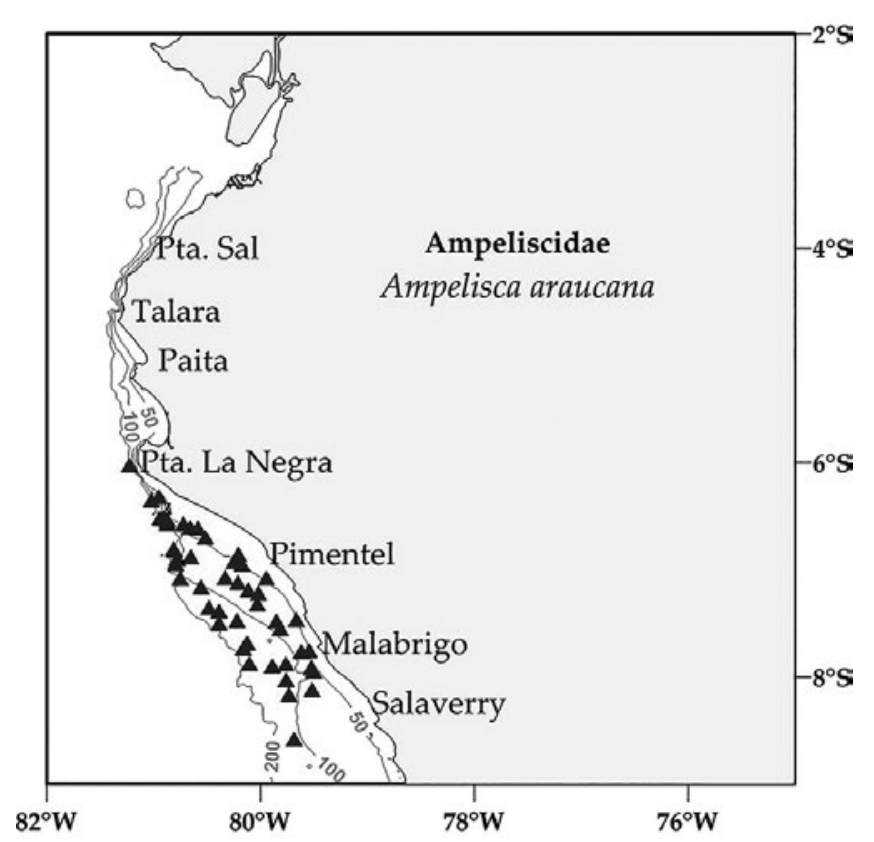

Figura 6. Distribución espacial de Ampelisca araucana en la plataforma continental centro norte peruana. 


\section{Ampelisca brevisimulata J.L. Barnard, 1954}

Figura $7-9$.

Diagnosis: Antena 1 más corta que la A2, no sobrepasa el pedúnculo de la A2. Gnatópodos simples, con palmas poco profundas y alargadas. Pereópodo 7 , artejo 2 lobulado con el margen inferior redondeado hasta el artejo 4, éste presenta un lóbulo posterior setoso y delgado, con terminación fina; artejo 5 y 6 expandidos; artejo 7 delgado (igual en tamaño que el artejo 6). La placa epimeral 3 presenta una joroba pronunciada, encima del diente. Telson hendido, cada lóbulo con terminación fina y dos espinas naciendo de cada muesca subterminal; cada lóbulo presenta entre 5 a 7 setas en su superficie (Figs. 7, 8).

Material examinado: se examinaron 124 especímenes, diseccionando un ejemplar hembra de la estación C48 $\left(06^{\circ} 16.8^{\prime} \mathrm{S}\right.$, $81^{\circ} 4.2^{\prime} \mathrm{W} ; 239 \mathrm{~m}$ ), del Crucero de Otoño del año 2015.

Hábitat: areno fangoso.

Profundidad: 24 a $282 \mathrm{~m}$.

Localidades en la plataforma centro norte: $03^{\circ} 30^{\prime} \mathrm{S}$, $80^{\circ} 42^{\prime} \mathrm{W}$ a $06^{\circ} 12^{\prime}$ 'S, $81^{\circ} 00^{\prime} \mathrm{W}$ (Fig. 9).

Distribución geográfica en el mundo: Alaska hasta Panamá (Barnard 1954) y reportado también hasta Paita (GarcíaMadrigal 2007).

Observaciones: los machos pelágicos se diferencian de las hembras, principalmente, por la presencia de un grupo de setas en los pedúnculos de ambas antenas y la antena 1 más grande que el pedúnculo de la $2^{\circ}$.

Referencias: Barnard 1954 (Págs. 33 -35), Dickinson 1982.
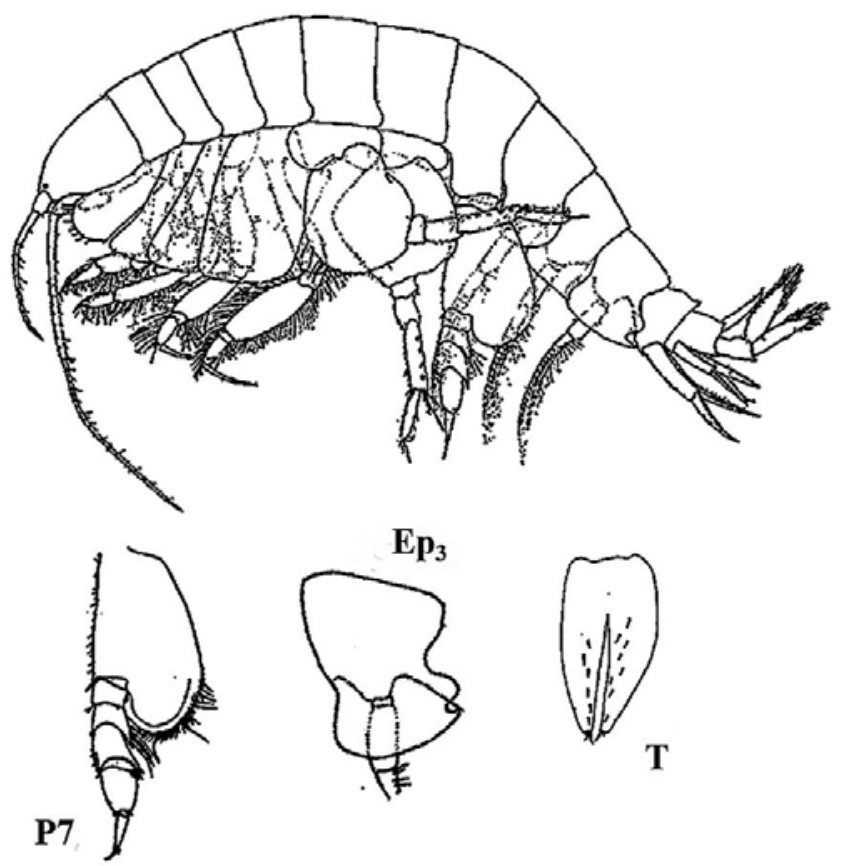

Figura 7. Características taxonómicas de Ampelisca brevisimulata J.L. Barnard, 1954: habitus, pereópodo 7 (P7), placa epimeral 3 (Ep3, sombreado) y telson (T), según Barnard (1954) y Dickinson (1982).
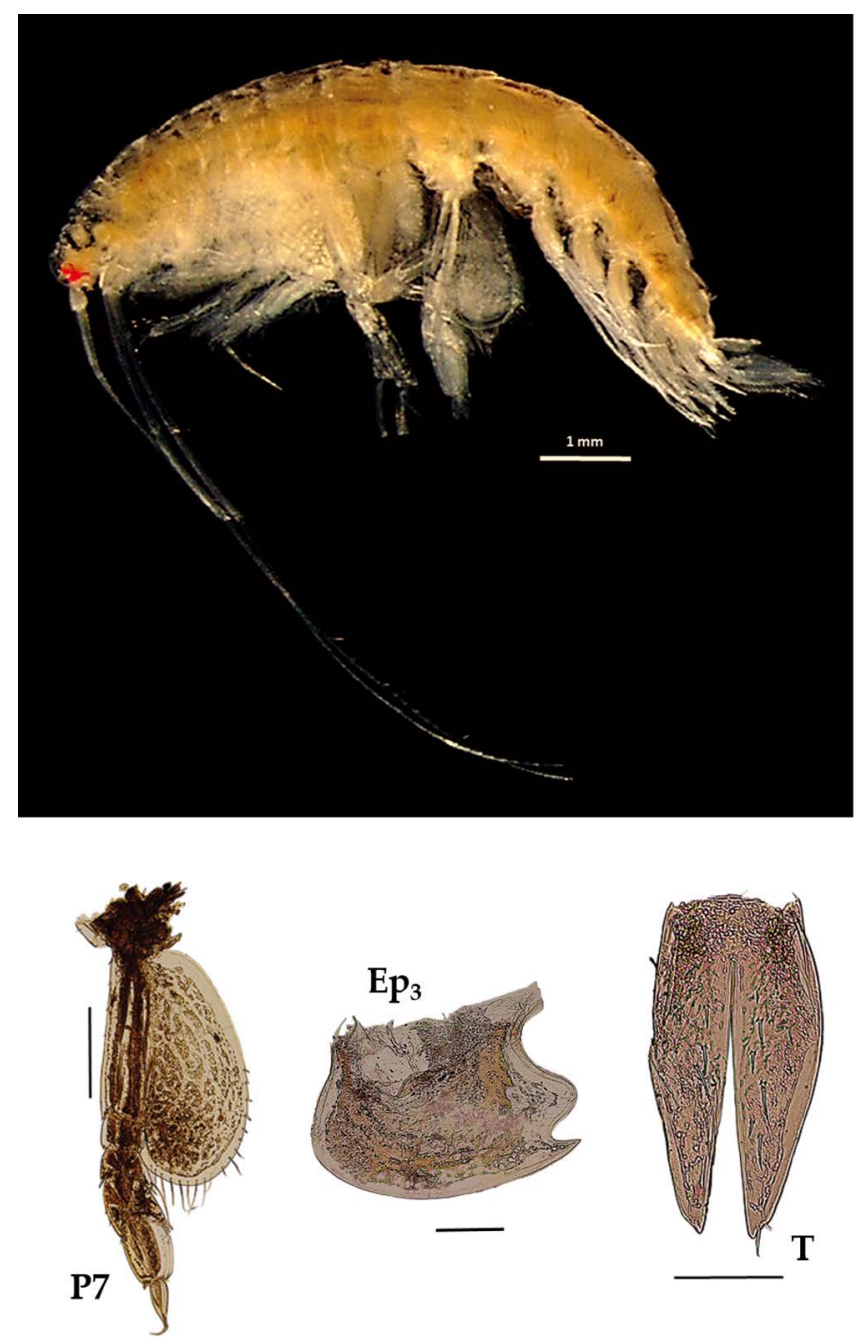

Figura 8. Ampelisca brevisimulata: pereópodo 7 (P7), placa epimeral 3 (Ep3) y telson (T). Escala: P7; 0.5 mm; Ep3: 50 $\mu \mathrm{m} ; \mathrm{T}: 50 \mu \mathrm{m}$.

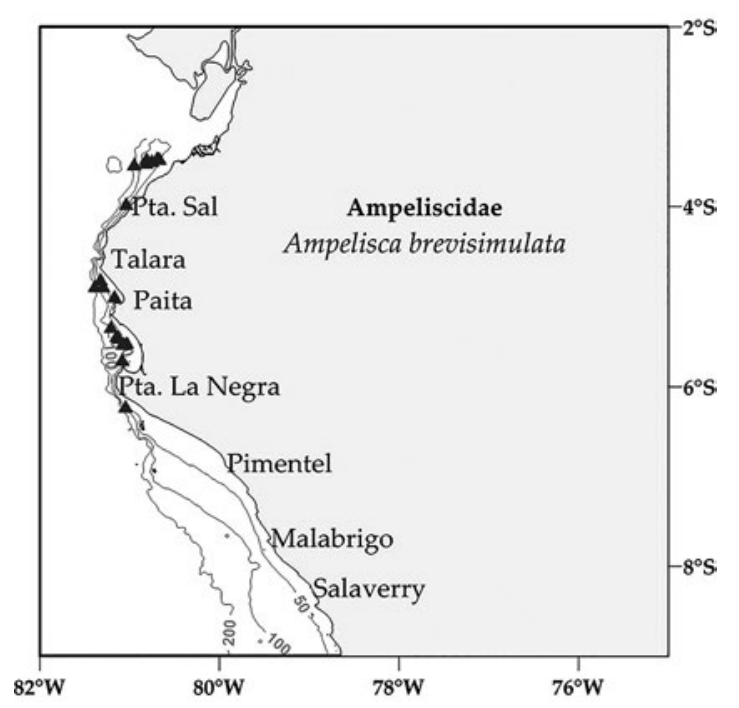

Figura 9. Distribución espacial de Ampelisca brevisimulata en la plataforma continental centro norte peruana. 


\section{Ampelisca cristata Holmes, 1908}

Figura $10-12$.

Diagnosis: Cabeza alargada. Antena 1 más corta que el pedúnculo que de la antena 2 . Longitud de la A2 representa $3 / 4$ del tamaño total del cuerpo. Gnatópodos simples, con palma poco profunda y alargada. Pereópodo 7, artejo 2 en forma de lóbulo expandido posteriormente y alcanzando hasta el artejo 4, casi truncado en la base con borde setoso; artejo 6 expandido y más largo que el artejo 5 y 7 . En la superficie dorsal anterior del urosomito 1 se sitúa una carina lamelar. Placa epimeral 3 con la esquina postero inferior dentado, no tan pronunciado. Telson hendido; cada lóbulo con terminación puntiaguda, ápice terminal con 2 espinas y una seta, naciendo de cada muesca; la superficie de cada lóbulo con un par de espinas (Figs. 10, 11).

Material examinado: se examinaron 31 especímenes, diseccionando un ejemplar hembra de la estación C63 (04² 42 'S, $81^{\circ} 24^{\prime} W ; 106 \mathrm{~m}$ ), del Crucero de Otoño del año 2004.

Hábitat: Sustrato blando, desde arena hasta fango.

Profundidad: 37 a $106 \mathrm{~m}$.

Localidades en la plataforma centro norte: $04^{\circ} 42^{\prime} \mathrm{S}$, $81^{\circ} 24^{\prime} \mathrm{W}$ a $07^{\circ} 48^{\prime} \mathrm{S}, 7^{\circ} 36^{\prime} \mathrm{W}$ (Fig. 12).

Distribución geográfica en el mundo: Archipiélago Alexan$\operatorname{der}\left(56^{\circ} 16^{\prime} \mathrm{N}, 135^{\circ} 30^{\prime} \mathrm{W}\right)$ hasta norte del Perú (Barnard 1954a, García-Madrigal 2007).

Observaciones: Ampelisca cristata es fácil de diferenciar por la forma de la carina urosomal (Fig. 10). Hembras no ovígeras y machos presenta característica pelágica.

Referencias: Barnard 1954a (Págs. 26-28), Dickinson 1982.

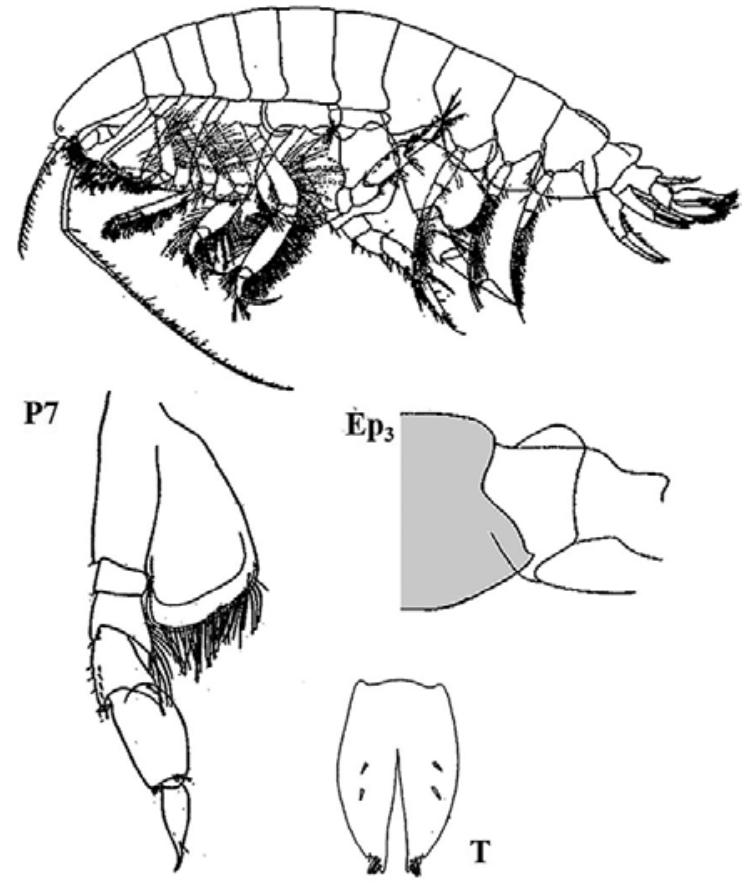

Figura 10. Características taxonómicas de Ampelisca cristata Holmes, 1908: habitus, pereópodo 7 (P7), placa epimeral 3 (Ep3) y telson (T), según Barnard (1954) y Dickinson (1982).
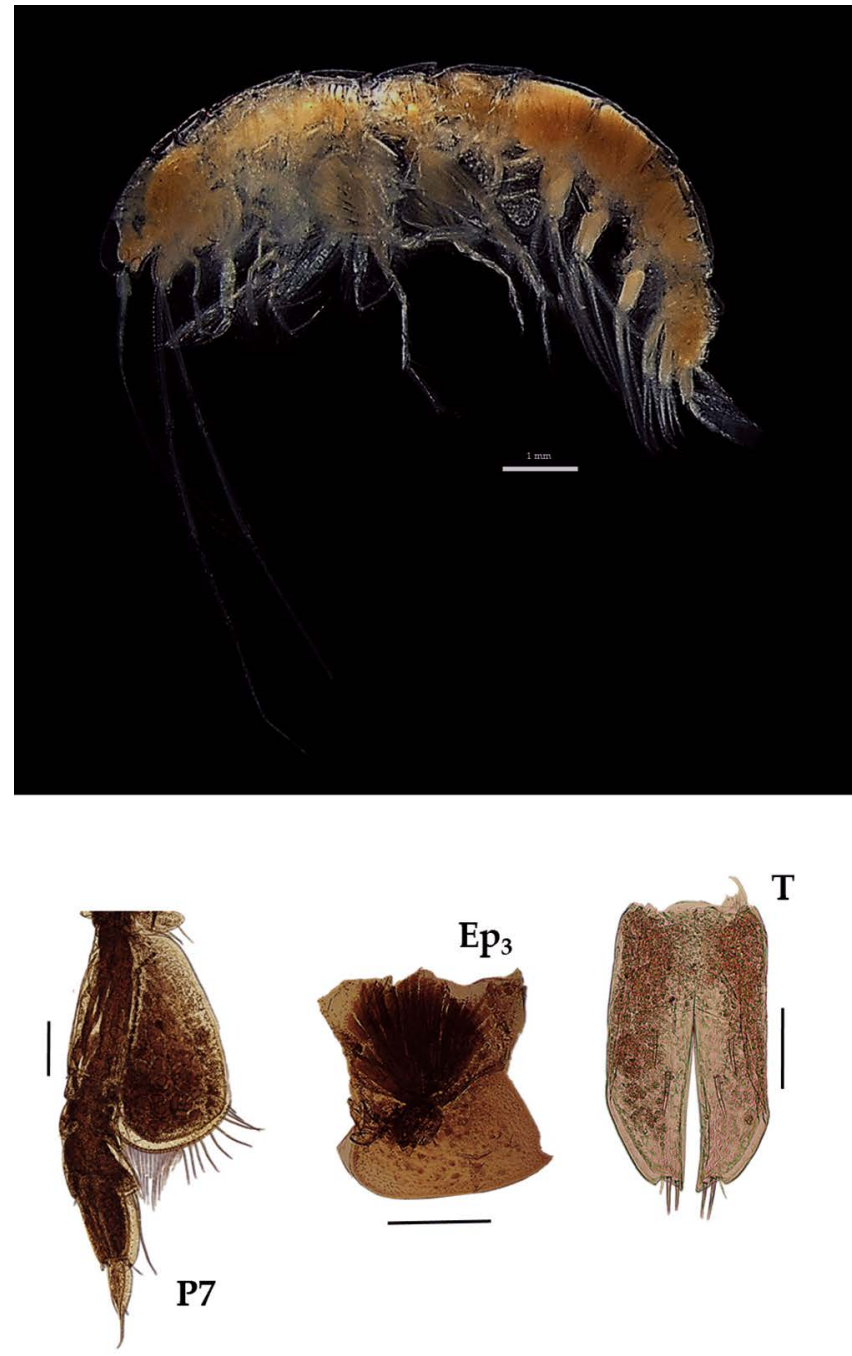

Figura 11. Ampelisca cristata: pereópodo 7 (P7), placa epimeral 3 (Ep3) y telson (T). Escala: P7; Ep3: 0.5 mm; T: $50 \mu \mathrm{m}$.

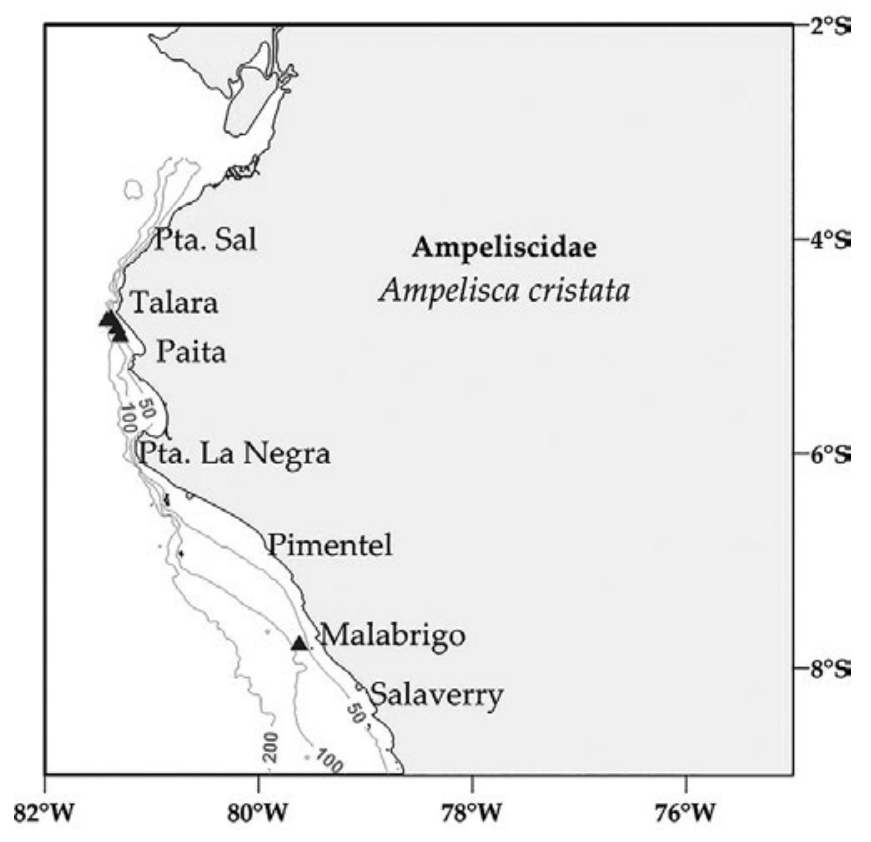

Figura 12. Distribución espacial de Ampelisca cristata en la plataforma continental centro norte peruana. 


\section{Ampelisca cristoides J.L. Barnard, 1954}

Figura $13-15$.

Diagnosis: cabeza alargada. Ojos encima del margen superior de la antena 1. La longitud de la A1, no mayor al pedúnculo de la antena 2, longitud de la A2 representa $3 / 4$ de tamaño total del cuerpo. Gnatópodos simples y alargados. Pereópodo 7, artejo 2 en forma de lóbulo expandido posteriormente y setoso, casi truncado en la base; artejo 4 con un pequeńo lóbulo posterior setoso y delgado; artejo 6 expandido; longitud del artejo 7 tanto como del artejo 5. En el ángulo postero inferior de la placa epimeral 3 presenta un pequeńo diente. La cresta dorsal del urosomito 1 presenta una carina lamelar sinuosa (ondeada). Telson hendido, cada lóbulo alargado con muesca lateral en el ápice con 3 o 4 setas; la superficie de cada lóbulo con 4 a 5 setas (Figs. 13, 14).

Material examinado: se examinaron 107 especímenes y se diseccionó un ejemplar hembra de la estación C20 (0449.8'S, 81 18.6'W; 38 m), del Crucero de Otoño del año 2015.

Hábitat: Sustrato blando, desde arena fangoso.

Profundidad: 24 a $87 \mathrm{~m}$.

Localidades en la plataforma centro norte: $03^{\circ} 30^{\prime} \mathrm{S}$, $81^{\circ} 06^{\prime} \mathrm{W}$ a $05^{\circ} 30^{\prime} \mathrm{S}, 80^{\circ} 42^{\prime} \mathrm{W}$ (Fig. 15).

Distribución geográfica en el mundo: Baja California hasta norte del Perú (Barnard 1954, García-Madrigal 2007).

Observaciones: esta especie es cercana a Ampelisca cristata, pero difiere en la forma de la cresta dorsal del urosomito 1 (Figs. 11, 14).

Referencias: Barnard 1954a (Págs. 21 - 31).

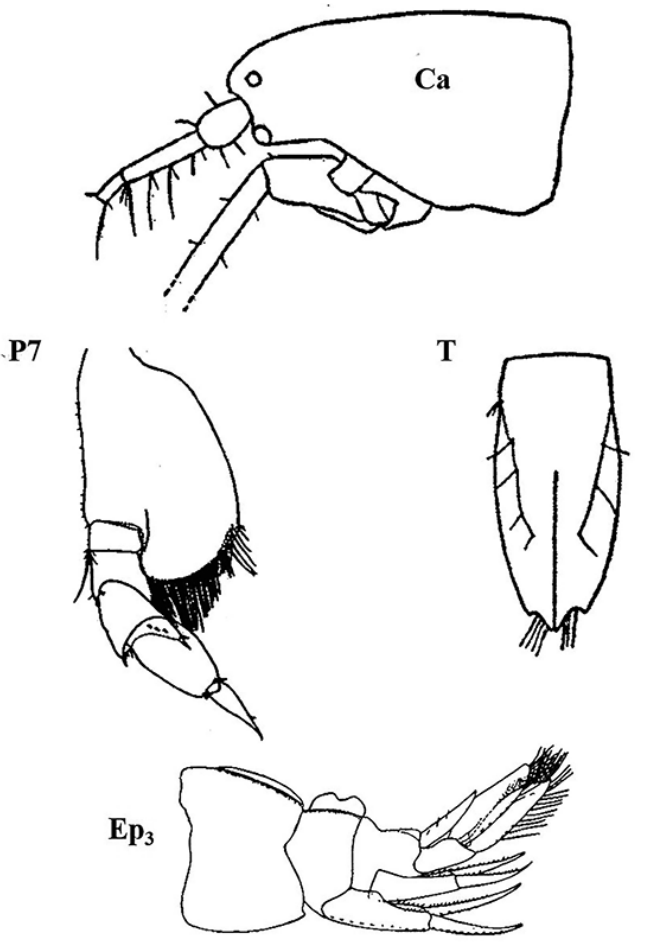

Figura 13. Características taxonómicas de Ampelisca cristoides J.L. Barnard, 1954: habitus, pereópodo 7 (P7), placa epimeral 3 (Ep3, sombreado) y telson (T), según Barnard (1954).
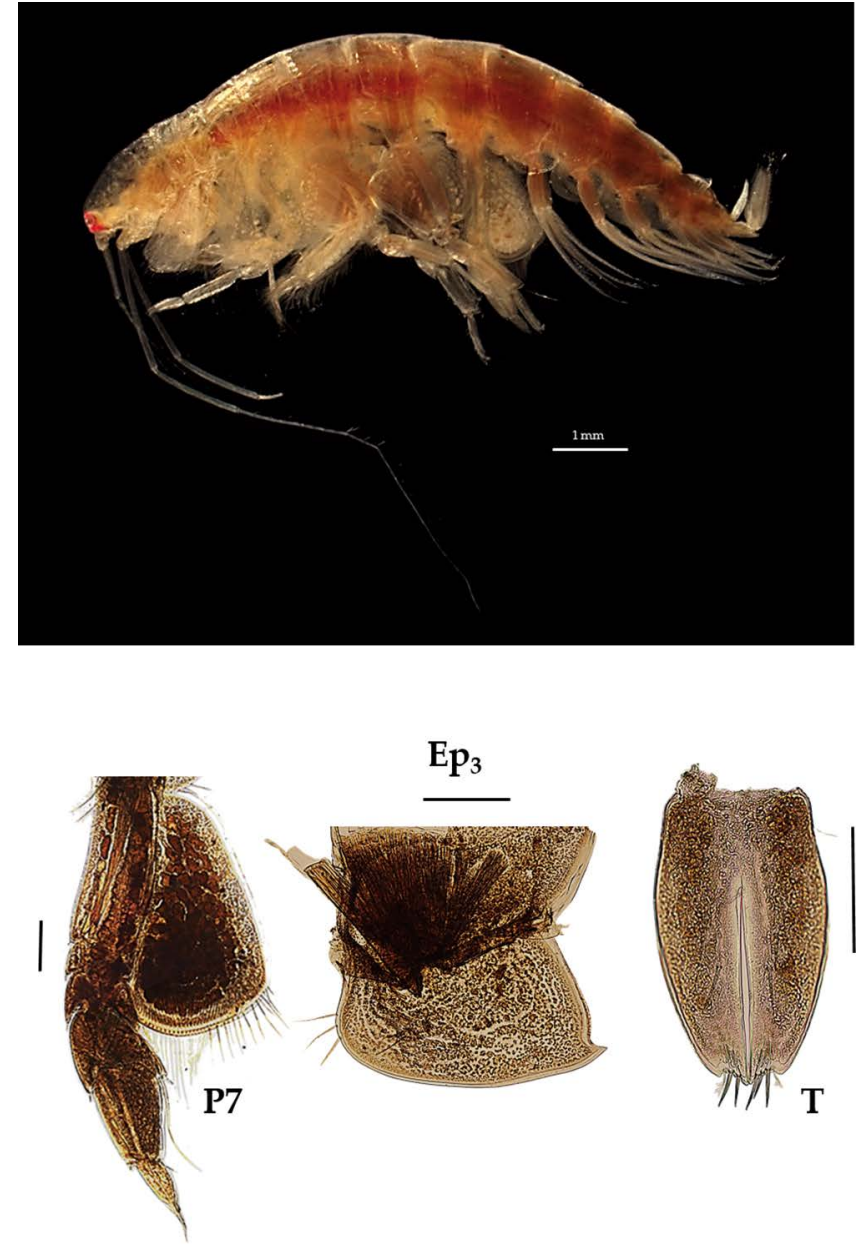

Figura 14. Ampelisca cristoides: pereópodo 7 (P7), placa epimeral 33 (Ep3) y telson (T). Escala: P7 y Ep3: 0.5 mm; $\mathrm{T}: 100 \mu \mathrm{m}$.

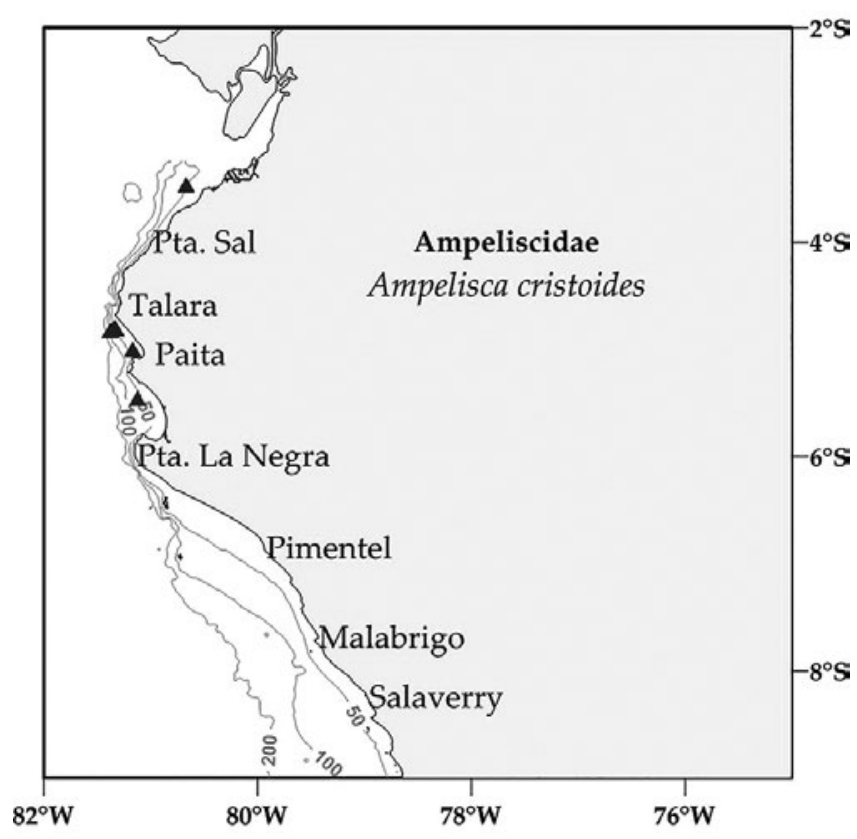

Figura 15. Distribución espacial de Ampelisca cristoides en la plataforma continental centro norte peruana. 


\section{Ampelisca hancocki J.L. Barnard, 1954}

Figura $16-18$.

Diagnosis: Cabeza no más larga que los 3 primeros segmentos del cuerpo. Antena 1 no alcanza el pedúnculo de la A2. Tamaño de la A2 sobre los 3/4 de la longitud total. Gnatópodos simples y delgados. Pereópodo 7 muy robusto, artejo 2 presenta un lóbulo expandido y alargado posteriormente hasta la mitad del artejo 4; artejo 3 y 4 igual en longitud; el artejo 4 con un lóbulo posterior setoso delgado; el artejo 6 expandido, más grande que 5; artejo 7 delgado y pequeño. El borde ínfero-lateral de la placa epimeral 3 con un diente pronunciado. Telson hendido delgado; cada lóbulo con ápice redondeado con una espina gruesa y una seta, la superficie con 2 espinas gruesas (Figs. 16, 17).

Material examinado: se examinó 86 especímenes, diseccionándose un ejemplar hembra de la estación C12 (03³5.4'S, 81ํ․6'W; $375 \mathrm{~m}$ ), del Crucero de Otońo del año 2011.

Hábitat: Sustrato blando, desde arena hasta fango.

Profundidad: 37 a $332 \mathrm{~m}$.

Localidades en la plataforma centro norte: $03^{\circ} 30^{\prime} \mathrm{S}$, $80^{\circ} 42^{\prime} \mathrm{W}$ a $06^{\circ} 00^{\prime} \mathrm{S}, 81^{\circ} 12^{\prime} \mathrm{W}$ (Fig. 18).

Distribución geográfica en el mundo: Columbia Británica hasta Costa Rica (Barnard, 1954), también reportada al norte peruano (García-Madrigal 2007).

Observaciones: esta especie es fácil de identificar por el dáctilo pequeño del pereópodo 7 y el ápice redondeado en los lóbulos del telson.

Referencias: Barnard 1954 (Págs. 37 - 38), Dickinson 1982 (Págs. 14 y 15).

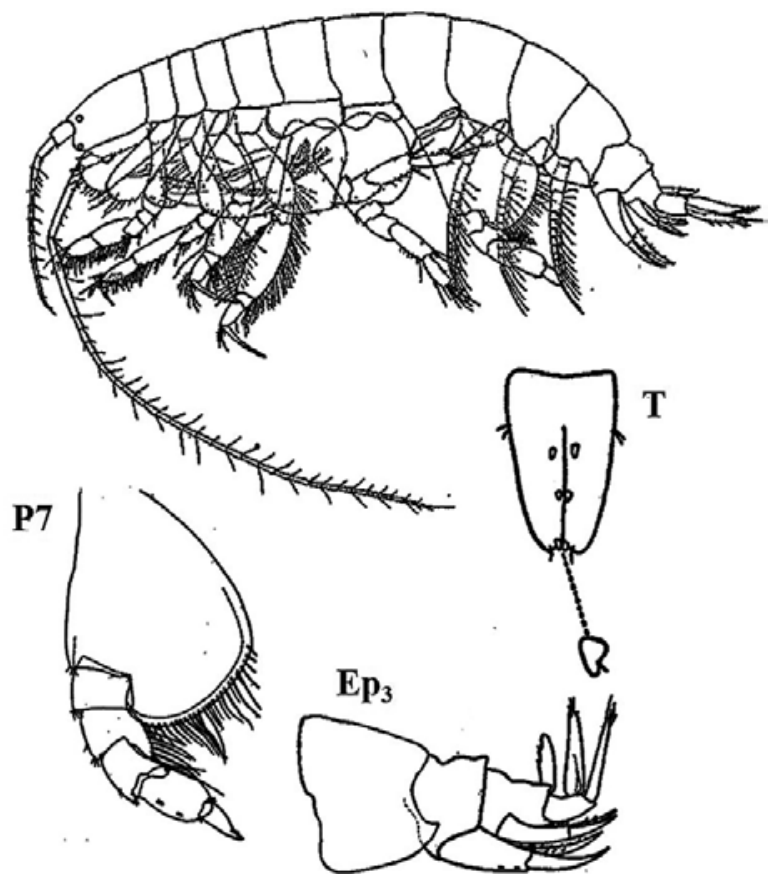

Figura 16. Características taxonómicas de Ampelisca hancocki J.L. Barnard, 1954: habitus, pereópodo 7 (P7), placa epimeral 3 (Ep3, sombreado) y telson (T), según Barnard (1954) y Dickinson (1982).
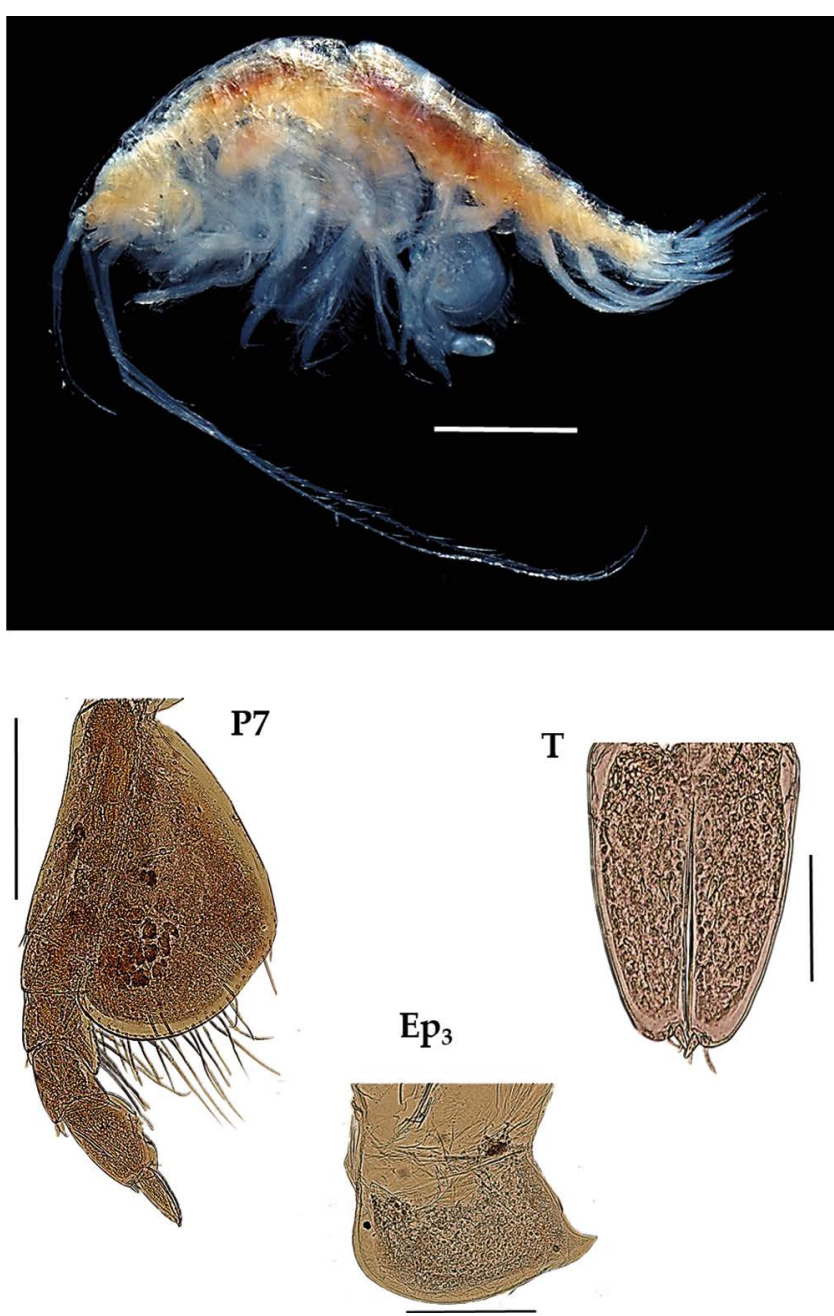

Figura 17. Ampelisca hancocki: pereópodo 7 (P7), placa epimeral 3 (Ep3) y telson (T). Escala: P7; 0.5 mm; Ep3: 250 $\mu \mathrm{m} ; \mathrm{T}: 100 \mu \mathrm{m}$.

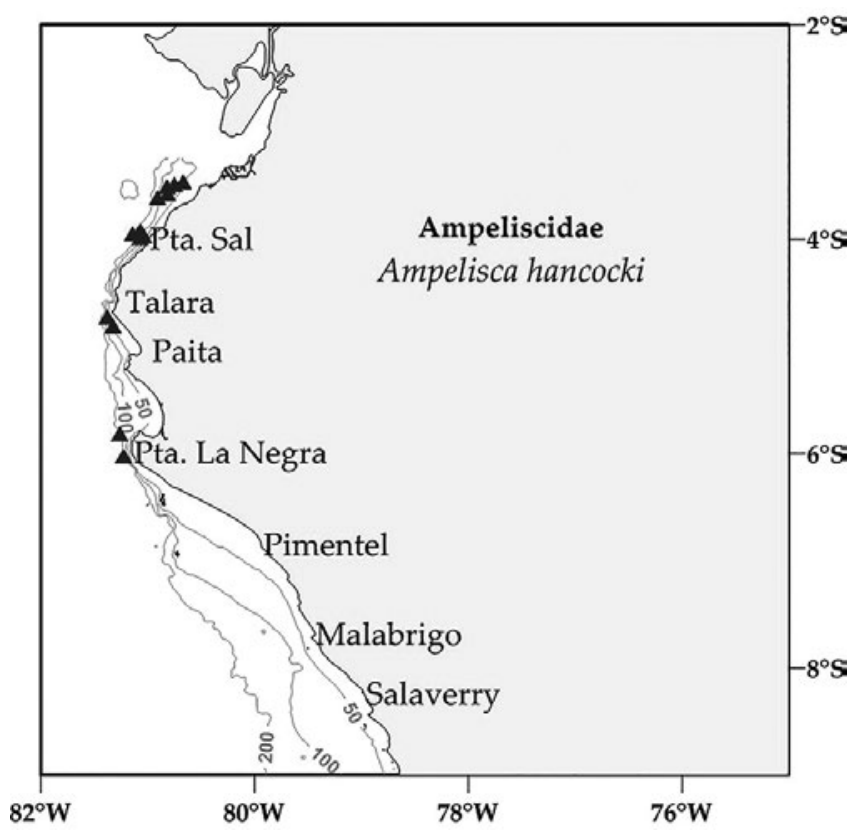

Figura 18. Distribución espacial de Ampelisca hancocki en la plataforma continental centro norte peruana. 


\section{Ampelisca lobata Holmes, 1908}

Figura $19-21$.

Diagnosis: Cabeza no tan largo que el tamaño de los 3 primeros segmentos del cuerpo. Antena 1 igual o sobrepasa la antena 2. Longitud de la A2 igual que el tamaño del cuerpo. Gnatópodos simples y delgados. Pereópodo 7 delgado, artejo 2 presenta un lóbulo expandido, redondeado y alargado posteriormente que alcanza el inicio del artejo 4; el lado posterior del artejo 4 con un lóbulo delgado y setoso; artejo 6 más largo que el 5 y 7. El ángulo postero inferior de la placa epimeral 3 con forma cuadrada, sin presencia de diente. Telson hendido; cada lóbulo presenta ápices con muesca y una espina terminal, la superficie con 3 espinas y una seta (no pudo ser enfocado en la foto) (Figs. 19, 20).

Material examinado: 65 especímenes fueron examinados; de donde se diseccionó un ejemplar hembra de la estación C63

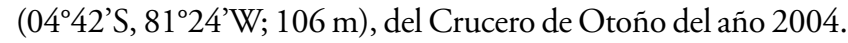

Hábitat: Sustrato blando, desde arena hasta fango.

Profundidad: 44 a $106 \mathrm{~m}$.

Localidades en la plataforma centro norte: $03^{\circ} 30^{\prime} \mathrm{S}$, $80^{\circ} 42^{\prime} \mathrm{W}$ a $04^{\circ} 42^{\prime} \mathrm{S}, 81^{\circ} 24 \mathrm{~W}$ (Fig. 21 )

Distribución geográfica en el mundo: California hasta Islas Lobos de Afuera, Perú (Barnard, 1954).

Observaciones: esta especie es similar a Ampelisca fagari, pero son diferenciables por el pereópodo 7 y urópodo 3 . Sinonimia con A. articulata (Stout 1913).

Referencias: Barnard 1954 (Págs. 11 - 14), Dickinson 1982 (Págs. 10 y 11).

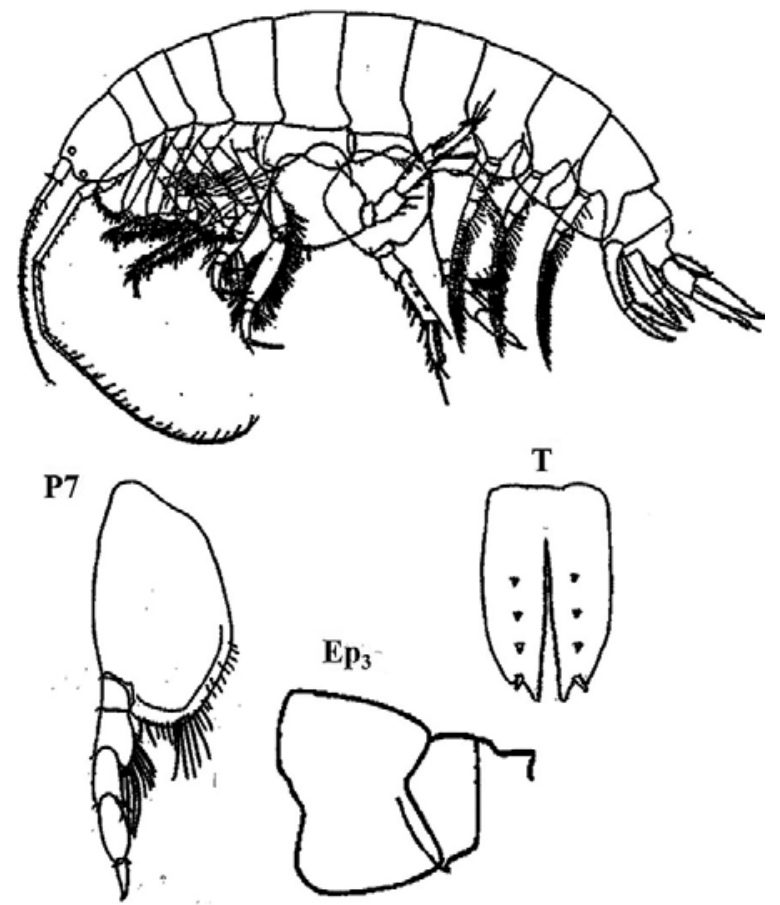

Figura 19. Características taxonómicas de Ampelisca lobata Holmes, 1908: habitus, pereópodo 7 (P7), placa epimeral 3 (Ep3, sombreado) y telson (T), según Barnard (1954) y Dickinson (1982).
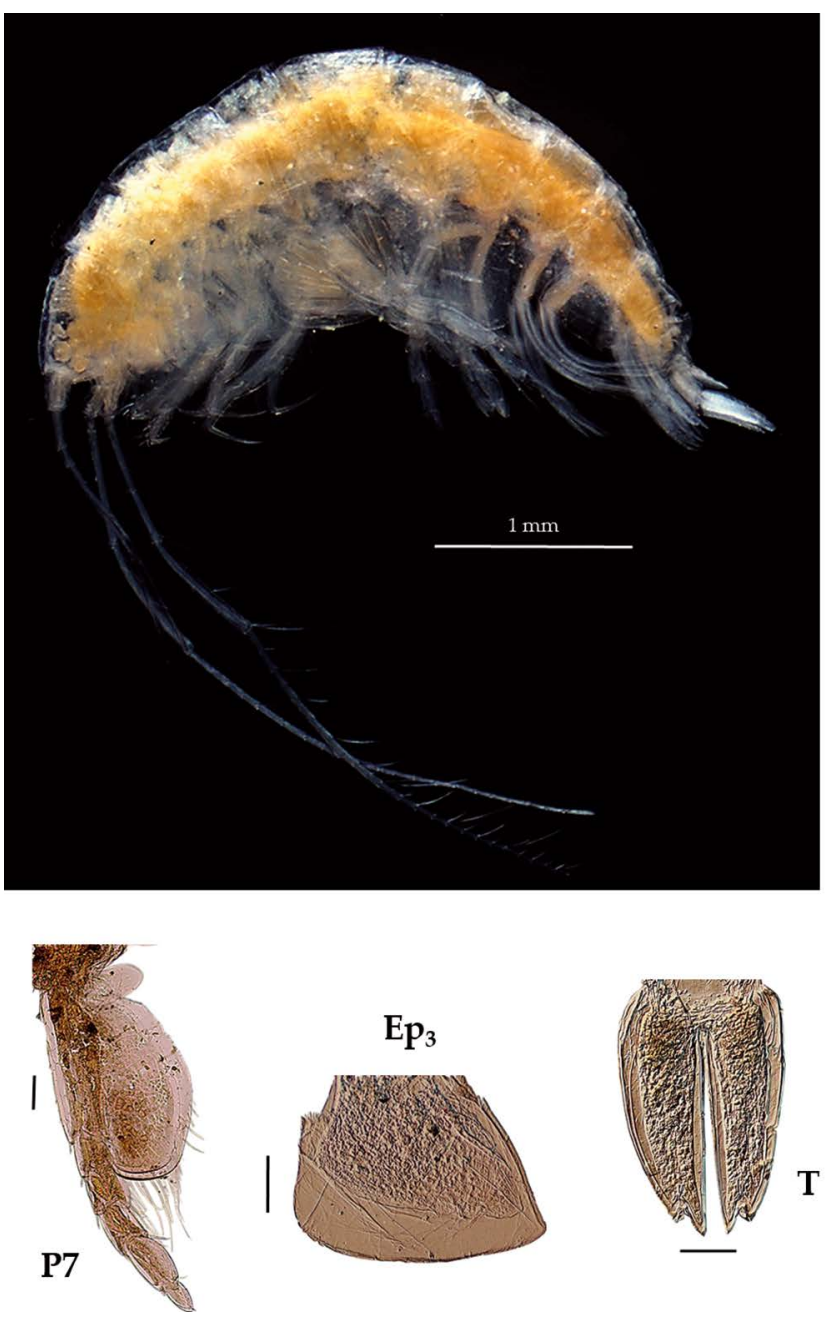

Figura 20. Ampelisca lobata: pereópodo 7 (P7), placa epimeral 3 (Ep3) y telson (T). Escala: P7; Ep3: $100 \mu \mathrm{m}$; T: $50 \mu \mathrm{m}$.

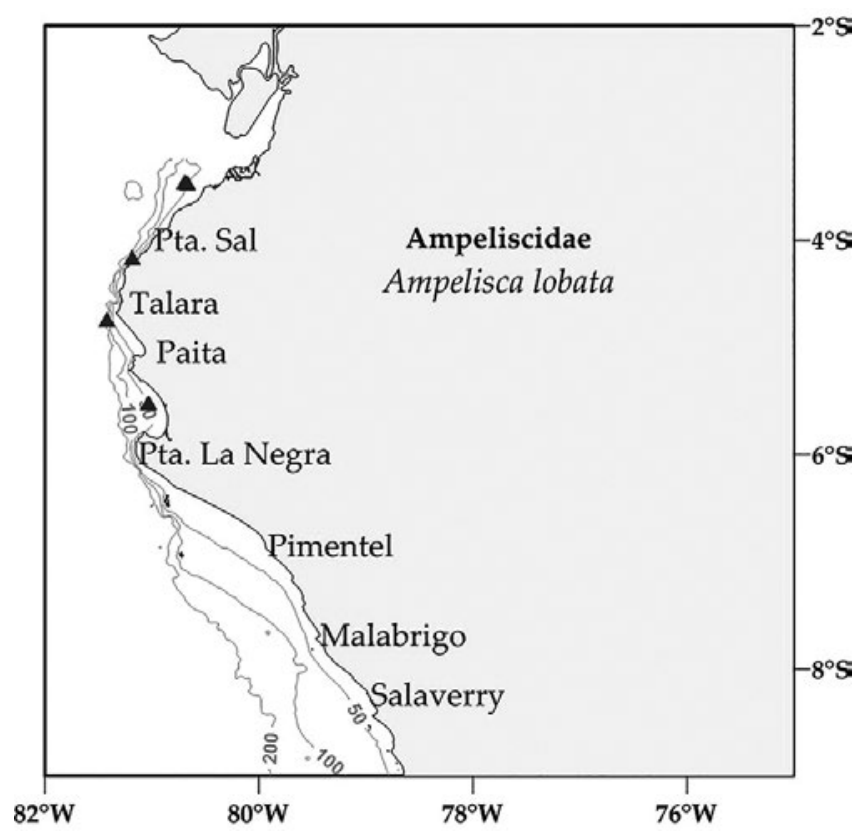

Figura 21. Distribución espacial de Ampelisca lobata en la plataforma continental centro norte peruana. 


\section{Ampelisca mexicana J.L. Barnard, 1954}

Figura $22-24$.

Diagnosis: cabeza no tan largo como la longitud de los 3 primeros segmentos. Antena 1 alcanza el final del pedúnculo de la antena 2. Gnatópodos simples y delgados. Pereópodo 7 , el artejo 2 con el lóbulo expandido posteriormente y truncado, alcanzando la mitad del artejo 4; artejo 3 más pequeño que el 4; artejo 5 corto; mientras que el artejo 6 es largo y expandido; artejo 7 delgado y fino. Urópodo 1 alcanza el final del U2. Placa epimeral 3 presenta una esquina postero-inferior con un diente fuerte. Telson hendido; cada lóbulo con muescas laterales en los ápices, la superficie con 3 setas (Figs. 22, 23).

Material examinado: 241 especímenes fueron examinados, diseccionando un ejemplar hembra de la estación C26 (04² $42^{\prime}$ S, $81^{\circ} 24$ 'W; 68 m.), del Crucero de Otońo del año 2005.

Hábitat: Sustrato blando, desde arena hasta fango.

\section{Profundidad: 45 a $340 \mathrm{~m}$.}

Localidades en la plataforma centro norte: $03^{\circ} 30^{\prime} \mathrm{S}$, $80^{\circ} 54^{\prime} \mathrm{W}$ a $05^{\circ} 42^{\prime} \mathrm{S}, 81^{\circ} 12^{\prime} \mathrm{W}$ (Fig. 24).

Distribución geográfica en el mundo: Baja California hasta Bahía Independencia (Perú) (Barnard 1954).

Observaciones: Presenta características similares a Ampelisca araucana, con algunas diferencias: la antena 1 no sobrepasa al pedúnculo de la antena 2 y el urópodo 1 no sobrepasa el final de U2. La distribución de $A$. mexicana se restringe al norte del grado $6^{\circ} \mathrm{S}$. La distribución descrita por Barnard (1954) la registra hasta Bahía independencia, pero fue antes del descubrimiento de A. araucana, lo que sugiere la confusión de las especies.

Referencias: Barnard 1954 (Págs. 45 - 46).

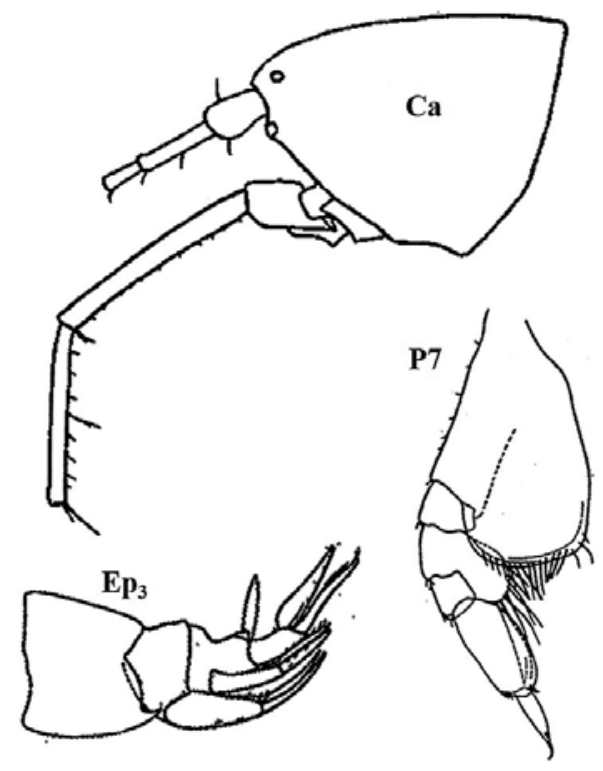

Figura 22. Características taxonómicas de Ampelisca mexicana J.L. Barnard, 1954: Cabeza (Ca), pereópodo 7 (P7), placa epimeral 3 (Ep3, sombreado) y telson $(T)$, según Barnard (1954).
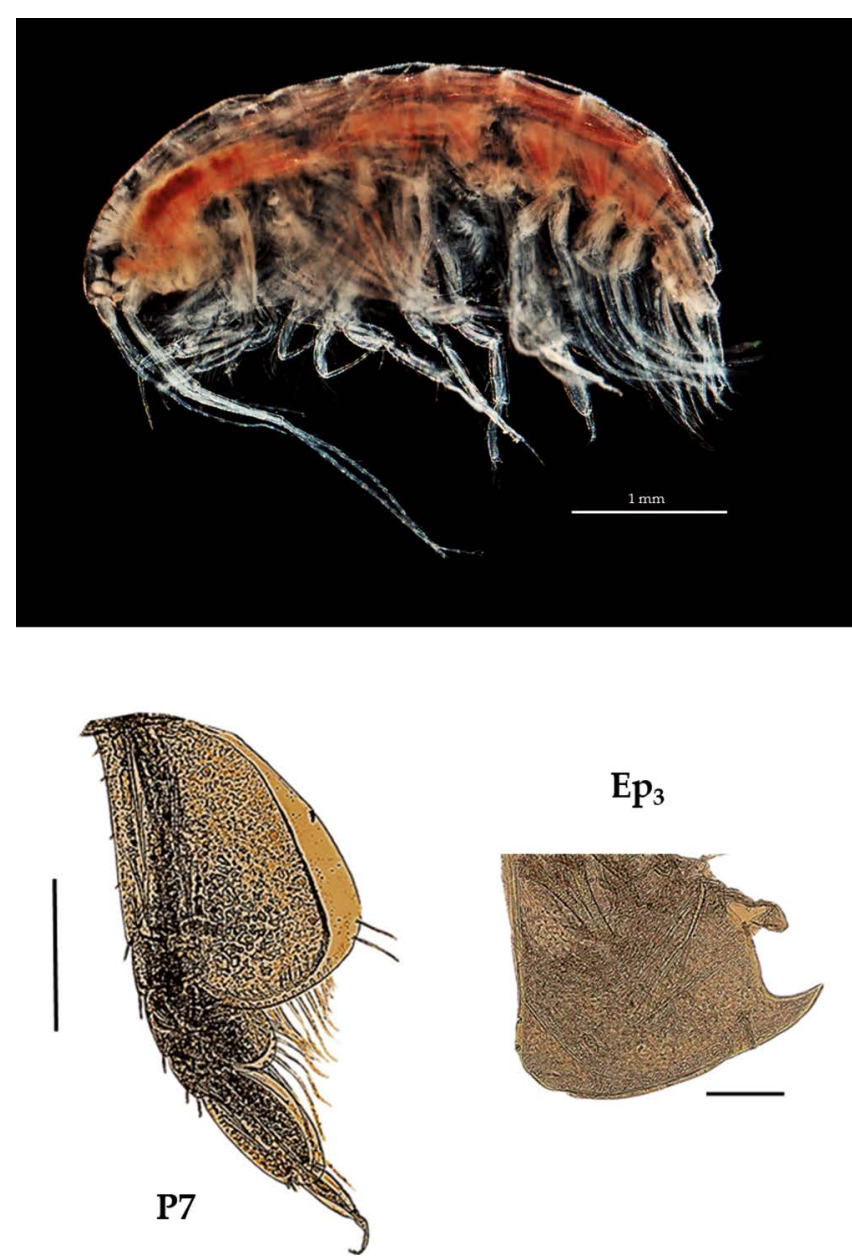

$\mathrm{Ep}_{3}$

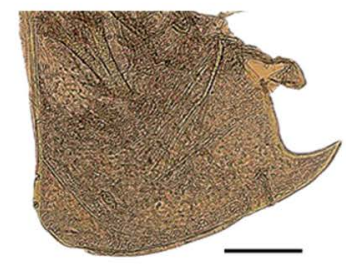

Figura 23. Ampelisca mexicana: pereópodo $7(\mathrm{P} 7)$ y placa epimeral 3 (Ep3). Escala: cuerpo: 1 mm; P7: 0.5 mm; Ep3: $50 \mu \mathrm{m}$.

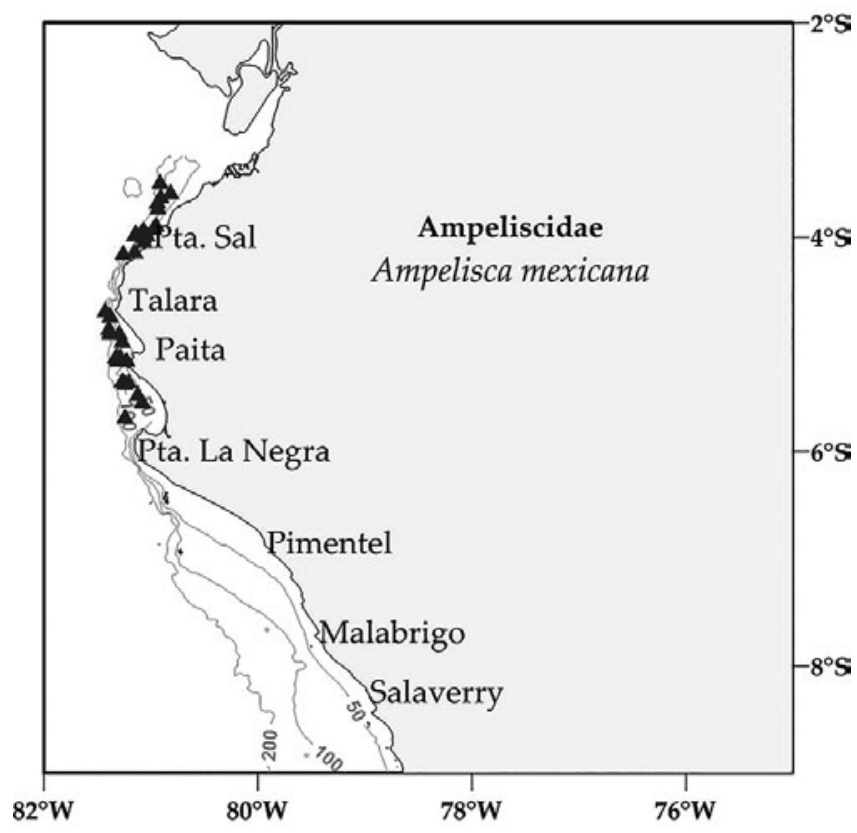

Figura 24. Distribución espacial de Ampelisca mexicana en la plataforma continental centro norte peruana. 


\section{Ampelisca pacifica Holmes, 1908}

Figura $25-27$.

Diagnosis: cabeza igual en longitud que los 3 primeros segmentos del cuerpo. Antena 1 no alcanza el final del pedúnculo de la antena 2. La longitud de la $\mathrm{A} 2$ representa $3 / 4 \mathrm{del}$ tamaño total del cuerpo. Gnatópodos 1 y 2 simples y delgados. Pereópodo 7, artejo 2 con forma de lóbulo, expandido posteriormente que alcanza más de la mitad del artejo 4; artejo 3 más pequeño que el artejo 4; el lado posterior del artejo 4 con un lóbulo delgado alargado, que alcanza a la mitad del artejo 5; artejo 5 más largo que el 4; mientras que el artejo 6 es largo y expandido; artejo 7 delgado y fino. Urópodo 3 con rama expandida y redondeada, con margen setoso. Telson hendido; cada lóbulo con 2 muescas centrales en los ápices y una seta bífida, la superficie con 3 setas bífidas (Figs. 25, 26).

Material examinado: 28 especímenes fueron examinados y un ejemplar hembra fue diseccionado de la estación C1 (03⒊ 35 ' 'S, 81ㄴ.4.8'W; $191 \mathrm{~m}$ ), del Crucero de Otońo del año 2016.

Hábitat: Sustrato blando, desde arena hasta fango.

Profundidad: 47 a $298 \mathrm{~m}$.

Localidades en la plataforma centro norte: $03^{\circ} 24^{\prime} \mathrm{S}$, $80^{\circ} 54^{\prime} \mathrm{W}$ a $04^{\circ} 24^{\prime} \mathrm{S}, 81^{\circ} \mathrm{W}$ (Fig. 27).

Distribución geográfica en el mundo: Sur de California (Punta Fermín) hasta Panamá.

Observaciones: esta especie se diferencia notablemente por la rama ancha, redondeada y setosa en el borde del urópodo 3. En la distribución descrita por Barnard (1954) y García-Madrigal (2007) sólo se registra hasta Panamá (Islas Secas) por lo que se considera como un nuevo registro para Sudamérica.

Referencias: Barnard 1954 (Págs. 21 - 22).

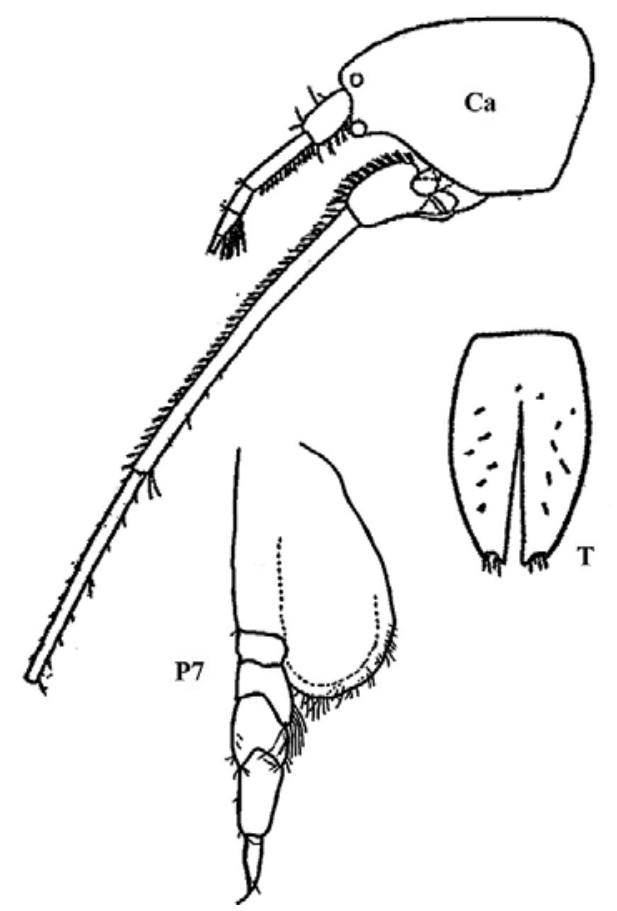

Figura 25. Características taxonómicas de Ampelisca pacifica Holmes, 1908: Cabeza (Ca), pereópodo 7 (P7), placa epimeral 3 (Ep3, sombreado) y telson (T), según Barnard (1954).
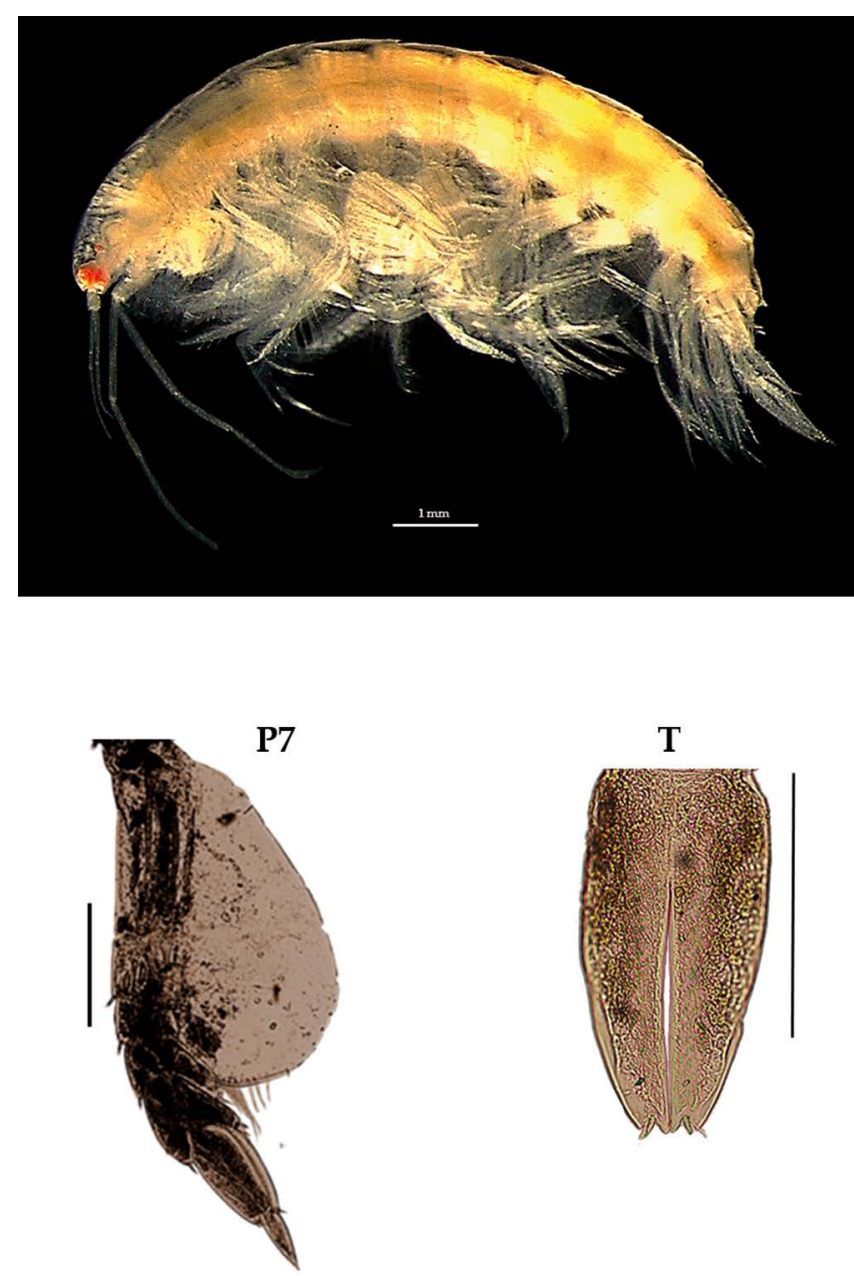

$\mathbf{T}$

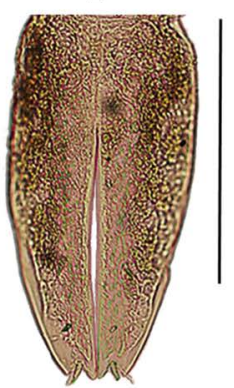

Figura 26. Ampelisca pacifica: pereópodo 7 (P7) y telson ( $\mathrm{T})$. Escala: P7; $0.5 \mathrm{~mm}$; T: $100 \mu \mathrm{m}$.

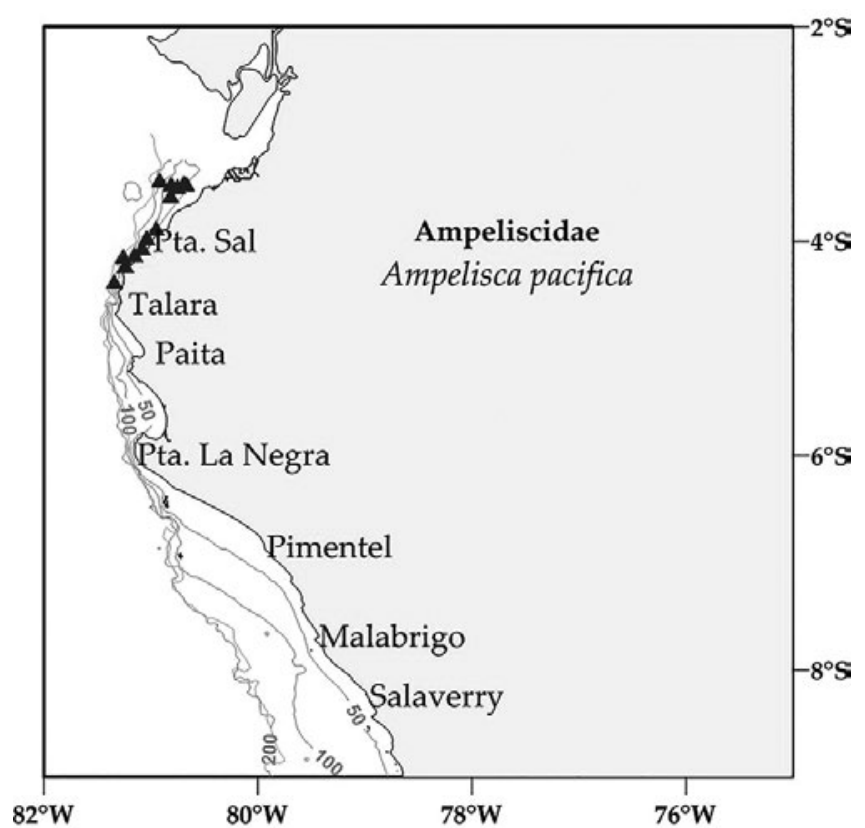

Figura 27. Distribución espacial de Ampelisca pacifica en la plataforma continental centro norte peruana. 


\section{Ampelisca pugetica Stimpson, 1864}

Figura $28-30$.

Diagnosis: Cabeza no tan larga como los tres primeros segmentos del cuerpo. Antena 1 no alcanza la longitud del pedúnculo de la antena 2; mientras que la longitud de la antena 2 más de $3 / 4$ la longitud del cuerpo. Gnatópodos 1 y 2 simples y alargados. Pereópodo 7, artejo 2 en forma de lóbulo, redondeado en la parte posterior y extendido hasta el final del artejo 4; artejo 3 corto e iguales en longitud al artejo 4, aunque el lóbulo posterior del artejo 4 alargado, expandido y setoso hasta la 3/4 del artejo 5; el artejo 6 amplio (dos veces su longitud); artejo 7 fino y expandido. El urópodo 3 presenta ramas iguales en tamaño, delgada y lanceolada, con setas terminales. La placa epimeral 3 con un pequeño diente posterior. Telson hendido, cada lóbulo con ápices puntiagudos y muesca en el borde externo con 2 a 3 setas alargadas, en la superficie presentan entre 2 a 4 setas alargadas (Figs. 28, 29).

Material examinado: 88 especímenes fueron examinados, diseccionando un ejemplar hembra de la estación C55 (06³0'S, $80^{\circ} 54$ 'W; 56 m), del Crucero de Otońo del año 2007.

Hábitat: Sustrato blando de fango y arena. Según Barnard (1954) también está asociada a macroalgas (Ulva sp.), rocas, esponjas, restos de conchuelas.

Profundidad: 35 a $363 \mathrm{~m}$.

Localidades en la plataforma centro norte: $03^{\circ} 36^{\prime} \mathrm{S}$, $80^{\circ} 48^{\prime} \mathrm{W}$ a $07^{\circ} 30^{\prime} \mathrm{S}, 80^{\circ} 12^{\prime} \mathrm{W}$ (Fig. 30 )

Distribución geográfica en el mundo: Costas de Baja California hasta Perú (Bahía Independencia), según Barnard (1954) y García-Madrigal (2007).

Observaciones: Sinonimia con Ampelisca californica Holmes 1908 (Págs. 513 - 515, fig. 23), Ampelisca gnathia Barnard 1954a (Págs. 48 - 51). Se encuentra en hábitats similares de Ampelisca araucana.

Referencias: Barnard 1954 (Págs. 49 - 51), Dickinson 1982 (Págs. 17 - 18, fig. 10).

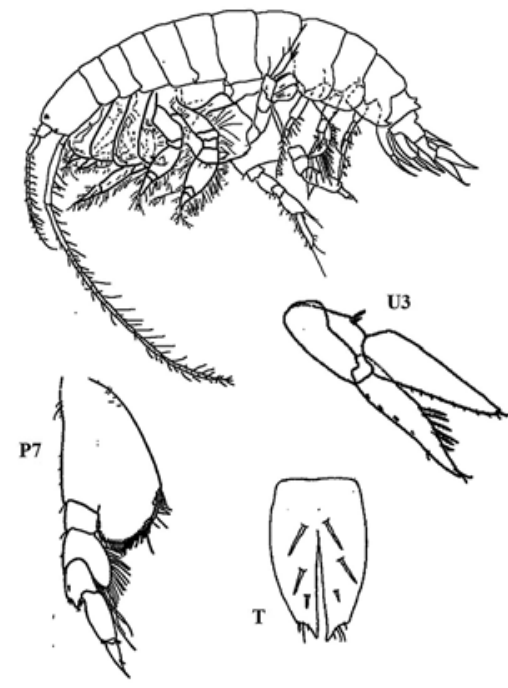

Figura 28. Características taxonómicas de Ampelisca pugetica Stimpson, 1864: habitus, pereópodo 7 (P7) y telson (T), según Barnard (1954) y Dickinson (1982).

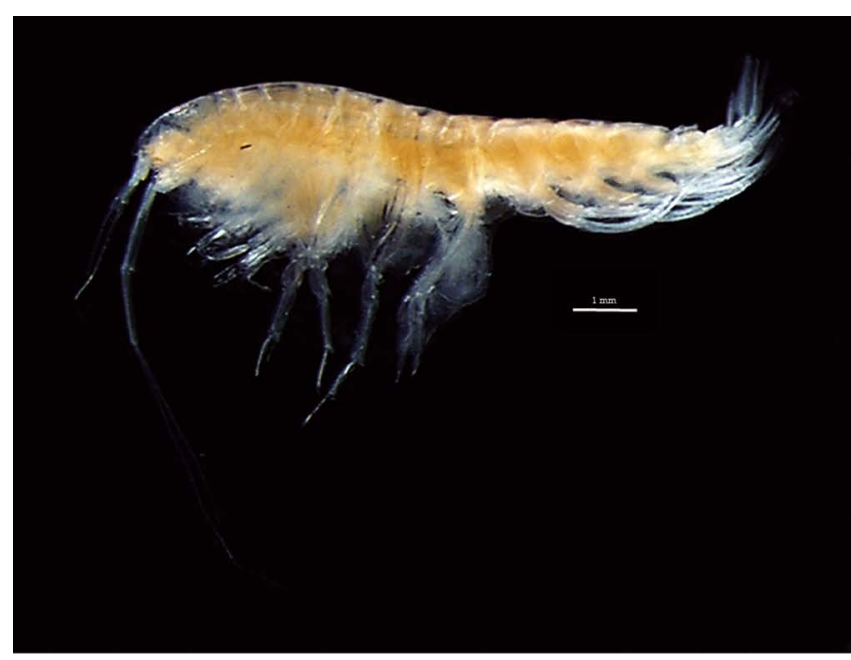

U3

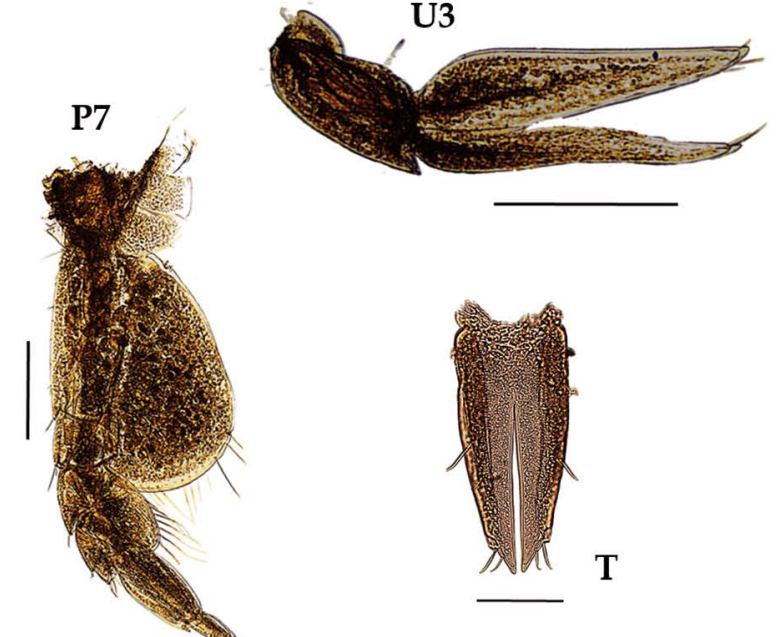

Figura 29. Ampelisca pugetica: pereópodo $7(\mathrm{P} 7)$ y telson (T). Escala: P7; $0.5 \mathrm{~mm}$; T: $50 \mu \mathrm{m}$.

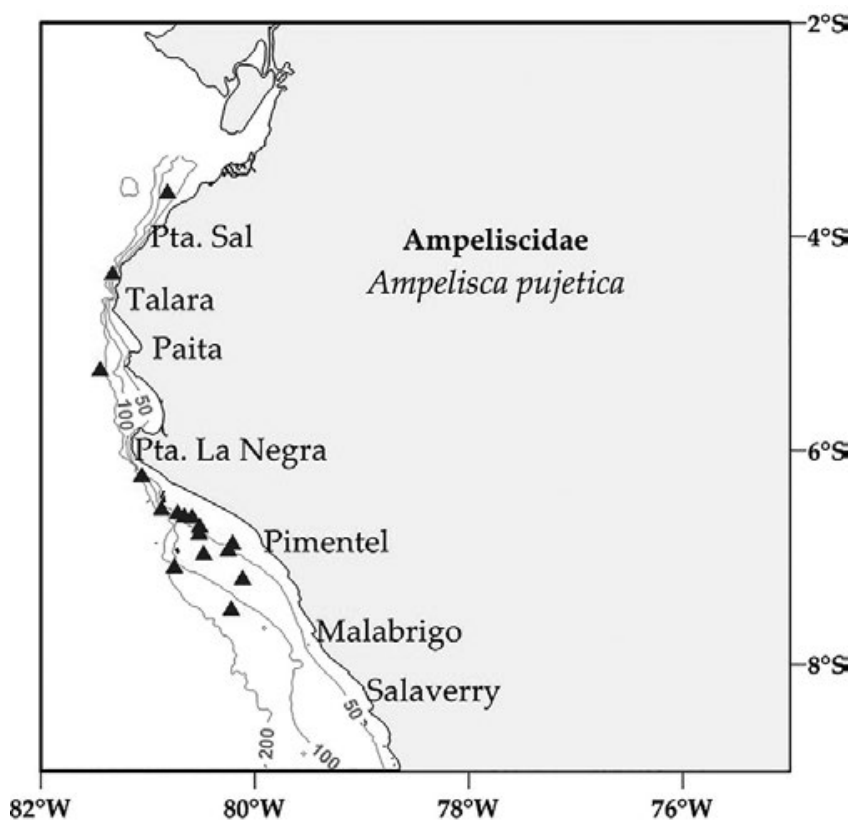

Figura 30. Distribución espacial de Ampelisca pugetica en la plataforma continental centro norte peruana. 


\section{Ampelisca sp.}

Figura $31-32$.

Diagnosis: Cabeza no tan larga como los tres primeros segmentos del cuerpo. Antena 1 no alcanza la longitud del pedúnculo de la antena 2 ; mientras que la longitud de la A2 no alcanza más de la mitad del tamaño del cuerpo. Gnatópodos 1 y 2 simples y alargados. Pereópodo 7 , artejo 2 formando un lóbulo expandido truncado y setoso en la parte terminal hasta la mitad del artejo 5; artejo 3 corto; artejo 3 y 4 de igual tamańo, aunque el lóbulo posterior del artejo 4 alargado setoso alcanza la mitad del artejo 5; el artejo 6 amplio (dos veces su longitud); artejo 7 expandido y fino. Placa epimeral 3 redondeado, sin presencia de setas o diente. El urópodo 3 presenta ramas iguales en tamańo, delgadas, con setas terminales alargadas y presencia de una espina terminal en una de las ramas. Telson hendido, cada lóbulo con ápice redondeado y muesca en el centro de cada lóbulo, con una seta alargada, en la superficie presenta una seta en la parte media central (Fig. 31).

Material examinado: se examinaron 74 especímenes, de donde se diseccionó un ejemplar hembra de la estación C44 (06 $12^{\circ}$ 'S, $\left.81^{\circ} 00^{\prime} W ; 37 \mathrm{~m}\right)$, Crucero de Otoño del año 2006.

Hábitat: Sustrato blando, fangoso.

Profundidad: 24 a $372 \mathrm{~m}$.

Localidades en la plataforma centro norte: $03^{\circ} 36^{\prime} \mathrm{S}$, $80^{\circ} 48^{\prime} \mathrm{W}$ a $07^{\circ} 54^{\prime} \mathrm{S}, 80^{\circ} 06^{\prime} \mathrm{W}$ (Fig. 32).

Observaciones: estos especímenes se diferencian del resto de especies del género Ampelisca descritos hasta la actualidad (Barnard 1954, Dickinson 1982, Mills 1967), por importantes caracteres, como la forma redondeada de la placa epimeral 3 sin diente en la zona lateral inferior y telson ligeramente más largo que ancho, con una espina en la parte posterior del lóbulo (estas características se asemeja más al descrito para el género Byblis); sin embargo esta especie puede estar relacionada con Ampelisca brachycladus (Roney 1990). Estos ejemplares podrían ser considerados como nueva para la ciencia, ya que los caracteres descritos no se evidencian en las publicaciones sobre el género.

Referencias: Barnard 1954, Dickinson 1982, Mills 1967, Roney 1990.

\section{Byblis cf. millsi Dickinson, 1983}

Figura 33 - 35.

Diagnosis: Cabeza anterior a la inserción de la antena 1; ojos bien desarrollados. Antena 1 no sobrepasa el pedúnculo de la antena 2. La longitud de A2 representa el 2/3 del tamańo total del cuerpo. Gnatópodos 1 y 2 simples y alargados. Pereópodo 7 , artejo 2 forma un lóbulo posterior expandido, llegando hasta el artejo 5; el artejo 4 soporta solo una espina larga en cada margen distal, al igual que el artejo 5; aunque este presenta más setas en los bordes; el artejo 6 con tres filas de espinas. Artejo 7 delgado y afinado, con una seta terminal. La rama del urópodo 1 igual en tamaño y longitud; rama externa del urópodo 3 ligeramente más grande que la interna y margen medio de ambas ramas $2 / 3$ aserradas. Placa epimeral 3 presenta el borde postero lateral redondeado. Telson hendido con una base amplia, similar al tamaño vertical; ápices festoneados con espinas pequeñas y
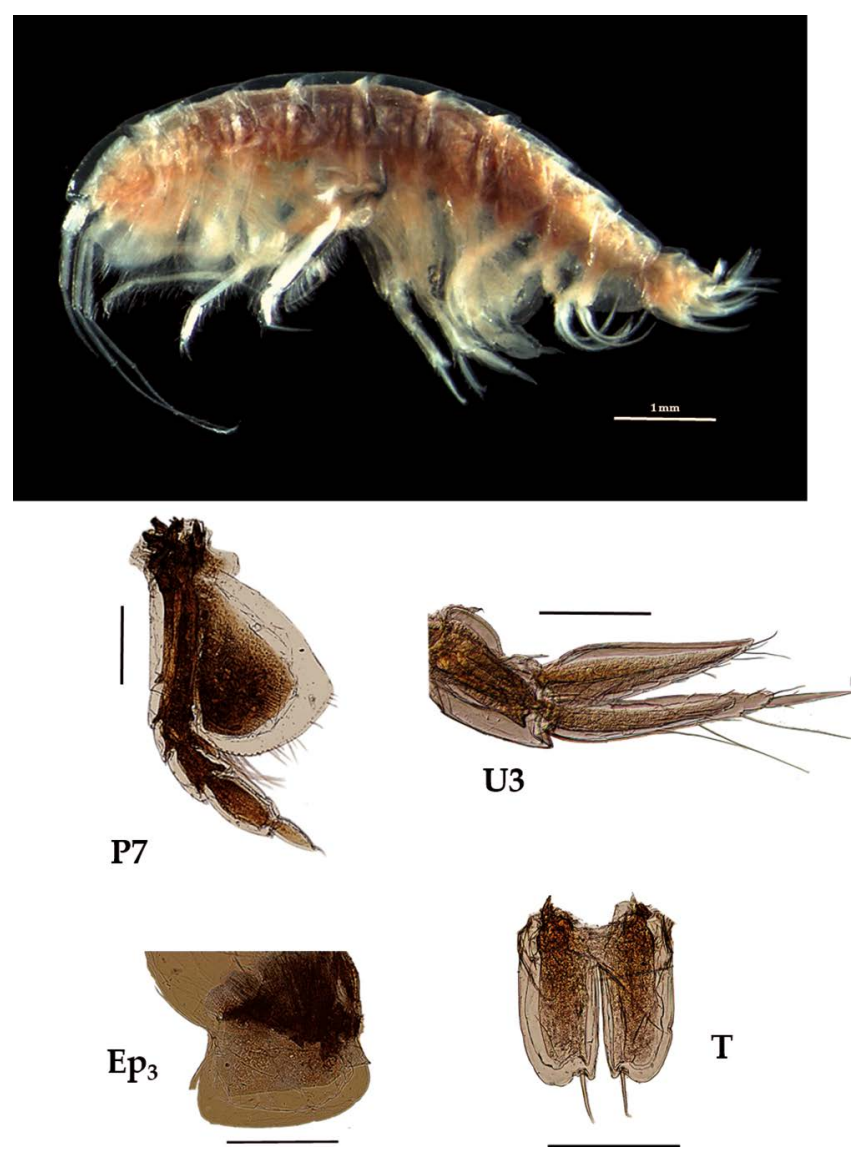

Figura 31. Características taxonómicas de Ampelisca sp.: pereópodo 7 (P7), urópodo 3 (U3); placa epimeral 3 (Ep7) y telson (T). Escala: P7 y Ep3: 0.5 mm; U3: $250 \mu \mathrm{m}$; T: $200 \mu \mathrm{m}$.

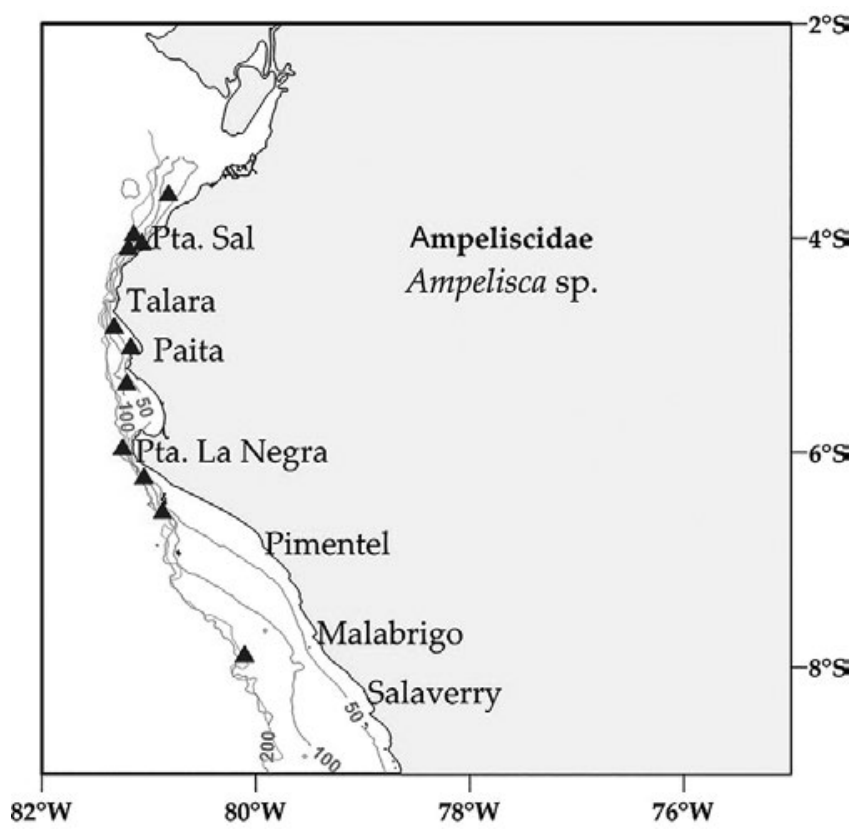

Figura 32. Distribución espacial de Ampelisca sp. en la plataforma continental centro norte peruana. 
espaciadas; hendidura que no alcanza la mitad de la longitud total; sobre cada lóbulo con un par de setas cerca al lado externo de la base y sobre la parte anterior (Figs. 33, 34).

Material examinado: 25 especímenes fueron examinados. Asimismo, se diseccionó un ejemplar hembra de la estación C39 $\left(05^{\circ} 10.2^{\prime}\right.$ S, 81 $\left.1^{\circ} 14.4^{\prime} \mathrm{W} ; 90 \mathrm{~m}\right)$, Crucero de Otoño del año 2016.

Hábitat: arena y fango.

Profundidad: 61 a $140 \mathrm{~m}$.

Localidades en la plataforma centro norte: $03^{\circ} 30^{\prime} \mathrm{S}$, $80^{\circ} 48^{\prime} \mathrm{W}$ a $05^{\circ} 42^{\prime}$ S, $81^{\circ} 06^{\prime} \mathrm{W}$ (Fig. 35 ).

Distribución geográfica en el mundo: Sur de California hasta el norte del mar peruano.

Observaciones: los especímenes analizados son considerados con características similares a Byblis millsi, como ojos bien desarrollados y ramas del urópodo 1 con la longitud subigual. Sin embargo, al sur de California, esta B. millsi se encontró junto a Byblis veleronis, con diferencias en el tamaño, la longitud de la antena 1 , forma y aserración de las coxas interiores y patrones de aserración del urópodo 3, por lo que es conveniente un análisis más fino, comparando todos los apéndices con ambas especies para definir la especie de esta parte del océano Pacífico.

Referencias: Dickinson 1982, 1983 (Pág. 11, Figs. 6-8).

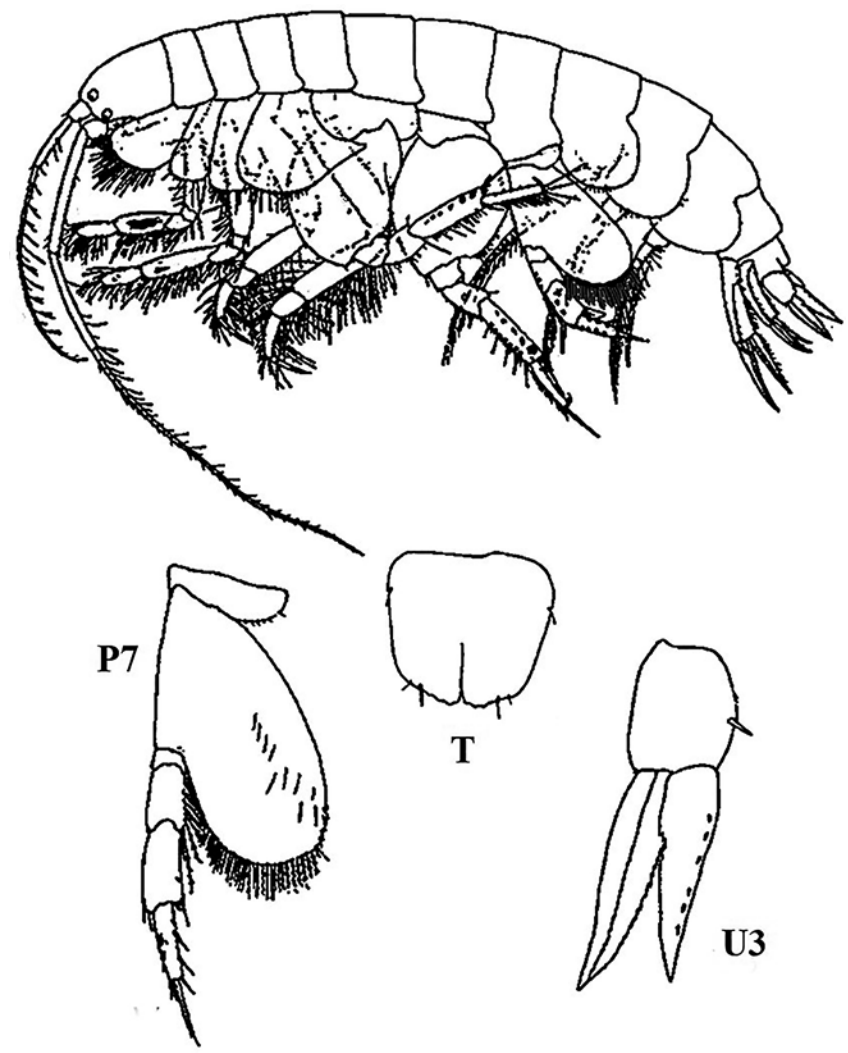

Figura 33. Características taxonómicas de Byblis cf. millsi Dickinson, 1983: Habitus, pereópodo 7 (P7), placa epimeral 3 (Ep3, sombreado) y telson (T), según Dickinson (1982).
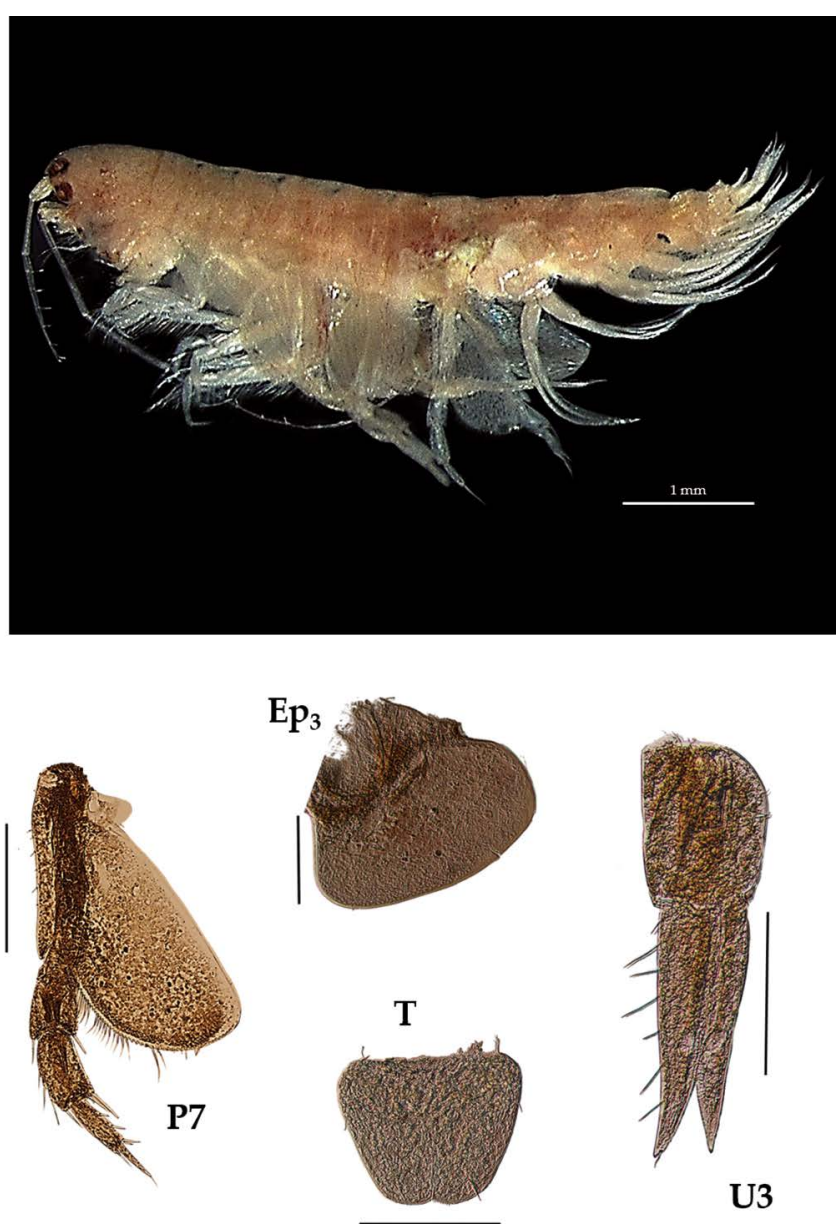

U3

Figura 34. Byblis cf. millsi: pereópodo 7 (P7), urópodo 3 (U3); placa epimeral 3 (Ep3) y telson (T). Escala: P7; 0.5 mm; U3 y Ep3: $250 \mu \mathrm{m}$; T: $200 \mu \mathrm{m}$.

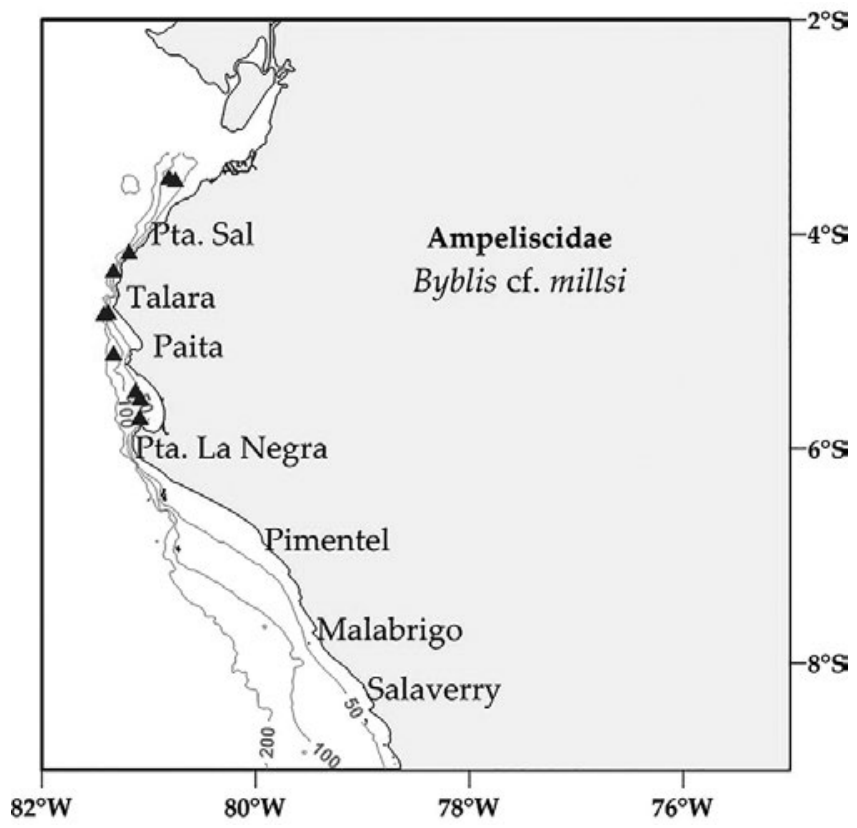

Figura 35. Distribución espacial de Byblis cf. millsi en la plataforma continental centro norte peruana. 


\section{FAMILIA ARgISSIDAE WALKER, 1904}

12. Argissa hamatipes Norman, 1869

Figura $36-38$.

Diagnosis: Flagelo accesorio presente en la antena 1. Antena 2 no llega a la mitad del tamaño total. El tamańo de la coxa 1 disminuye sucesivamente hacia la 3; siendo la Coxa 4 la de mayor tamańo. Gnatópodos 1 y 2 débiles simples. Pereópodo 7 parecido en forma de la familia Ampeliscidae, con base lobular expandida y redondeada que no alcanza el final del artejo 4; los artejos bordeados con setas alargadas plumosas y artejo 7 corto y puntiagudo. Urópodo 3 birrámeo, con presencia de setas plumosas en los bordes. Telson con hendidura hasta la base, dando lugar a lóbulos que presentan 2 setas en el ápice (Figs. 36, 37).

Material examinado: siete (07) especímenes fueron examinados y un ejemplar hembra fue diseccionado, de la estación C20 (449.8'S, 81¹8.6'W; 38 m), Crucero de Otońo del año 2015.

Hábitat: fondo blando, areno fangoso.

Profundidad: 24 a $106 \mathrm{~m}$.

Localidades en la plataforma centro norte: $04^{\circ} 42^{\prime} \mathrm{S}$, $81^{\circ} 24^{\prime} \mathrm{W}$ a $06^{\circ} 12^{\prime} \mathrm{S}, 81^{\circ} 00^{\prime} \mathrm{W}$ (Fig. 38).

Distribución geográfica en el mundo: Atlántico Norte, Costas de América del Norte, Océano Ártico, Mar del Norte, costas de Europa (Noruega hacia Canal Ingles), Sudáfrica (Shoemaker 1930, Griffiths 1976, Lincoln 1979).

Observaciones: en ambientes someros pueden observarse especímenes con presencia de ojos con 4 lentes, a diferencia de los ampelíscidos con 2 lentes; sin embargo a mayores profundidades no se evidencian lentes, como lo reporta Lincoln (1979) hasta en $1000 \mathrm{~m}$. Se ha registrado sinonimia por su amplia distribución Syrrhoe hamatipes Norman, 1869; Argissa typica Boeck, 1871.

Referencias: Stebbing 1906 (Pág. 277), Shoemaker 1930 (Págs. 255 - 258, Figs. 15, 16), Griffiths 1976 (Págs. 27, fig. 11), Lincoln 1979 (Págs. 334 - 335, Fig. 157).

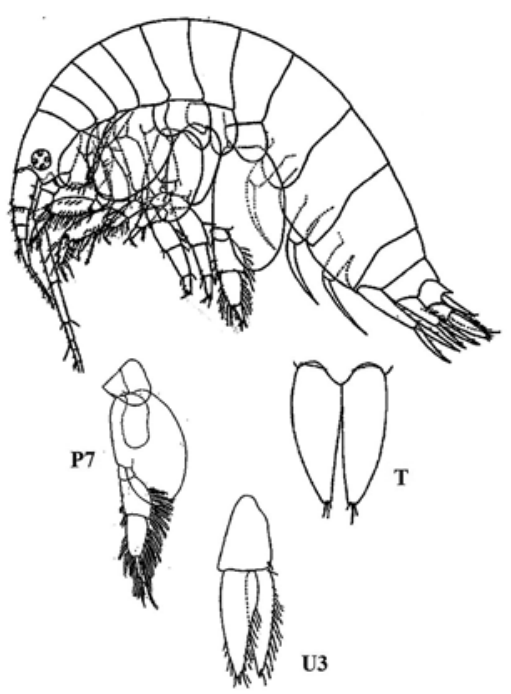

Figura 36. Características taxonómicas de Argissa hamatipes Norman, 1869: Habitus, pereópodo 7 (P7), urópodo 3 (U3) y telson (T), según Shoemaker (1930) y Bousfield (1973).
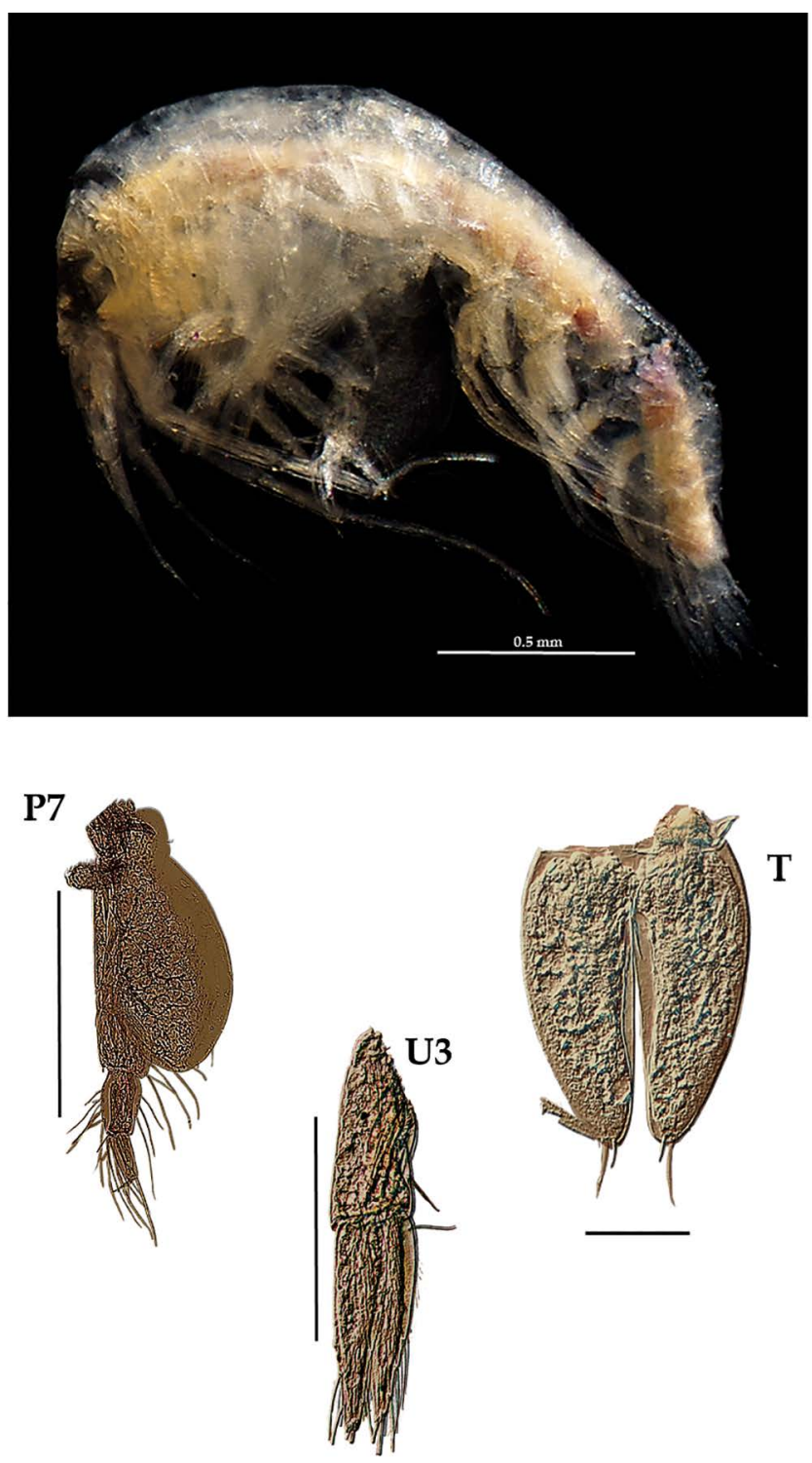

Figura 37. Argissa hamatipes: pereópodo 7 (P7), urópodo 3 (U3) y telson (T). Escala: P7; 0.5 mm; U3: $200 \mu \mathrm{m}$; T: $50 \mu \mathrm{m}$.

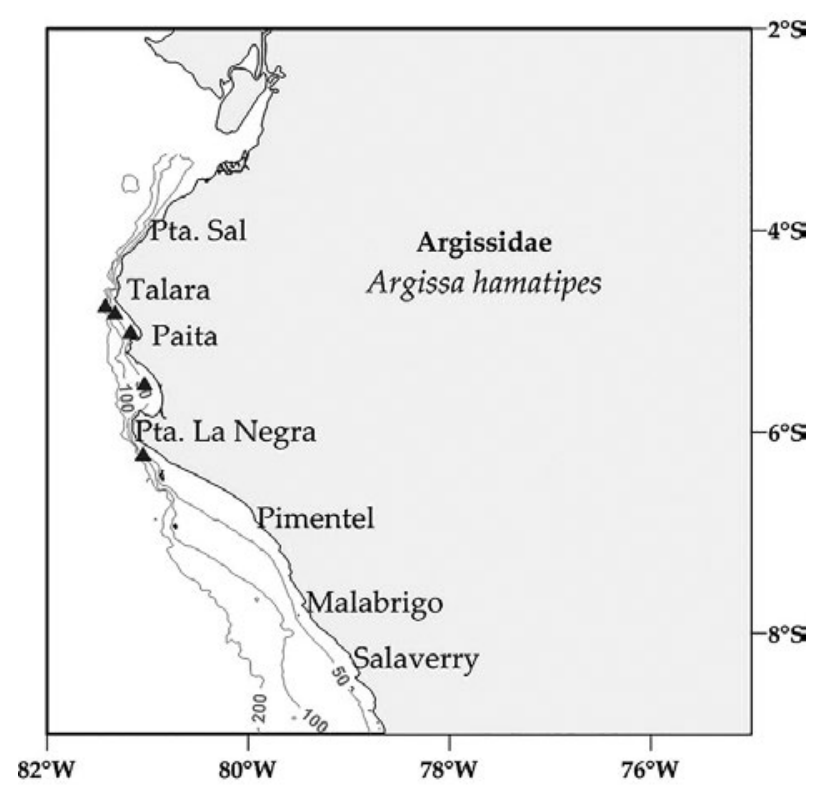

Figura 38. Distribución espacial de Argissa hamatipes en la plataforma continental centro norte peruana. 


\section{FAMILIA EUSIRIDAe StebBING, 1888}

\section{Rhachotropis sp.}

$$
\text { Figura } 39-41
$$

Diagnosis: la cabeza presenta un rostro largo, puntiagudo, encorvado. Ojos pigmentados. Gnatópodos 1 y 2, el artejo 5 alargado, con lóbulo posterior ancho y unido próximamente al artejo 6. Pleón 2 dorsalmente aguzado o dentado. Urópodo 3 birrámeo, subigual, márgenes con setas cortas. Telson hendido hasta $1 / 3$ de la longitud total, alargado y aguzado en la parte terminal. Borde posterior de la placa epimeral 3 dorsalmente dentado (Figs. 39, 40).

Material examinado: cuatro (04) ejemplares fueron examinados, de donde un ejemplar hembra fue diseccionado de la estación EA ( $\left.05^{\circ} 24^{\prime} \mathrm{S}, 81^{\circ} 18^{\prime} \mathrm{W} ; 128 \mathrm{~m}\right)$, del Crucero de Otoño del año 2004.

Hábitat: fondo blando.

Profundidad: 128 a $179 \mathrm{~m}$.

Localidades en la plataforma centro norte: $05^{\circ} 24^{\prime} \mathrm{S}$, $81^{\circ} 18^{\prime} \mathrm{W}$ a $06^{\circ} 18^{\prime} \mathrm{S}, 81^{\circ} 00^{\prime} \mathrm{W}$ (Fig. 41 ).

Distribución geográfica en el mundo: Este género se encuentra ampliamente distribuido, tanto a nivel geográfico, como de profundidad (Bellan-Santini 2006) y especialmente en el Pacífico norte desde Alaska hacia Baja California.

Observaciones: las características morfológicas de los especímenes presentan diferencias con las especies descritas actualmente (61 spp. WoRMS, 2018), por la forma y tamańo de la hendidura del telson. Estas características le permitirían ser considerada como una especie nueva para la ciencia. Asimismo, la familia Eusiridae es considerada dentro las familias nadadoras por su especialidad predadora pelágica (Bousfield \& Hendrycks 1995).

Referencias: Thurston 1980, Bellan-Santini 2006, Lorz 2010, Bousfield \& Hendrycks 1995.

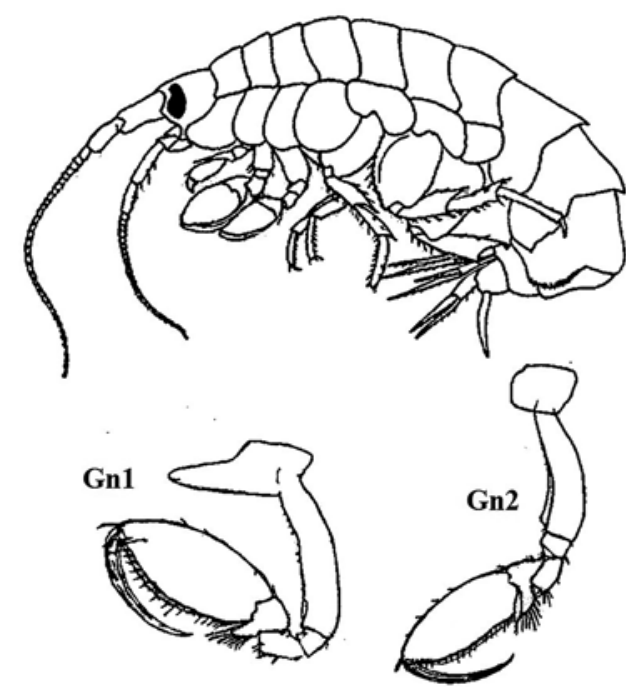

Figura 39. Características taxonómicas de Rhachotropis macropus G. O. Sars, 1896: Habitus, Gnatópodo 1 (Gn1), Gnatópodo 2 (Gn2), según Bousfield \& Hendrycks (1995).
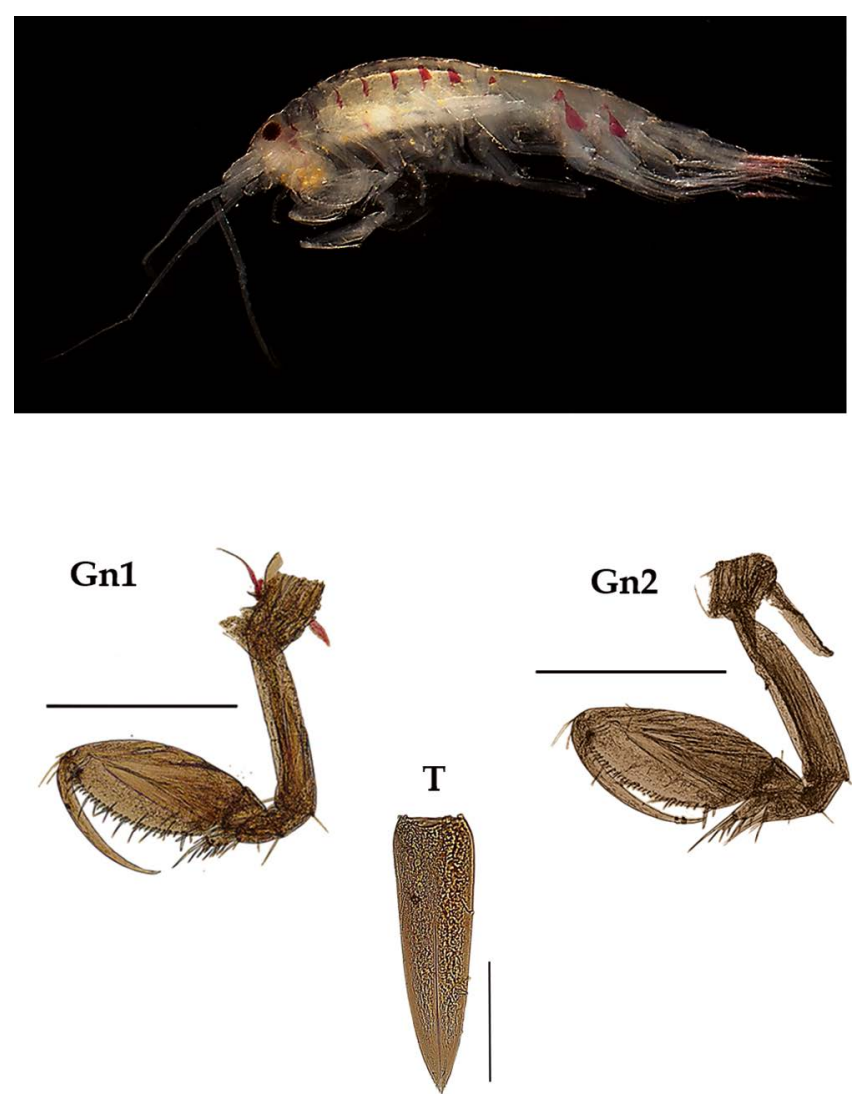

Figura 40. Rhachotropis sp.: Gnatópodo 1 (Gn1), Gnatópodo 2 (Gn2) y telson (T). Escala: Gn1 y Gn2; 0.5 mm; T: $250 \mu \mathrm{m}$.

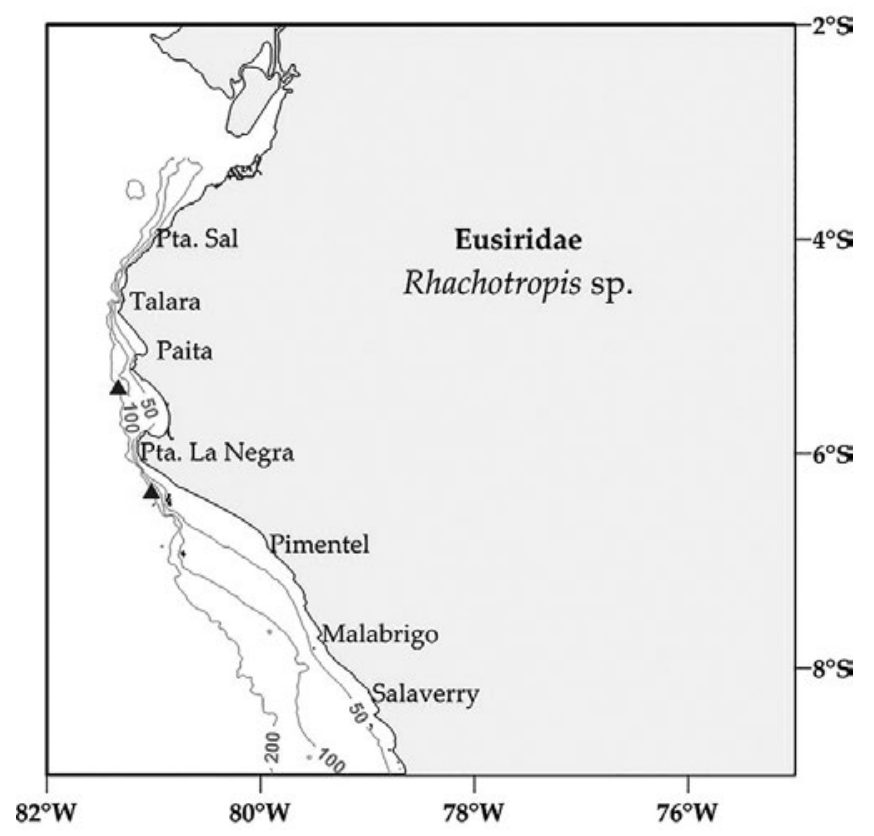

Figura 41. Distribución espacial de Rhachotropis sp. en la plataforma continental centro norte peruana. 
FAmilia Megaluropidae Thomas \& J.L. BARNARD 1986

\section{Resupinus coloni Thomas \& J.L. Barnard 1986}

$$
\text { Figura } 42-44 .
$$

Diagnosis: La cabeza presenta un rostro alargado y puntiagudo. Los ojos elongados, alargados, compuesto de omatidios redondeados de color rojo oscuro. Gnatópodos 1 y 2 pequeños, simples. Gnatópodo 1 con el artejo 4 no más largo y expandido que el artejo 5 . Gnatópodo 2, artejo 5 forma un lóbulo expandido, dispuesto de forma triangular, setas agrupadas en el margen distal de lóbulo. La placa epimeral 3, dorsalmente aserrado en el margen posterior, con 3 setas posteriores. Telson marginado (hendido), cada lóbulo con 3 setas en el ápice (Figs. 42, 43).

Material examinado: 18 especímenes fueron examinados, de donde se diseccionó un ejemplar hembra de la estación E20 $\left(05^{\circ} 00^{\prime} \mathrm{S}, 81^{\circ} 12^{\prime} \mathrm{W} ; 24 \mathrm{~m}\right)$, Crucero de Otońo del año 2010.

Hábitat: fondo de arena, arcilla o limo.

Profundidad: 24 a $81 \mathrm{~m}$.

Localidades en la plataforma centro norte: $04^{\circ} 48^{\prime} \mathrm{S}$, $81^{\circ} 18^{\prime} \mathrm{W}$ a $07^{\circ} 54^{\prime} \mathrm{S}, 79^{\circ} 30^{\prime} \mathrm{W}$ (Fig. 44 ).
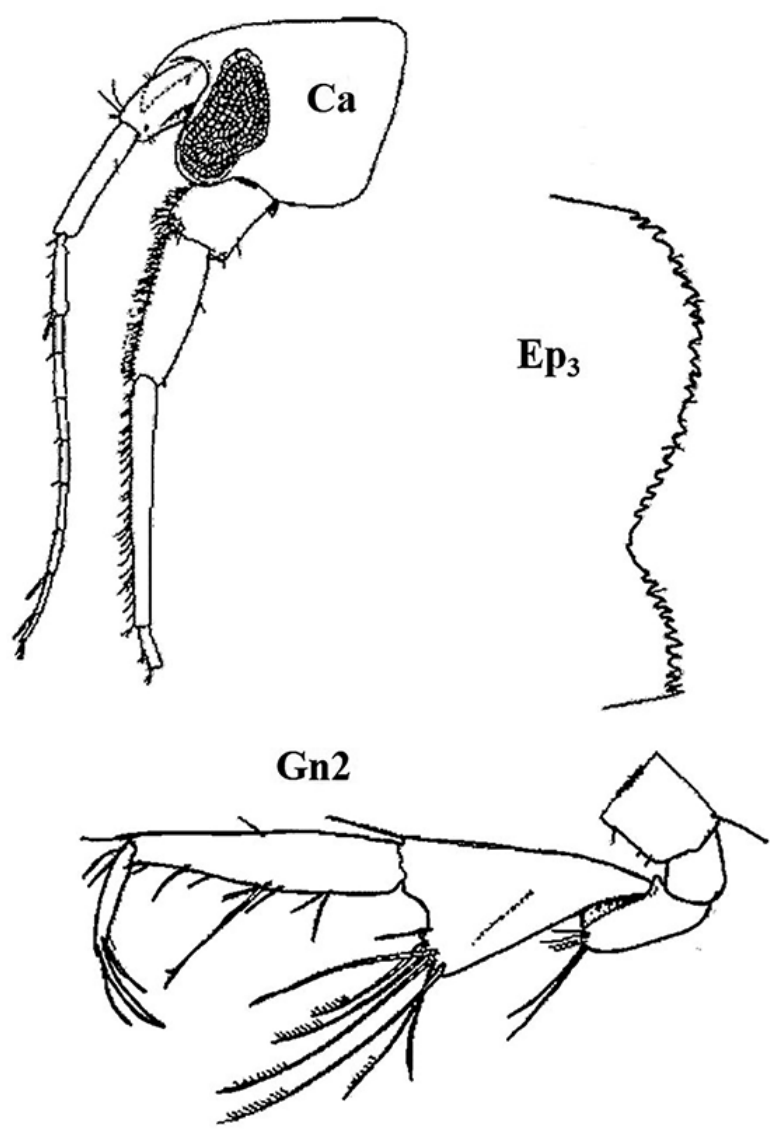

Figura 42. Características taxonómicas de Resupinus coloni: cabeza $(\mathrm{Ca})$, gnatópodo $2(\mathrm{Gn} 2)$ y placa epimeral 3 (Ep3), según Thomas y Barnard (1986).
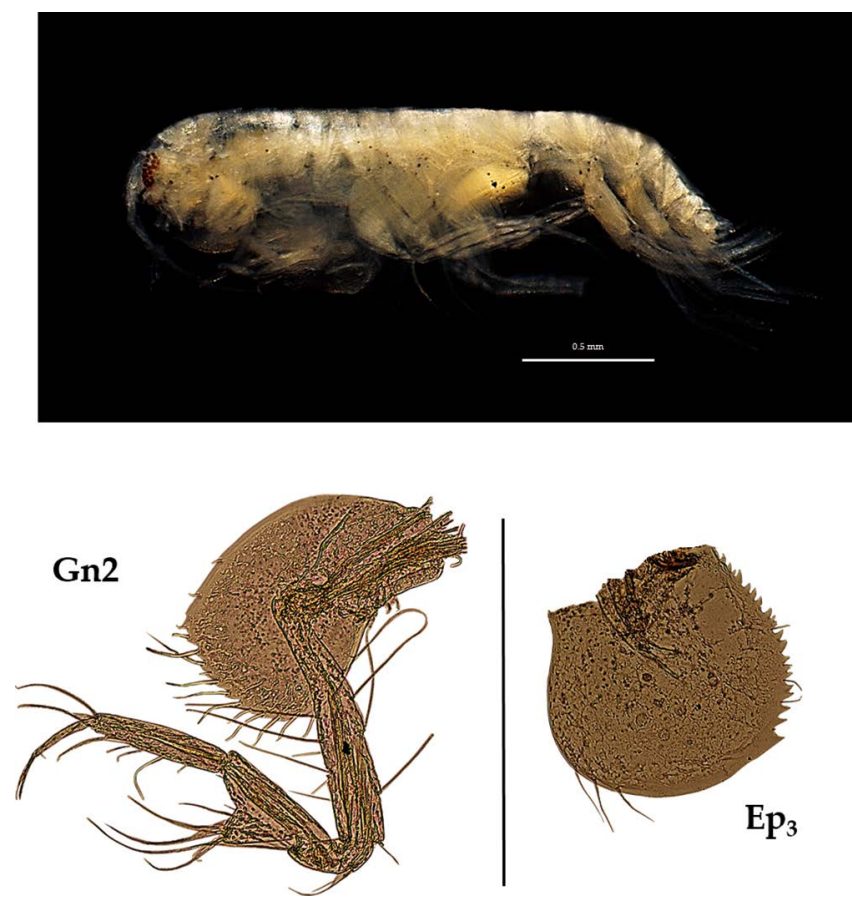

Figura 43. Resupinus coloni Thomas \& J.L. Barnard 1986: gnatópodo $2(\mathrm{Gn} 2)$ y placa epimeral 3 (Ep3). Escala: Gn2; $0.5 \mathrm{~mm}$; Ep3: $250 \mu \mathrm{m}$.

Distribución geográfica en el mundo: Panamá (océano Pacífico) a Costa Rica (de $0 \mathrm{~m}$ a $9 \mathrm{~m}$ ).

Observaciones: fue registrada en Bahía Independencia (a 5 $\mathrm{m}$ ) e identificada como una posible nueva especie (Megaluropus breviramus), en Allan Hancock Foundation Velero III (Thomas \& Barnard 1986).

Referencias: Thomas \& Barnard 1986 (Págs. 454 - 457).

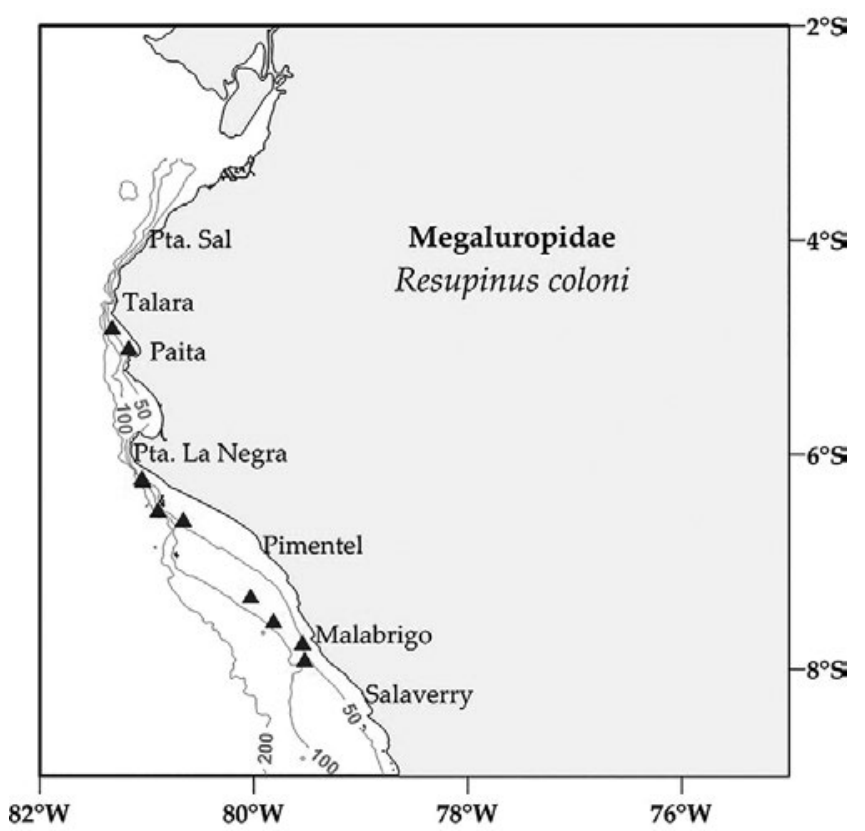

Figura 44. Distribución espacial de Resupinus coloni en la plataforma continental centro norte peruana. 


\section{FAMILIA LILJEBorgiIdAe StebBING, 1899}

15. Idunella diffusa (J.L. Barnard, 1959)

$$
\text { Figura } 45-47
$$

Diagnosis: cuerpo pigmento de manera difusa (observado a ser fijado con formol y/o alcohol), alrededor de las coxas, segmentos del pereón y artejos de pereópodos. Ojos bien desarrollados. Gnatópodos de similar tamaño, ligeramente más grande el gnatópodo 2; las palmas del artejo 6 expandido, con bordes llenos de setas. Urópodo 3 con la longitud de las ramas mayor que el soporte; la rama externa sin artejos. Telson hendido hasta más de $3 / 4$ de la longitud total, cada lóbulo con 2 espinas distales (Figs. 45, 46).

Material examinado: de los 10 especímenes examinados, un ejemplar hembra fue diseccionado, de la estación C20 (0449.8'S, 81²18.6'W; 38 m), Crucero de Otońo del año 2015.

Hábitat: fondo arenoso y fangoso.

Profundidad: 37 a $175 \mathrm{~m}$.

Localidades en la plataforma centro norte: $03^{\circ} 30^{\prime} \mathrm{S}$, $80^{\circ} 42^{\prime} \mathrm{W}$ a $6^{\circ} 12^{\prime}$ S, $81^{\circ} 00^{\prime} \mathrm{W}$ (Fig. 47).

Distribución geográfica en el mundo: México (Punta Concepción), Punta SW de San Mateo (California), Bahía San Cristóbal, Bahía Monterrey; distribuidos de 12 a 172 m de profundidad (Barnard, 1959; 1964; 1966).

Observaciones: Esta especie puede ser confundida con Idunella melanica, debido al patrón de pigmentación.

Referencias: Barnard 1959 (Pág. 18, Figs. 3-5), 1964, 1966; Karaman 1980 (Págs. 419).
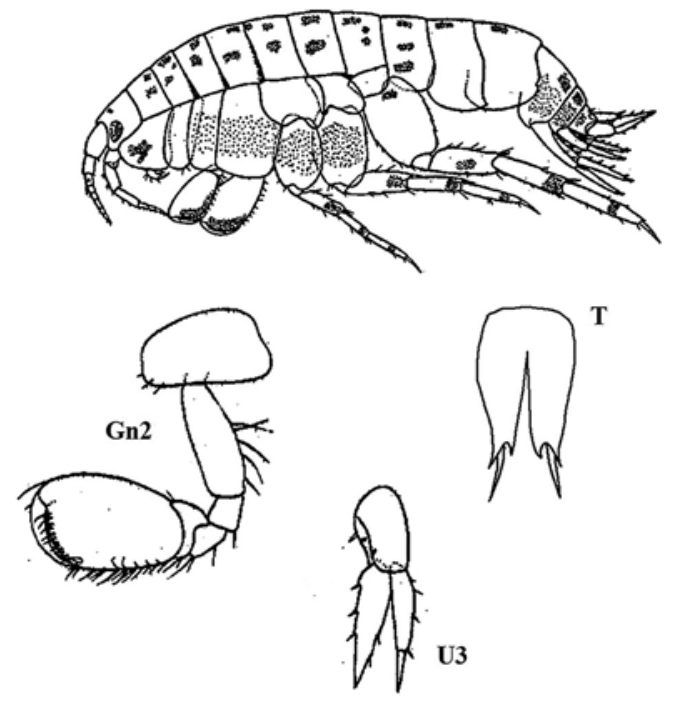

Figura 45. Características taxonómicas de Idunella diffusa (J.L. Barnard, 1959): habitus, gnatópodo 2 (Gn2), urópodo 3 (U3) y telson (T), según Barnard (1959).
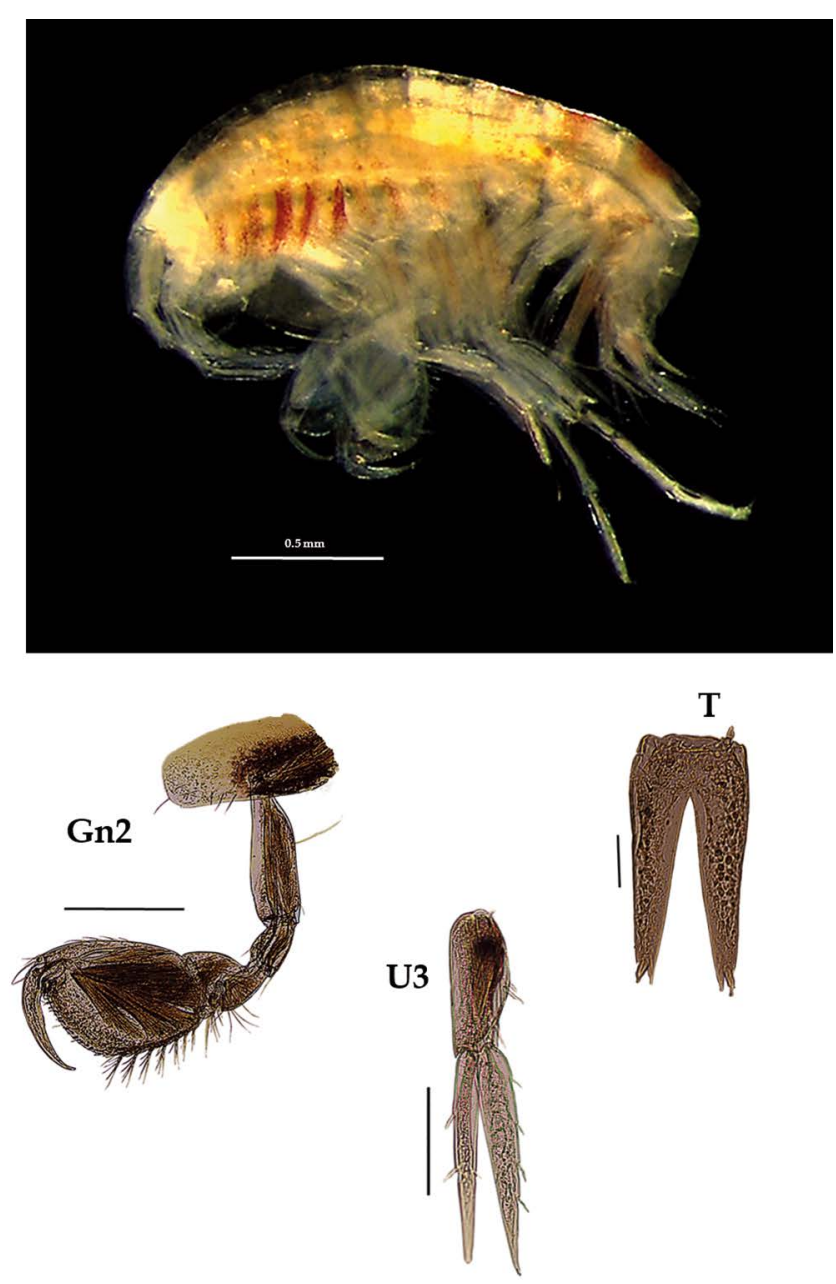

Figura 46. Idunella diffusa: gnatópodo 2 (Gn2), urópodo 3 (U3) y telson (T). Escala: Gn2; $0.5 \mathrm{~mm}$; U3 y T: $50 \mu \mathrm{m}$.

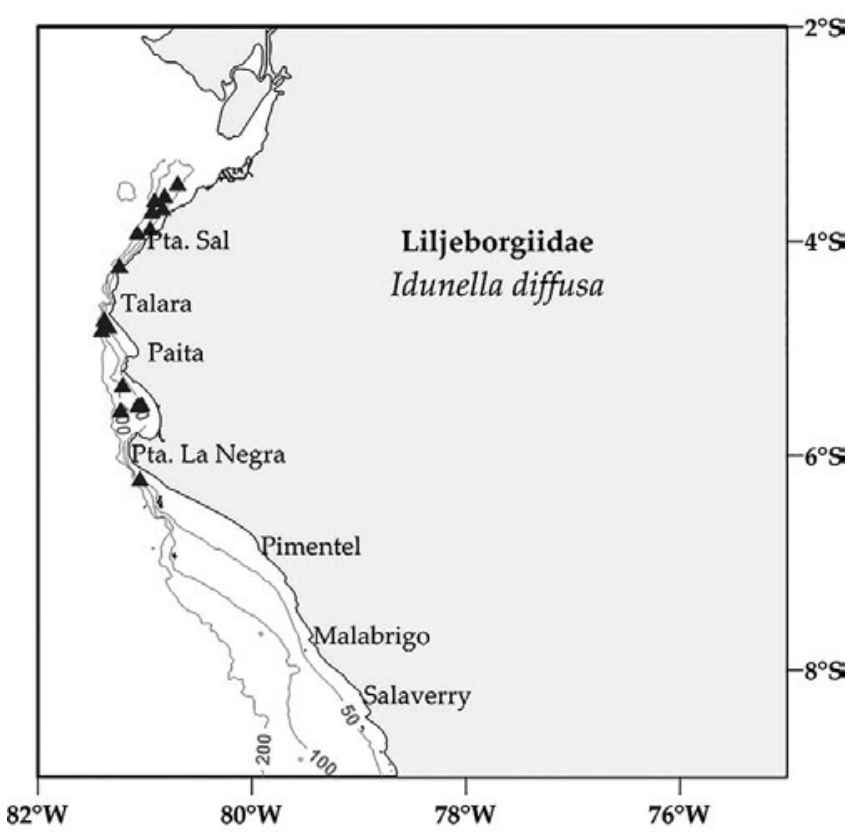

Figura 47. Distribución espacial de Idunella diffusa en la plataforma continental centro norte peruana. 


\section{FAMILIA TRYPHOSIDAE LOWRY \& STODDART, 1997}

\section{Orchomenella sp.}

Figura $48-50$.

Diagnosis: La cabeza presenta lóbulo subtriangular, con terminaciones redondeadas. Ojos largos, ovalados compuestos de omatidios. Gnatópodo 1 subquelado, coxa 1 larga, tan larga como la coxa 2, subrectangular con terminaciones redondeada. Gnatópodo 2 diminutamente quelado. Pereópodos 7 con el artejo 2 más largo que ancho, redondeado posteriormente. Placa epimeral 3 con lo esquina posterior subcuadrado. Urópodo 3 presenta rama externa biarticulada, una rama ligeramente más grande que la otra, con presencia de setas. Telson más larga que ancha, hendido más del 3/4 del tamaño, en la parte terminal de cada lóbulo uno o dos espinas (Figs. 48, 49).

Material examinado: dos (02) especímenes fueron examinados, una hembra fue disectada, de la estación C94 (03⒉ ${ }^{\prime} \mathrm{S}$, $80^{\circ} 48^{\prime} \mathrm{W} ; 75 \mathrm{~m}$.), del Crucero de Otońo del año 2009.

Hábitat: fango con conchuelas.

Profundidad: en el área de estudio se encuentró a $75 \mathrm{~m}$.

Localidades en la plataforma centro norte: $03^{\circ} 24^{\prime} \mathrm{S}$, $80^{\circ} 48^{\prime} \mathrm{W}$ (Fig. 50).

Distribución geográfica en el mundo: Género distribuido ampliamente distribuido, en el océano Atlántico, Mar del Norte, Mediterráneo.

Observaciones: con el estudio de De Broyer (1984, 1985) se dividió al género Orchemene en cuatro géneros, donde se incluye a Orchemenella, basado en análisis con algunos caracteres morfológicos importantes, como piezas bucales y longitud de la hendidura del telson. Durante este análisis se determinó que los especímenes analizados corresponden al género Orchomenella; y algunos caracteres fueron semejantes a $O$. pacifica Gurjanova,
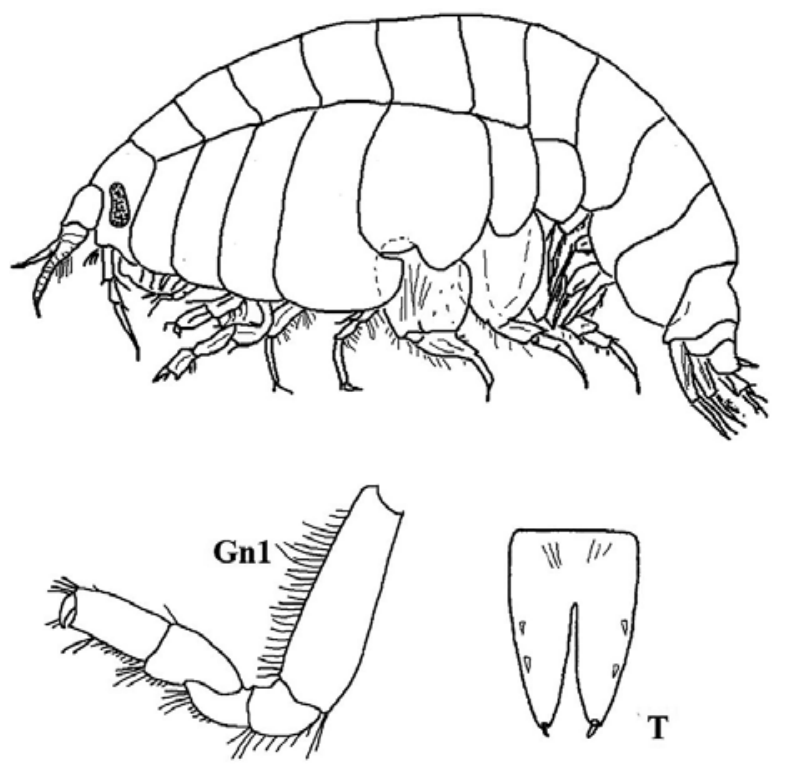

Figura 48. Características taxonómicas de Orchomenella minuta (Krøyer, 1846) con similitudes con la especie registrada: habitus, gnatópodo 1 (Gn1), gnatópodo 2 (Gn2), urópodo 3 (U3) y telson (T), según Sars (1895).
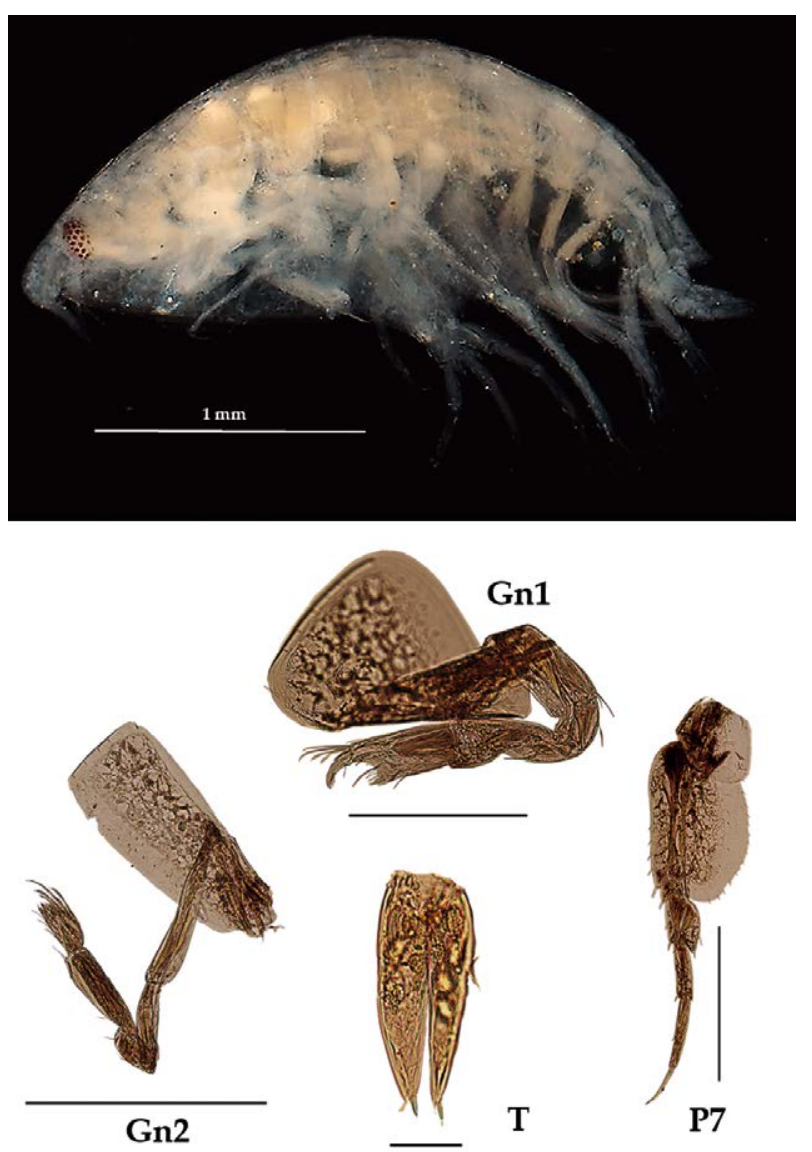

Figura 49. Orchomenella sp.: gnatópodo $1(\mathrm{Gn} 1)$, gnatópodo 2 (Gn2), pereópodo 7 (P7); urópodo 3 (U3) y telson (T). Escala: Gn1: $250 \mu \mathrm{m}, \mathrm{Gn} 2$ y P7: $0.5 \mathrm{~mm}$; T: $50 \mu \mathrm{m}$.

1938; sin embargo debido al limitado número de individuos no se pudo determinar la especie. Por lo tanto, los especímenes serán incluidos en futuros trabajos, a fin de identificarlos y/o determinar si corresponden a una nueva especie para el mar peruano.

Referencias: Sars 1895, Gurjanova 1938, De Broyer (1984, 1985).

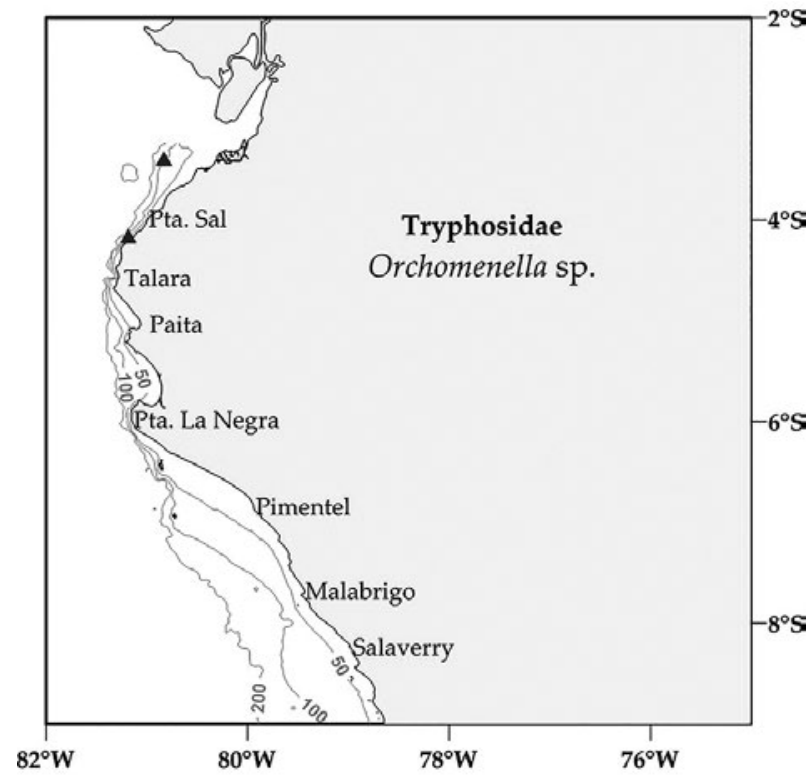

Figura 50. Distribución espacial de Orchomenella sp. en la plataforma continental centro norte peruana. 


\section{FAmilia Oedicerotidae LiLlJeborg, 1865}

17. Hartmanodes hartmanae J.L.Barnard, 1962

$$
\text { Figura } 51 \text { - } 53 .
$$

Diagnosis: Rostro con quilla ventral, formando una curva y terminación puntiaguda. Ojos delgados y reniformes, desde una vista lateral, y ocupan la parte finar de rostro. Gnatópodos carpoquelados; el artejo 5 del gnatópodo 1 es lobado esbelto que llega a la palma del artejo 6. Gnatópodo 2 con propodio (artejo 6) alongado, más de tres veces más largo que ancho; lóbulo del artejo 5 cubre el margen posterior del artejo 6 (llega a la palma). Telson suavemente convexo detrás. Telson entero, convexo con setas (Figs. 51, 52).

Material examinado: tres (03) especímenes fueron examinados. Se diseccionó un ejemplar macho de la estación C20 (04²9.8'S, 81¹8.6'W; $38 \mathrm{~m}$ ), del Crucero de Otoño del año 2015.

Hábitat: en ambientes de plataforma continental, con comunidades de los géneros Tellina, Diopatra y Onuphis.

Profundidad: 56 a $126 \mathrm{~m}$.

Localidades en la plataforma centro norte: $03^{\circ} 24^{\prime} \mathrm{S}$, $80^{\circ} 54^{\prime} \mathrm{W}$ a $06^{\circ} 30^{\prime}$ S, $80^{\circ} 54^{\prime} \mathrm{W}$ (Fig. 53).

Distribución geográfica en el mundo: Punta Concepción (California) hasta Bahía de San Quintín (Baja California), con rango de profundidad de 10 a $147 \mathrm{~m}$.

Observaciones: Barnard (1962c) describió a esta especie como Monoculodes hartmanae; sin embargo, Bousfield y Chevrier (1996) realizaron un revisión del género y crearon el género Hartmanodes, donde está incluida esta especie.

Referencias: Barnard 1962c (Págs. 363 - 365, Figs. 6 y 7); Bousfield \& Chevrier 1996.

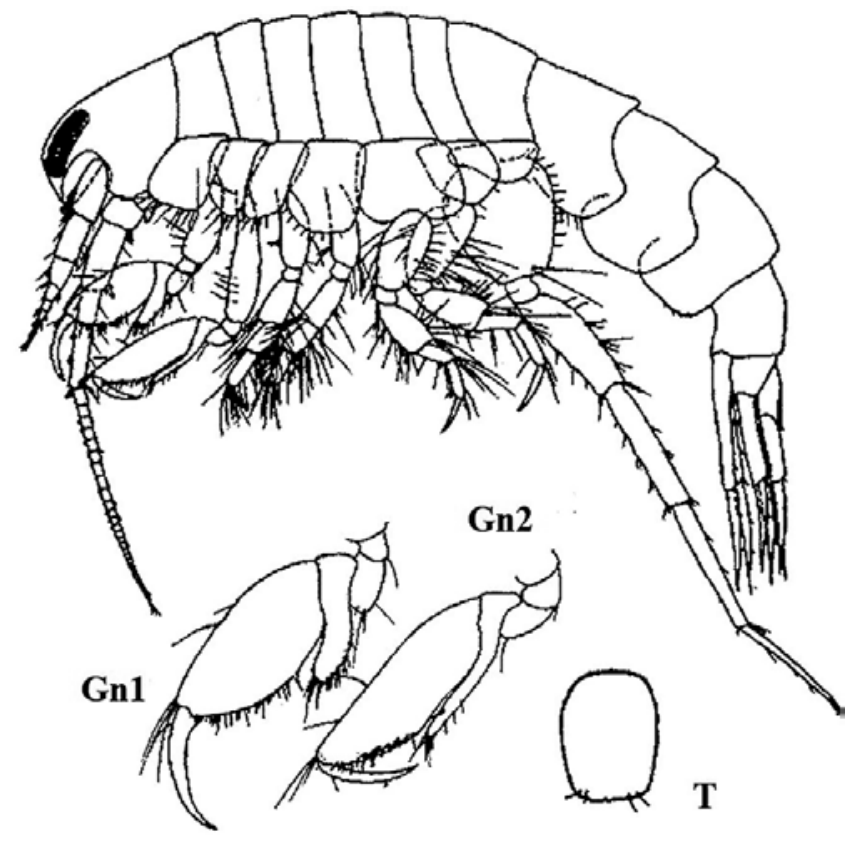

Figura 51. Características taxonómicas de Hartmanodes hartmanae J.L. Barnard, 1962: habitus, gnatópodo 1 (Gn1), gnatópodo 2 (Gn2) y telson (T), según Barnard (1962c).
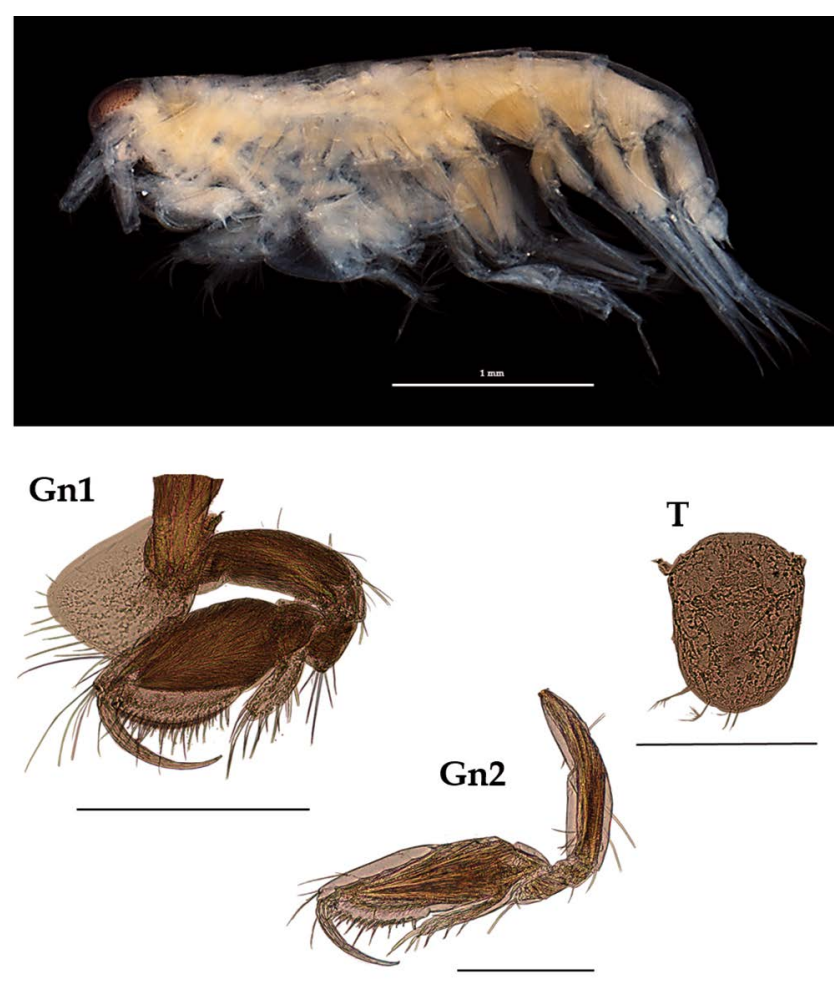

Figura 52. Hartmanodes hartmanae: gnatópodo 1 y 2 (Gn1 y 2) y telson (T). Escala: Gn1: 0.5 mm; Gn2: $250 \mu \mathrm{m}$; T: $200 \mu \mathrm{m}$.

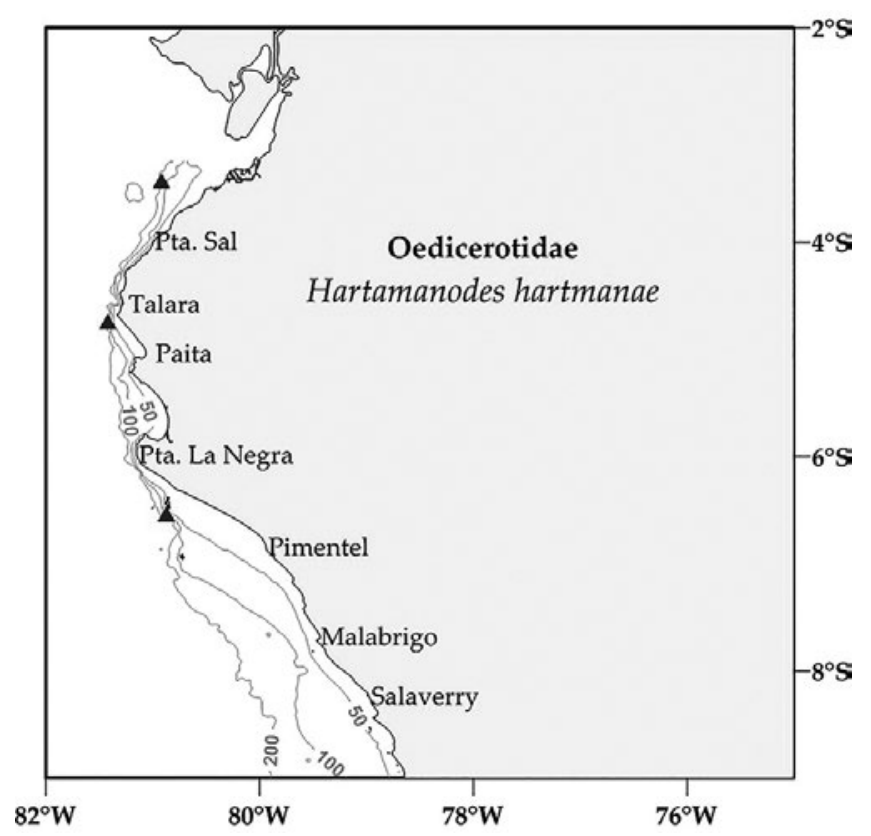

Figura 53. Distribución espacial de Hartmanodes hartmanae en la plataforma continental centro norte peruana. 


\section{Americhelidium sp.}

Figura $54-56$.

Diagnosis: rostro alargado, con terminación curvada. Ojos alargados en la parte final del rostro (sin pigmentación al estar fijado con alcohol). Gnatópodo 1 carpoquelado, artejo 2 alargada con setas en el borde; artejo 5 con una base ancha, forma un lóbulo posterior, ápice con una espina, extendido más allá de la palma del artejo siguiente; artejo 6 robusto, expandido y estrecho distalmente; palma oblicua; Gnatópodo 2 quelado, artejo 2 delgado; artejo 6 relativamente grueso, más alargado que ancho; artejo 7 robusto, $1 / 4$ de la longitud del artejo 6 . Telson entero ancho, margen apical sinuoso (Figs. 54, 55).

Material examinado: 12 especímenes fueron examinados, un ejemplar hembra fue diseccionado de la estación C14 ( $03^{\circ} 43.8^{\prime} \mathrm{S}$, 81ํ․6'W; $324 \mathrm{~m}$ ), Crucero de Otońo del año 2015.

Hábitat: fondos de arena o fango.

Profundidad: 44 a $160 \mathrm{~m}$.

Localidades en la plataforma centro norte: $04^{\circ} 48^{\prime} \mathrm{S}$, $81^{\circ} 24^{\prime} \mathrm{W}$ a $6^{\circ} 54^{\prime} \mathrm{S}, 80^{\circ} 48^{\prime} \mathrm{W}$ (Fig. 56).

Distribución geográfica en el mundo: las especies del género se distribuyen en la costa Norte del Pacífico y Pacífico asiático (Japón) y Atlántico norte.

Observaciones: $\mathrm{Al}$ examinar los ejemplares se observó diferencias con las demás especies del género Americhelidium, descritas en el trabajo de Bousfield \& Chevrier (1996), por lo que será necesario incluirla en un trabajo posterior, como especie nueva. Asimismo, este género está emparentado con Synchelidium (sensu stricto), el cual se encuentra expandido en el Atlántico europeo.

Referencias: Bousfield \& Chevrier 1996 (Págs. 125 - 128; Fig. 32).
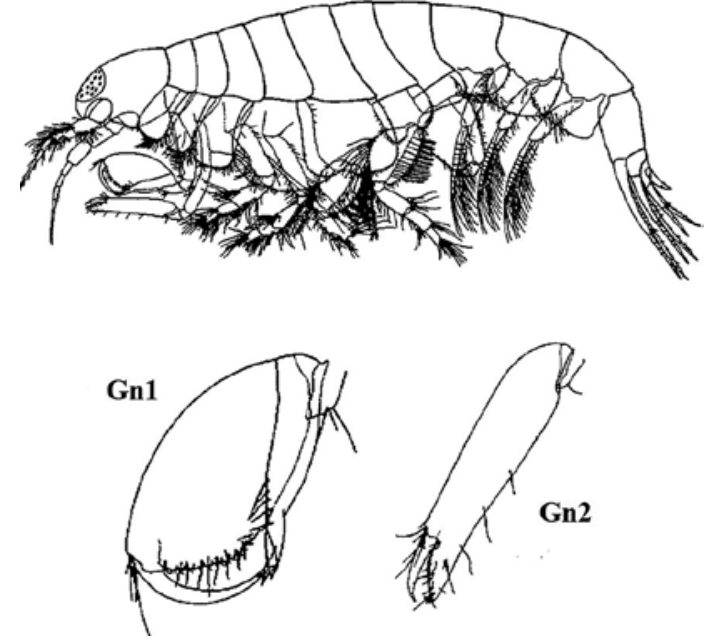

Figura 54. Características taxonómicas de Americhelidium setosum Bousfield \& Chevrier, 1996; con características similares de Americhelidium sp. como: habitus, gnatópodo $1(\mathrm{Gn} 1)$, gnatópodo $2(\mathrm{Gn} 2)$ y telson $(\mathrm{T})$, según Bousfield \& Chevrier (1996).
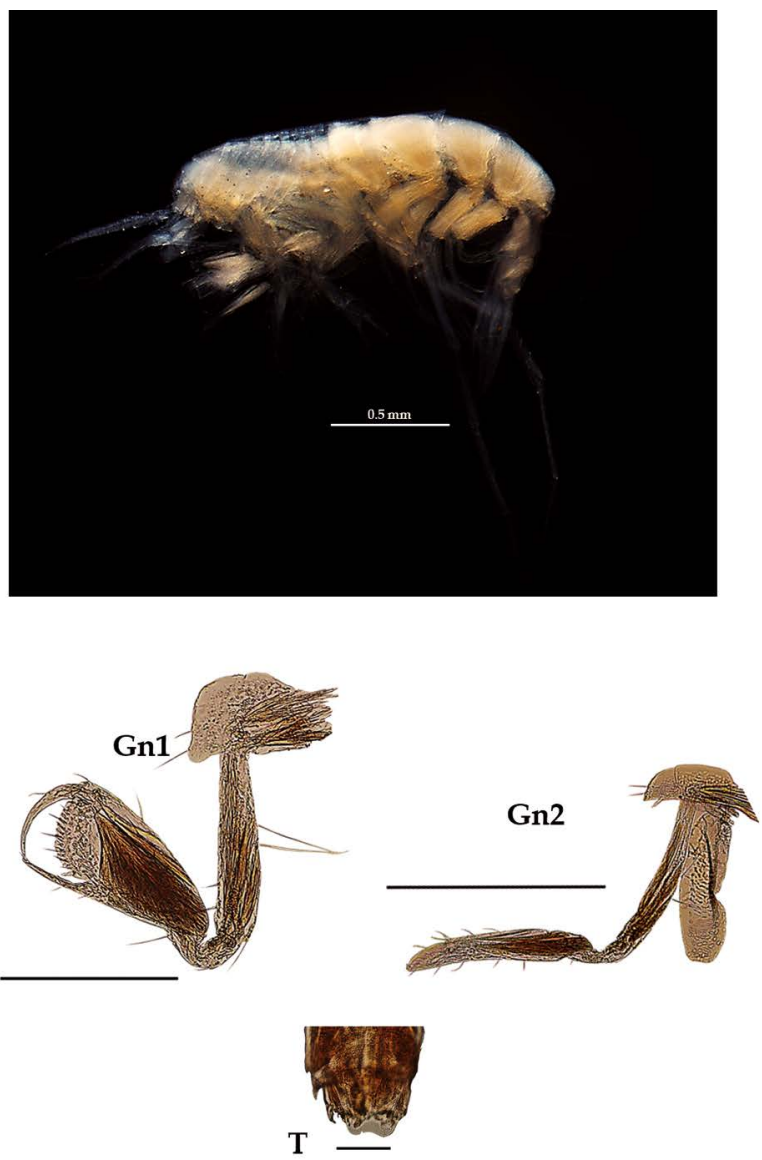

Figura 55. Americhelidium sp.: gnatópodo $1(\mathrm{Gn} 1)$, gnatópodo 2 (Gn2) y telson (T). Escala: Gn1: $250 \mu \mathrm{m}$; Gn2: $0.5 \mathrm{~mm}$; T: $100 \mu \mathrm{m}$.

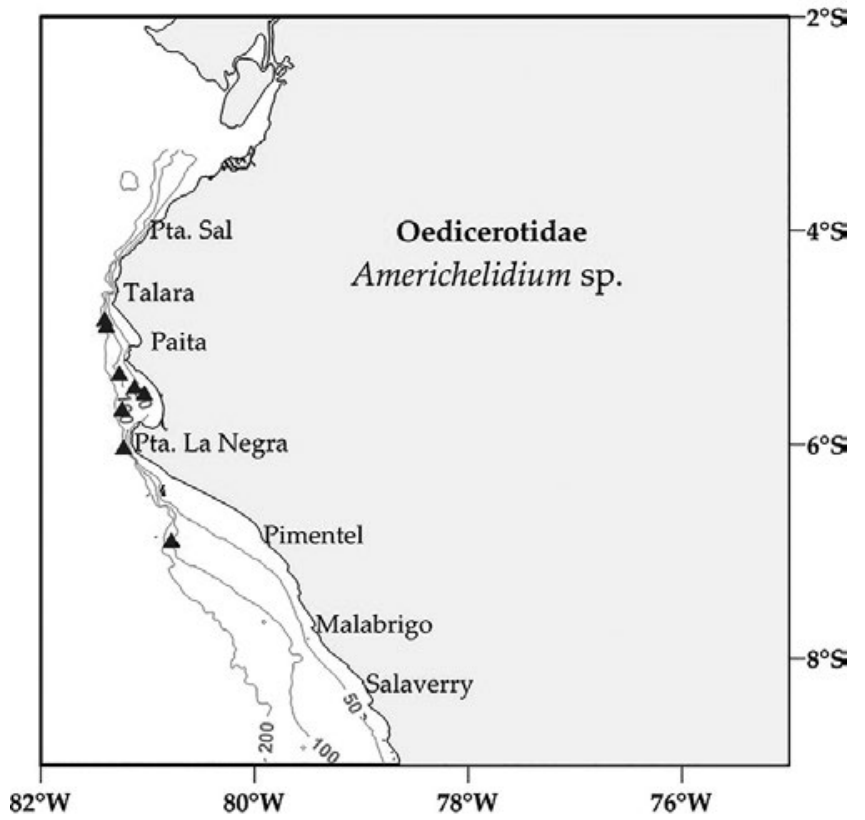

Figura 56. Distribución espacial de Americhelidium sp. en la plataforma continental centro norte peruana. 


\section{Westwoodilla tone Jansen, 2002}

Figura 57 - 59.

Diagnosis: Rostro alargado, con terminación puntiaguda. Ojos pigmentados. Coxa 1, expandida antero - distalmente, más ancha que la coxa 2 . Gnatópodos subquelados; gnatópodo 1, artejo 5 más largo que ancho; artejo 6 dos veces más largo que el ancho; setas alrededor de la palma. Gnatópodo 2, artejo 4 truncado, artejo 5 tres veces más largo que ancho; artejo 6 dos veces más largo que ancho, con setas alrededor de la palma. Telson más largo que ancho, convexo (Figs. 57, 58).

Material examinado: 87 especímenes fueron examinados y un ejemplar hembra fue diseccionado, de la estación C1 (035 5.8'S, 81 6.6'W; 191 m), Crucero de Otońo del año 2016.

Hábitat: areno fangoso.

Profundidad: 63 a $173 \mathrm{~m}$.

Localidades en la plataforma centro norte: $04^{\circ} 12^{\prime} \mathrm{S}$, $81^{\circ} 12^{\prime} \mathrm{W}$ a $07^{\circ} 54^{\prime}$ S, $79^{\circ} 48^{\prime} \mathrm{W}$ (Fig. 59).

Distribución geográfica en el mundo: British Columbia (Canadá) a California (USA), de 22 a $223 \mathrm{~m}$ de profundidad (Jansen 2002).

Observaciones: en el estudio de Jansen (2002) se detalló las diferencia de esta especie con Westwoodilla caecula, por la falta de un diente sobre el mero del gnatópodos 2 y por la presencia del telson distalmente redondeado. Asimismo, es un el primer registro de Westwoodilla tone en el Pacífico Sudamericano, después de W. cayapa Ortiz et al. 2007.

Referencias: Jansen 2002 (Págs. 125 - 134; Figs. 23 - 27), Ortiz et al. 2007.

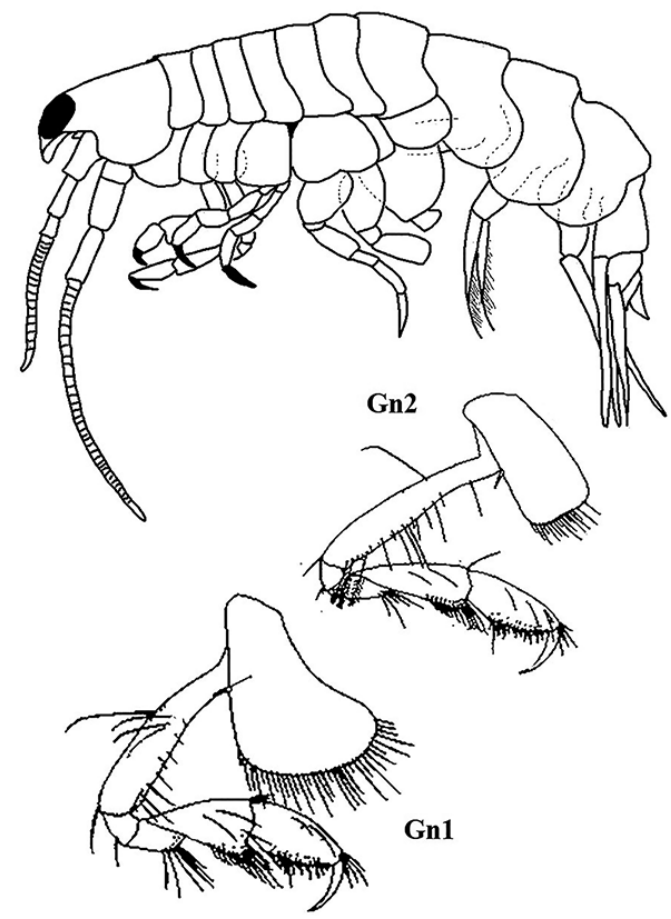

Figura 57. Características taxonómicas de Westwoodilla tone Jansen, 2002: habitus, gnatópodo 1 (Gn1), gnatópodo 2 (Gn2) y telson (T), según Jansen (2002).
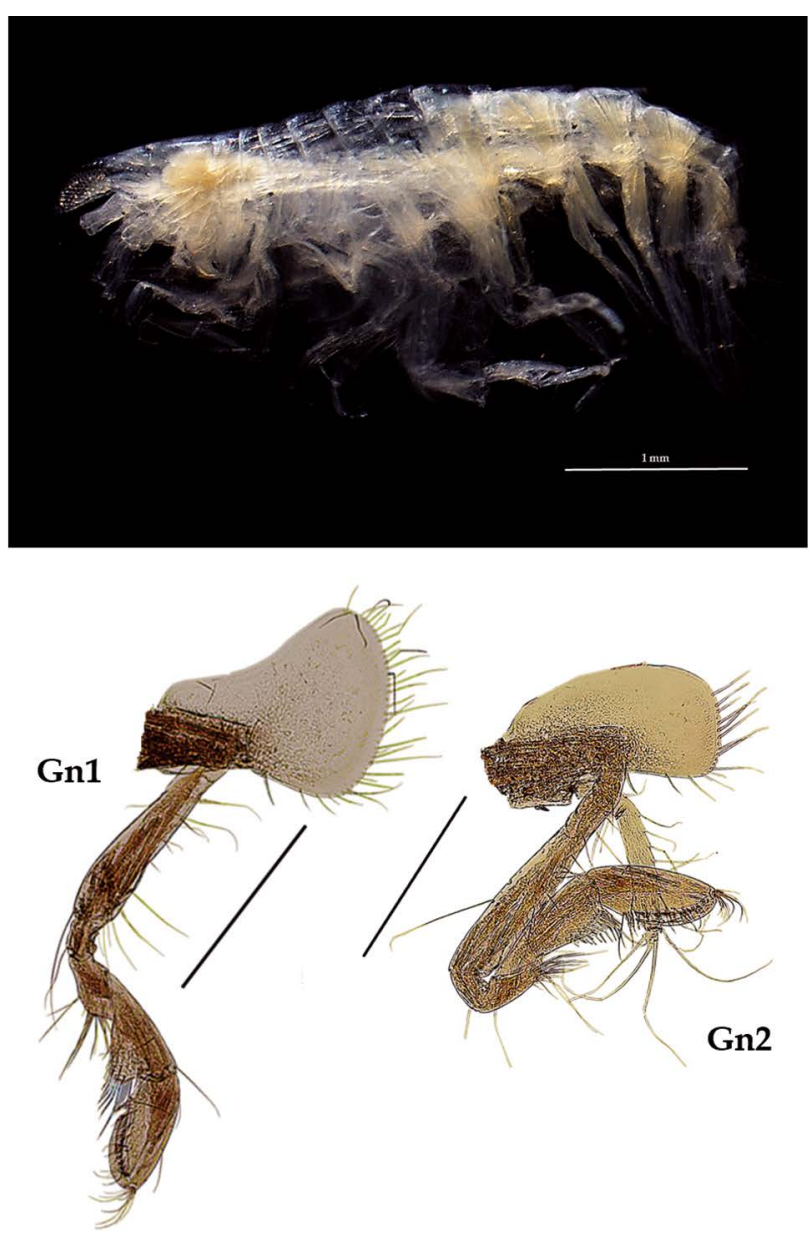

Figura 58. Westwoodilla tone: gnatópodo $1(\mathrm{Gn} 1)$ y gnatópodo 2 (Gn2). Escala: $\mathrm{Gn} 1$ y Gn2: $0.5 \mathrm{~mm}$.

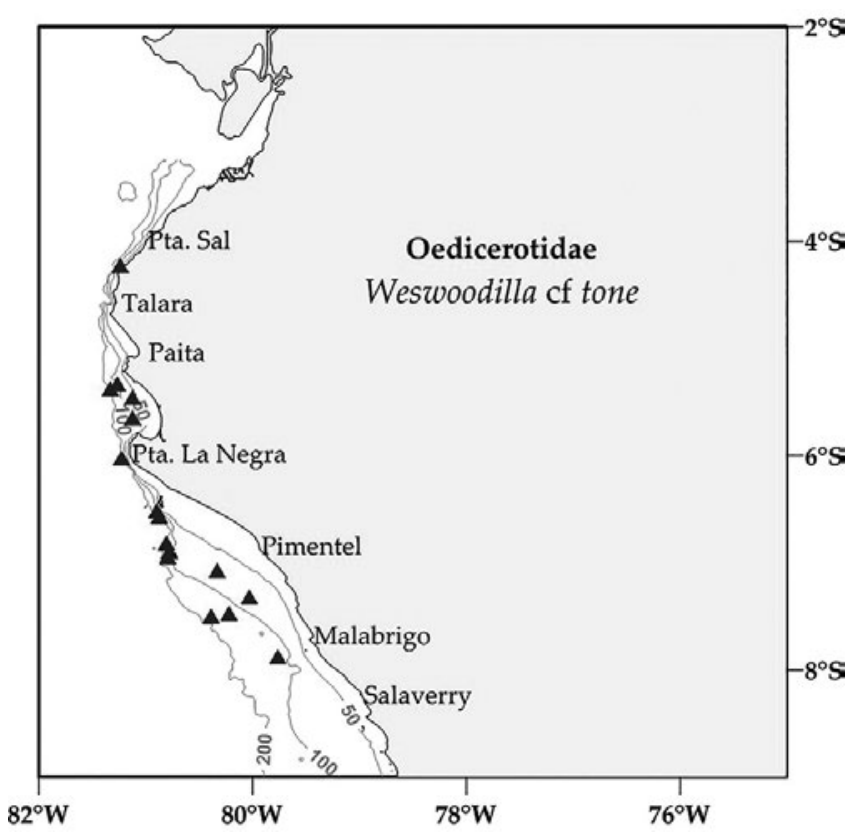

Figura 59. Distribución espacial de Westwoodilla tone en la plataforma continental centro norte peruana. 


\section{FAmilia Phoxocephalidae G.O. SARS, 1891}

\section{Heterophoxus oculatus Holmes, 1908}

$$
\text { Figura } 60-62 \text {. }
$$

Diagnosis: Rostro alargado, con terminación aguda. Ojos pigmentados pequeños, algunas (ocasiones invisibles por la poca pigmentación) en forma redondeada (en machos alargados y reniforme). Gnatópodos similares y subquelados. Pereópodo 6 más largo que el P7. Artejo 2 del pereópodo 7 con forma lobada y expandida, bordes dentados agudos con presencia de setas plumosas. Placa epimeral 3 con una esquina posterior pronunciada, terminación puntiaguda curvada. Urópodo 3 birrámeo, con margen basal con 10 a 12 setas. Telson hendido pequeño, con lóbulos redondeados y fusionados en la base; cada lóbulo con dos espinas terminales (Figs. 60, 61).

Material examinado: 194 especímenes fueron examinados y un ejemplar hembra fue diseccionado, de la estación C20 (04²49.8'S, 81 $\left.{ }^{\circ} 18.6^{\prime} \mathrm{W} ; 38 \mathrm{~m}\right)$, Crucero de Otońo del año 2015.

Hábitat: fondo fangoso.

Profundidad: 37 a $363 \mathrm{~m}$.

Localidades en la plataforma centro norte: $03^{\circ} 24^{\prime} \mathrm{S}$, $80^{\circ} 54^{\prime} \mathrm{W}$ a $06^{\circ} 36^{\prime} \mathrm{S}, 80^{\circ} 54^{\prime} \mathrm{W}$ (Fig. 62).

Distribución geográfica en el mundo: Alaska hasta Costa Rica; dentro de los 50 a $1049 \mathrm{~m}$ de profundidad.

Observaciones: Característica que diferencia al género Heterophoxus es que en la antena 2 , el primer segmento es de forma ensiforme (similar a un lóbulo).

Referencias: Barnard 1960 (Págs. 320 - 325); Jarrett \& Bousfield 1994 (Págs. 126 - 130; Figs. 29).

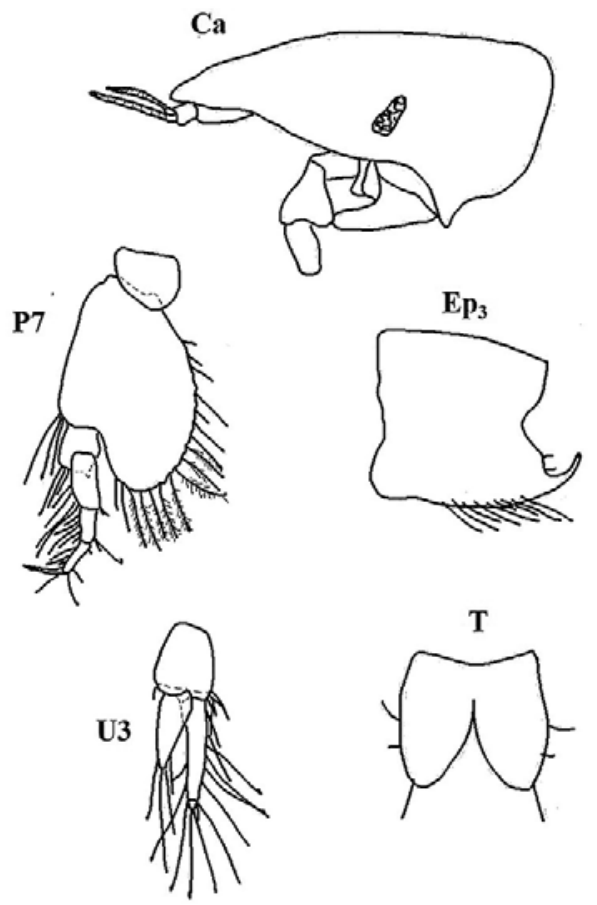

Figura 60. Características taxonómicas de Heterophoxus oculatus Holmes, 1908: cabeza (Ca), pereópodo 7 (P7), placa epimeral 3 (Ep3) y Telson (T), según Barnard (1960).

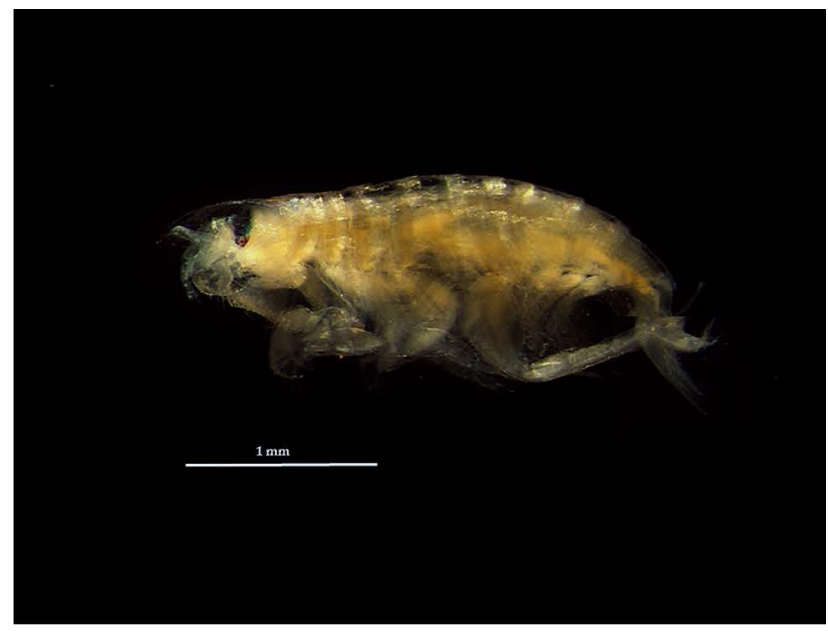

$\mathrm{Ep}_{3}$
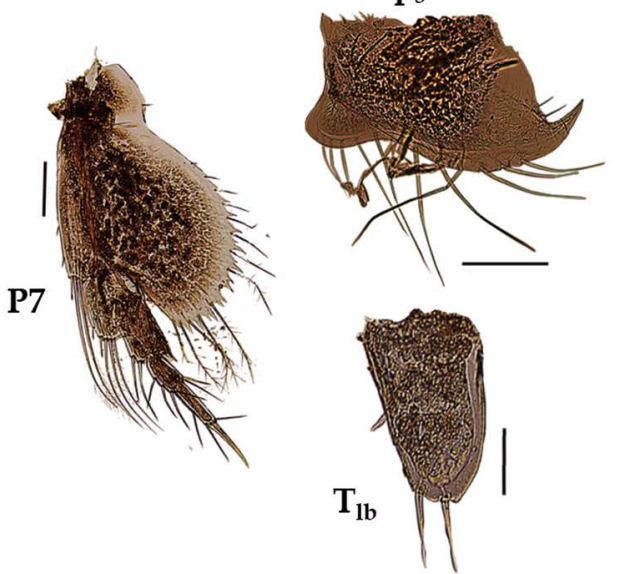

U3

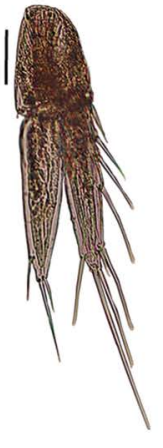

Figura 61. Heterophoxus oculatus: pereópodo 7 (P7), placa epimeral 3 (Ep3), urópodo 3 (U3) y un lóbulo de telson (T). Escala: P7; $200 \mu \mathrm{m}$; Ep3 y T: $50 \mu \mathrm{m}$; U3: $20 \mu \mathrm{m}$.

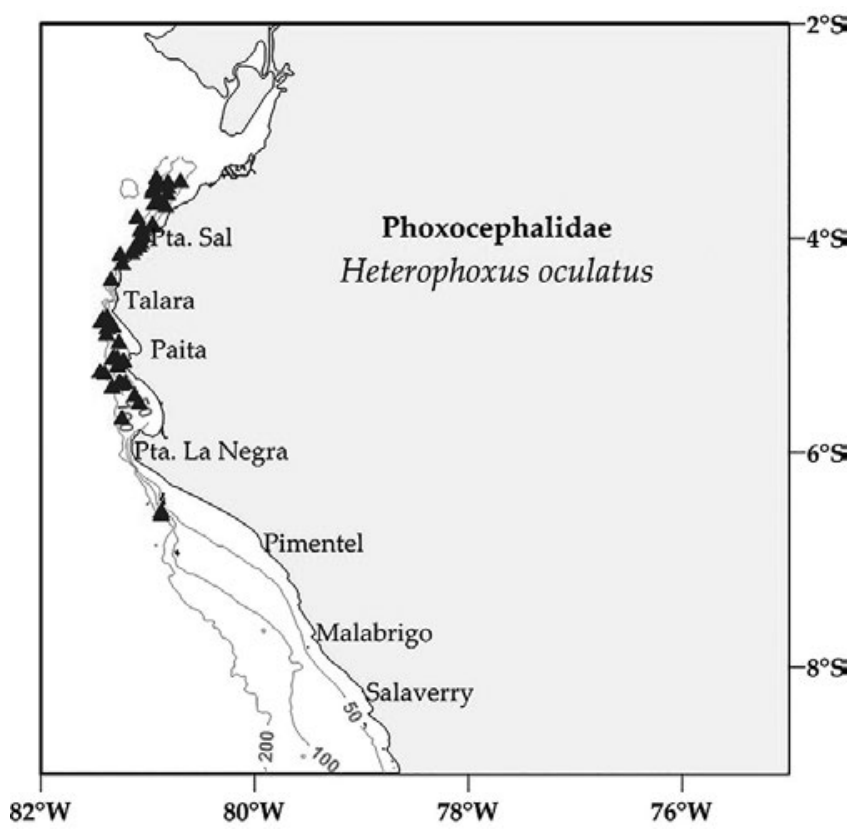

Figura 62. Distribución espacial de Heterophoxus oculatus en la plataforma continental centro norte peruana. 


\section{FAMILIA PLATYISCHNOPIDAE BARNARD \& DRUMMOND, 1979}

\section{Eudevenopus honduranus Thomas \&J.L.Barnard, 1983}

$$
\text { Figura } 63-65 .
$$

Diagnosis: Cabeza con un rostro constreñido alargado, entre las antenas subapicales. Ojos medianos pigmentados. Gnatópodos similares, fuertemente quelados. Pereópodo 7 , artejo 2 ancho, en forma de lóbulo, presenta una muesca posteroventral; artejo 7 largo y puntiagudo. Telson hendido superficialmente en la parte terminal, tan ancho como largo; cada lóbulo presenta dos ápices puntiagudas, seguidas de un par de espinas; cada margen lateral forma un grupo de 4 setas espinosas largas (Figs. 63, 64).

Material examinado: 47 especímenes fueron examinados, se diseccionó un ejemplar hembra de la estación C44 (06²12'S, $81^{\circ} 00^{\prime} \mathrm{W} ; 37 \mathrm{~m}$ ), del Crucero de Otońo del año 2006.

Hábitat: areno fangoso.

Profundidad: 24 a $358 \mathrm{~m}$.

Localidades en la plataforma centro norte: $03^{\circ} 24^{\prime} \mathrm{S}, 80^{\circ} 4$ 8'W a $06^{\circ} 12^{\prime}$, S $81^{\circ} 00^{\prime} \mathrm{W}$ (Fig. 65).

Distribución geográfica en el mundo: Océano Atlántico (Sur de Carolina hasta Brasil), Océano Pacífico: Costa Rica a Perú (Isla Lobos de Afuera), desde 1 a $40 \mathrm{~m}$. de profundidad.

Observaciones: La característica reconocible de esta especie radica en la presencia de cuatro setas gruesas laterales largas en el telson.

Referencias: Thomas \& Barnard 1983 (Págs. 12 - 19; Figs. $3-6)$.

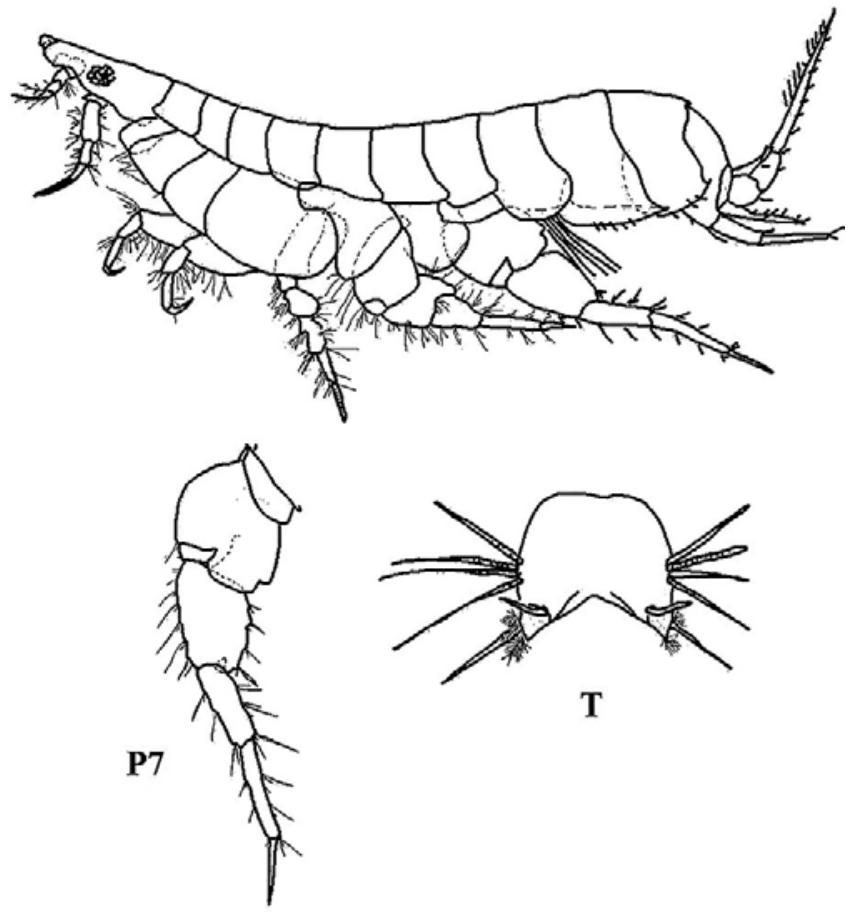

Figura 63. Características taxonómicas de Eudevenopus honduranus Thomas \& J.L. Barnard, 1983: habitus, pereópodo 7 (P7) y telson (T), según Darwin \& Barnard (1983).
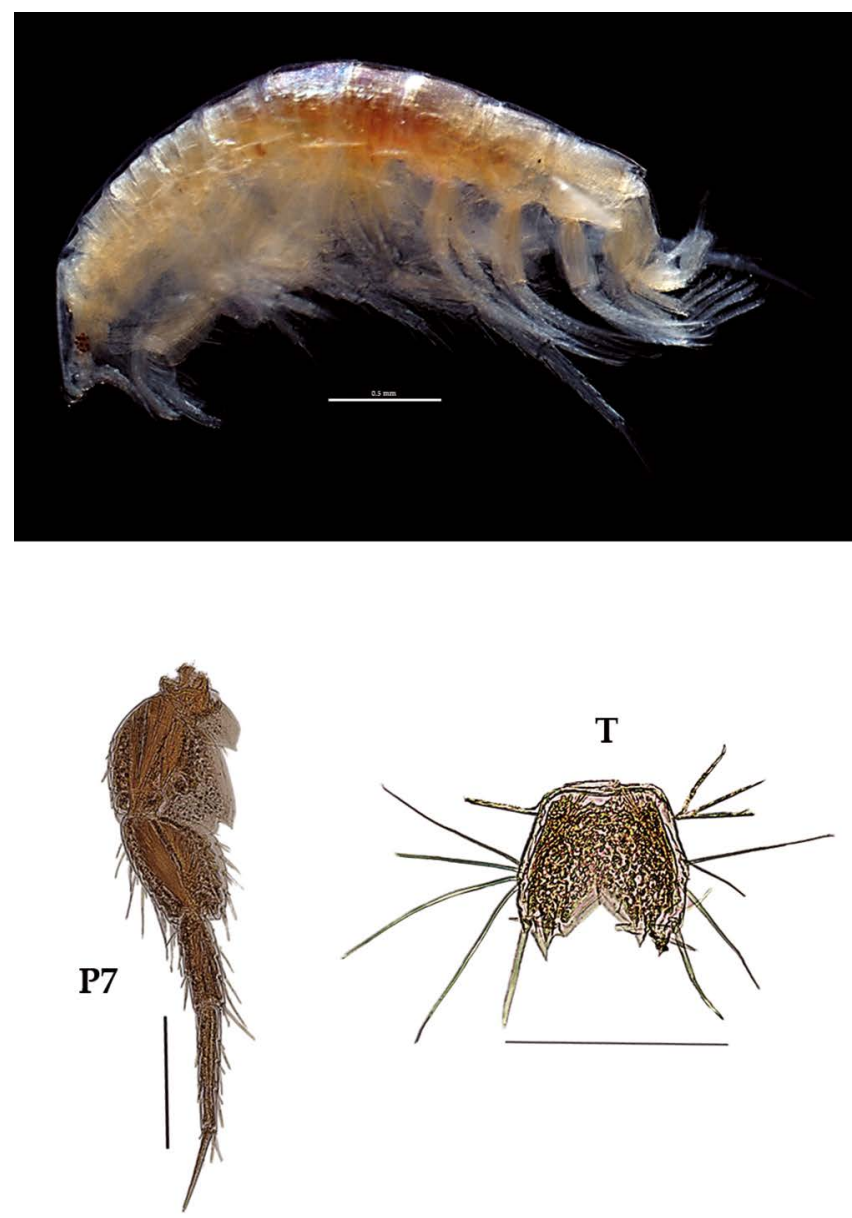

Figura 64. Eudevenopus honduranus: pereópodo 7 (P7) y telson (T). Escala: P7; $0.5 \mathrm{~mm}$; T: $250 \mu \mathrm{m}$.

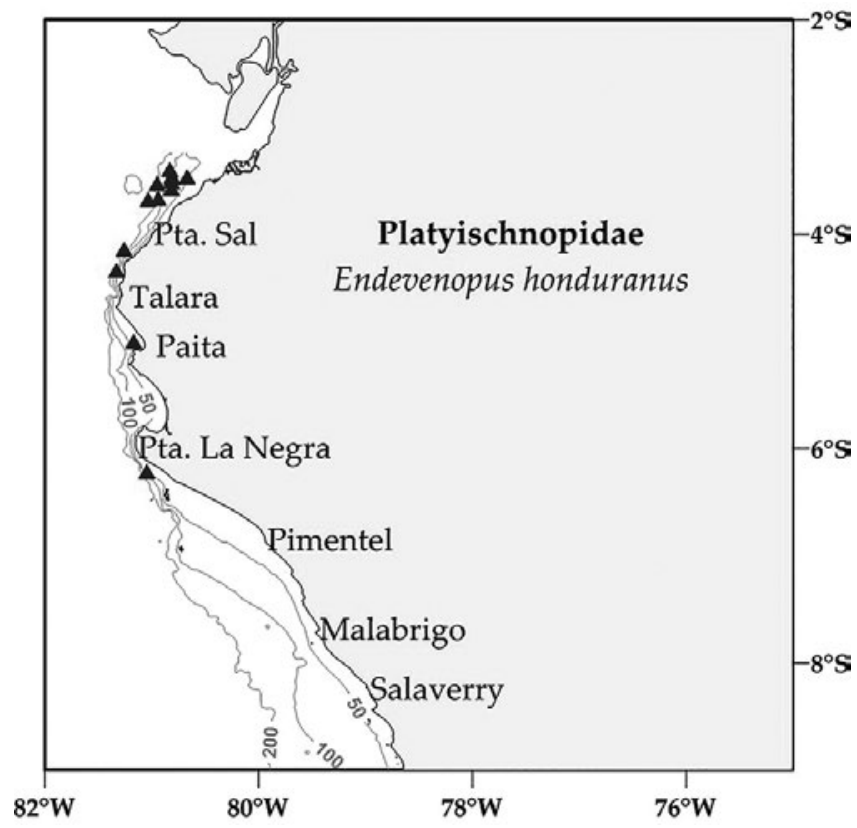

Figura 65. Distribución espacial de Eudevenopus honduranus en la plataforma continental centro norte peruana. 


\section{Familia Pleustidae Buchrolz, 1874}

22. Gracilipleustes monocuspis Barnard \& Given, 1960

Figura $66-68$.

Diagnosis: Cuerpo curvado, en forma de C (después de la fijación), rostro corto. Ojos romboidales largos. Segmento 2 del pleon con un diente dorsal posterior. Gnatópodos subquelados; artejo 6 ovalado, con palma convexa, cada uno con un diente aguzado, más largo que el artejo 5. Placa epimeral 3 con borde posterior aserrado. Urópodo 3 birramio; las ramas presenta tamaños diferentes, con borde setoso. Telson entero y corto (Figs. 66, 67).

Material examinado: 23 especímenes fueron examinados y un ejemplar hembra fue diseccionado, de la estación E48 ( $\left.6^{\circ} 16.8^{\prime} \mathrm{S}, 81^{\circ} 04^{\prime} \mathrm{W} ; 239 \mathrm{~m}\right)$, Crucero de Otońo del ańo 2016.

Hábitat: fondo areno fangoso.

Profundidad: 53 a $167 \mathrm{~m}$.

Localidades en la plataforma centro norte: $03^{\circ} 30^{\prime} \mathrm{S}$, $80^{\circ} 42^{\prime} \mathrm{W}$ a $06^{\circ} 54^{\prime} \mathrm{S}, 80^{\circ} 48^{\prime} \mathrm{W}$ (Fig. 68).

Distribución geográfica en el mundo: California (La Jolla, Baja California), a $156 \mathrm{~m}$ de profundidad.

Observaciones: es la única especie del género Gracilipleustes con presencia de diente dorsal y con el margen posterior de la placa epimeral 3 aserrado.

Referencias: Barnard \& Given 1960 (Págs. 47, 48; Fig. 6), Hendrycks \& Bousfield 2004 (Págs. 57).

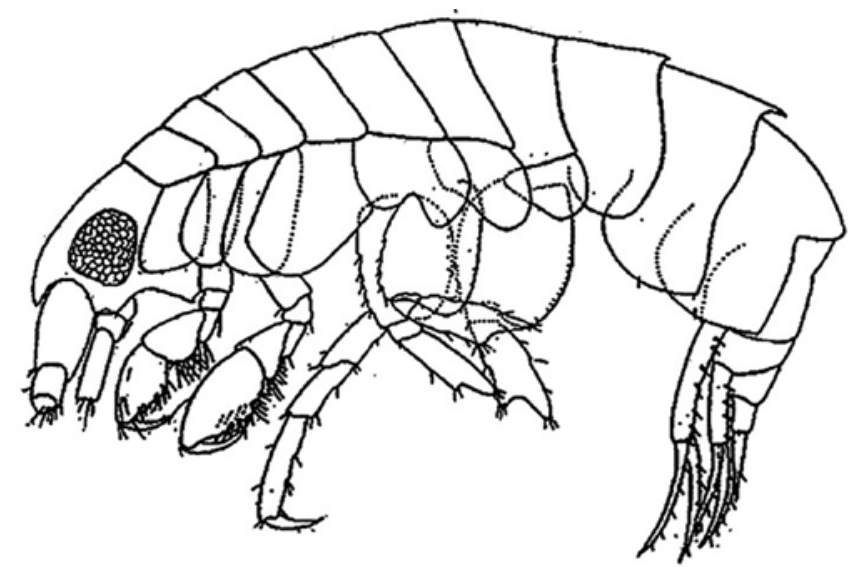

Figura 66. Características taxonómicas de Gracilipleustes monocuspis Barnard \& Given, 1960: Habitus según Hendrycks \& Bousfield (2004)

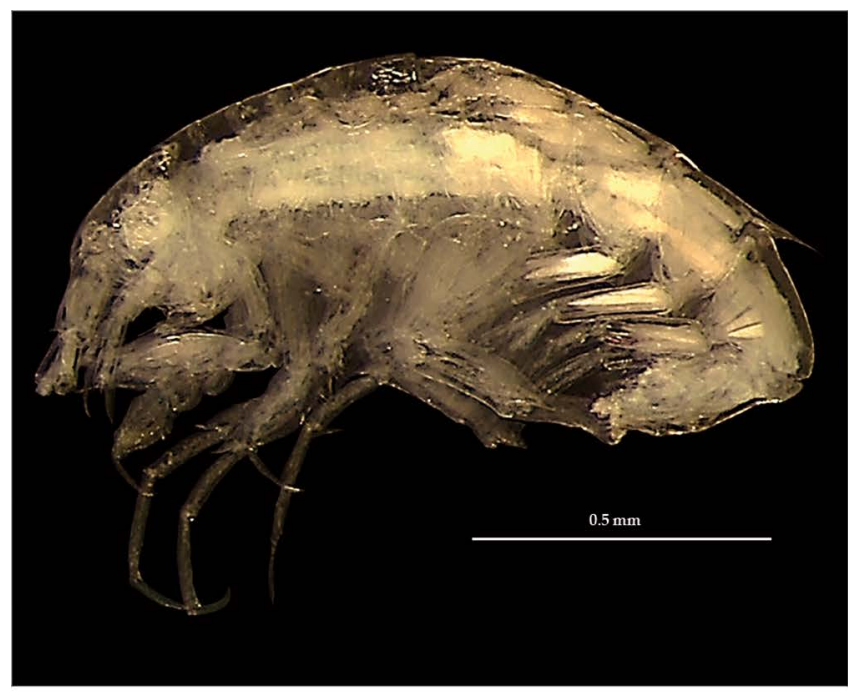

U3
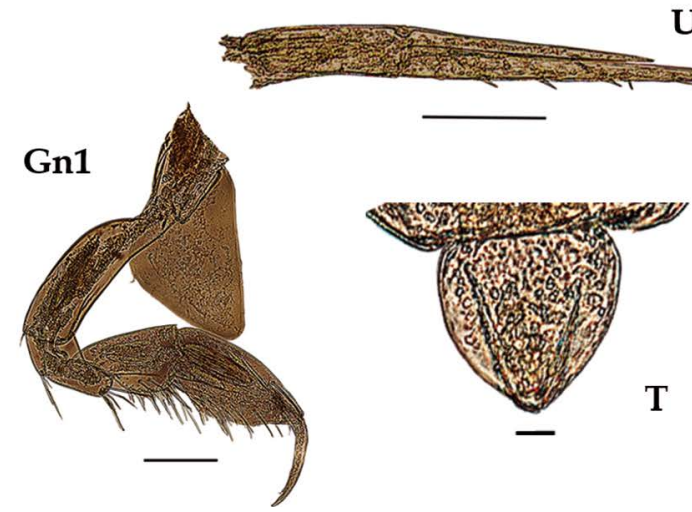

Figura 67. Gracilipleustes monocuspis: gnatópodo $1(\mathrm{Gn} 1)$ y

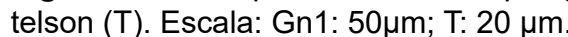

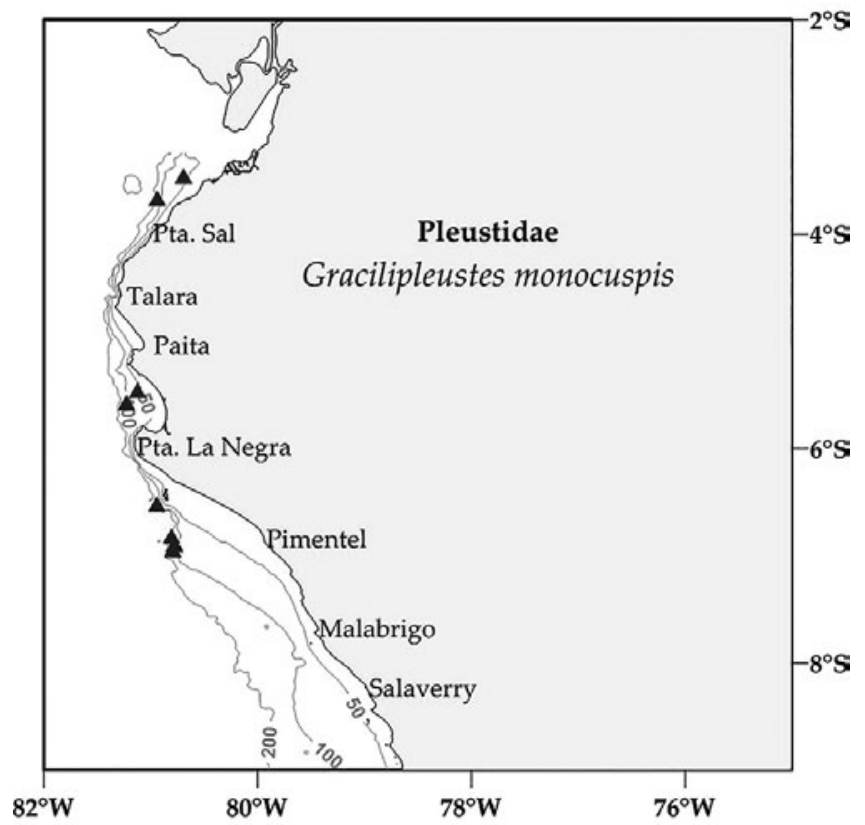

Figura 68. Distribución espacial de Gracilipleustes monocuspis en la plataforma continental centro norte peruana. 


\section{FAmilia Stenothoidae Boeck, 1871}

23. Metopella aporpis J.L. Barnard, 1962

$$
\text { Figura } 69-71
$$

Diagnosis: Ojos redondeados pigmentados. Antenas largas, más de la mitad de la longitud del cuerpo. Gnatópodo 1 simple, artejo 6 representa el doble del artejo 7, con cuatro setas cortas en el borde posterior. Gnatópodo 2 subquelado, artejo 6 con palma oblicua, formando una excavación cuadrada poco profunda, limitada en un diente largo; cerca a este presentan dientes diminutos; artejo 7 llega hasta el final de la palma. Coxa 4 ovalada, que cubre cerca de la mitad del tamaño de cuerpo. Telson entero, con terminación redondeada; dos espinas en cada lado, cerca de la base (Figs. 69, 70).

Material examinado: cinco (05) especímenes fueron examinados, de donde un ejemplar macho fue diseccionado, de la estación C48 (05³0'S, 8100'W; 44 m.), Crucero de Otońo del año 2004.

Hábitat: fondo blando y rocoso.

\section{Profundidad: 44 a $100 \mathrm{~m}$.}

Localidades en la plataforma centro norte: $05^{\circ} 18^{\prime} \mathrm{S}$, $81^{\circ} 18^{\prime} \mathrm{W}$ a $05^{\circ} 30^{\prime} \mathrm{S}, 81^{\circ} 00^{\prime} \mathrm{W}$ (Fig. 71 ).

Distribución geográfica en el mundo: Sur de California hasta Bahía Monterrey.

Observaciones: Esta especies puede diferenciarse por la forma y tamaño de la coxa 4, la cual puede llegar a cubrir gran parte del cuerpo y el telson entero ovalado.

Referencias: Barnard 1962b (Págs. 142 - 145; Figs. 12, 13).
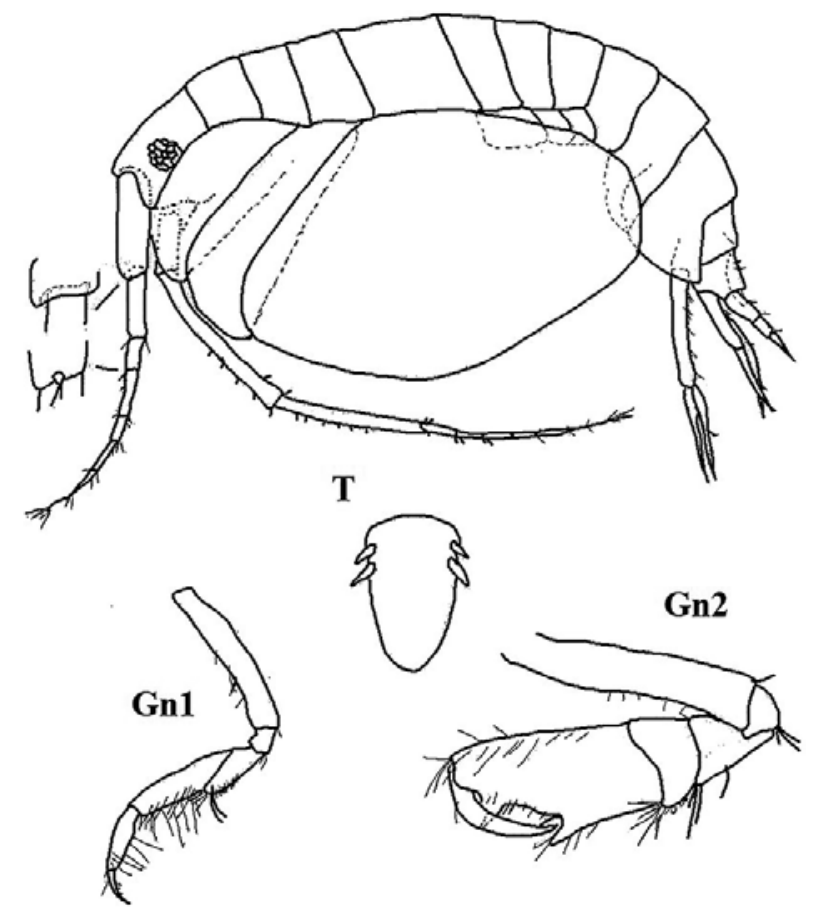

Figura 69. Características taxonómicas de Metopella aporpis J.L. Barnard, 1962: habitus, gnatópodo 1 (Gn1), gnatópodo 2 (Gn2) y telson (T), según Barnard (1962b).
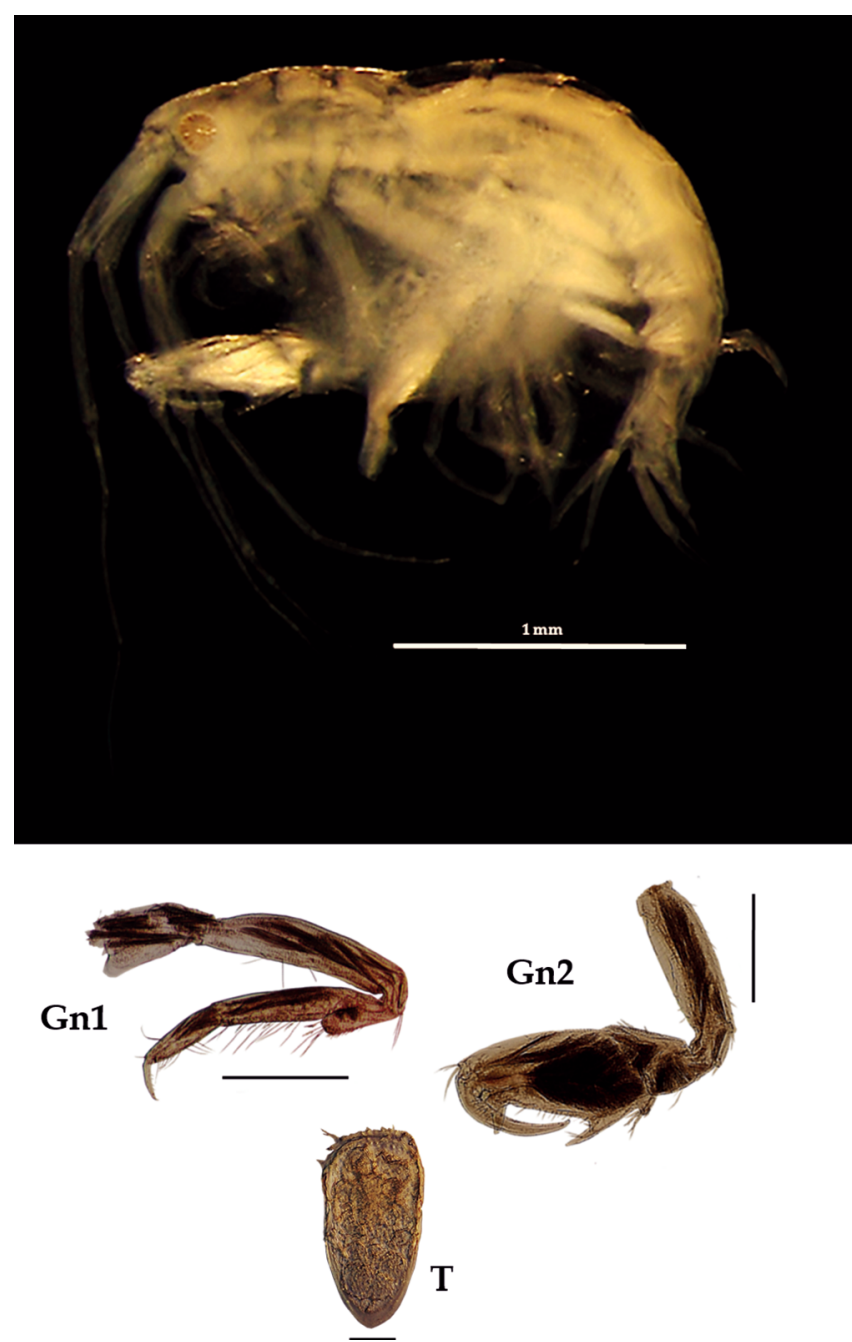

Figura 70. Metopella aporpis: gnatópodo 1 y 2 (Gn1 y 2) y

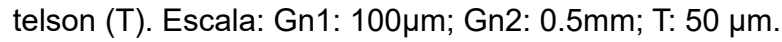

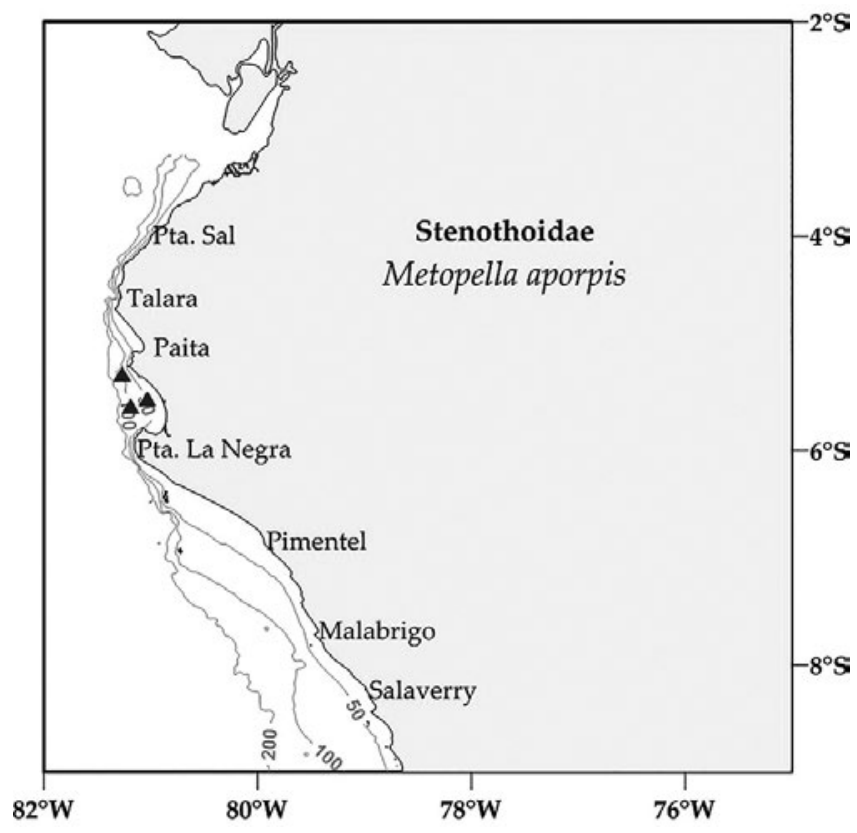

Figura 71. Distribución espacial de Metopella aporpis en la plataforma continental centro norte peruana. 


\section{FAMILIA SYNOPIIDAE DANA, 1853}

\section{Syrrhoe sp.}

Figura $72-74$

Diagnosis: Rostro alargado, con frente pronunciada redondeada, con terminación aguda. Ojos pigmentados con omatidios, vistos lateralmente. Gnatópodos subquelados, con palma transversa, con espinas largas, con el artejo 6 (propodio) corto. Pleonitos 1 y 2 con un pequeńo diente dorsal; pleonito 3, con pequeńos dentículos dorsales. Placa epimeral 3 con el borde posterior aserrado. Telson alargado, hendido hasta la base, cada lóbulo con terminación aguda y con una seta corta (Figs. 72, 73).

Material examinado: 22 especímenes fueron examinados, de donde un ejemplar hembra fue diseccionado, procedente de la estación C46 (05 $\left.18^{\prime} \mathrm{S}, 81^{\circ} 18^{\prime} \mathrm{W} ; 110 \mathrm{~m}\right)$, Crucero de Otoño del año 2005.

Hábitat: fondo blando fangoso.

Profundidad: 91 a $160 \mathrm{~m}$.

Localidades en la plataforma centro norte: $05^{\circ} 18^{\prime} \mathrm{S}$, $81^{\circ} 18^{\prime} \mathrm{W}$ a 6³6'S, $80^{\circ} 54^{\prime} \mathrm{W}$ (Fig. 74).

Distribución geográfica en el mundo: El género está distribuido ampliamente en los Océanos Atlántico y Pacífico (sin reportes que incluyan al mar peruano).

Observaciones: durante la revisión del género Syrrhoe, se registra que existen algunas características morfológicas resaltantes para cada especie, donde los especímenes examinados evidencian caracteres distintivos, como la forma y extensión de los dientes en la placa epimeral 3, cubriendo por completo el lado posterior y la profundidad de la hendidura del telson (hasta la base) con setas en la parte final de cada lóbulo. Estas

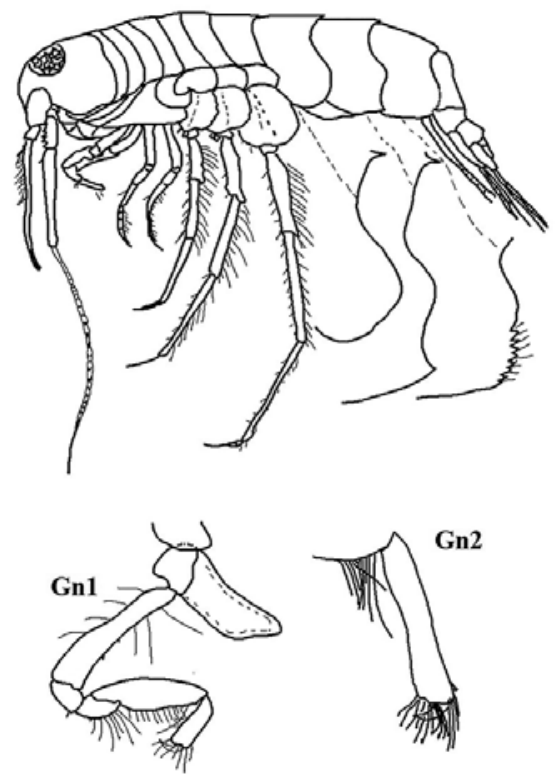

Figura 72. Características taxonómicas de Syrrhoe semiserrata Stebbing, 1888, con similitudes a Syrrhoe sp.: Habitus, gnatópodo 1 y 2 (Gn 1 y 2), según Barnard (1972).
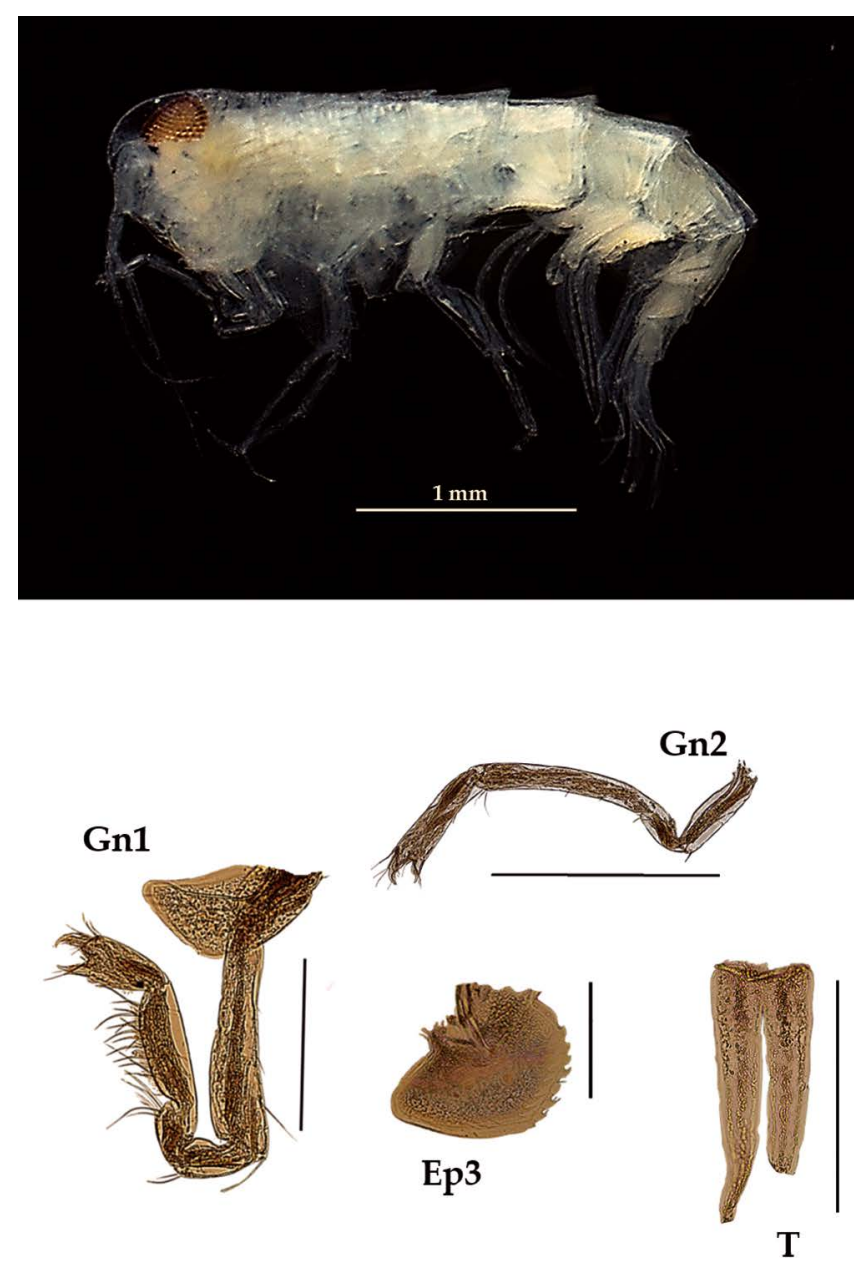

Figura 73. Syrrhoe sp.: gnatópodo 1 y 2 (Gn1 y 2), placa epimeral 3 (Ep3) y telson (T). Escala: Gn1 y 2: 0.5 mm; Ep3: $250 \mu \mathrm{m}$; T: $0.5 \mathrm{~mm}$.

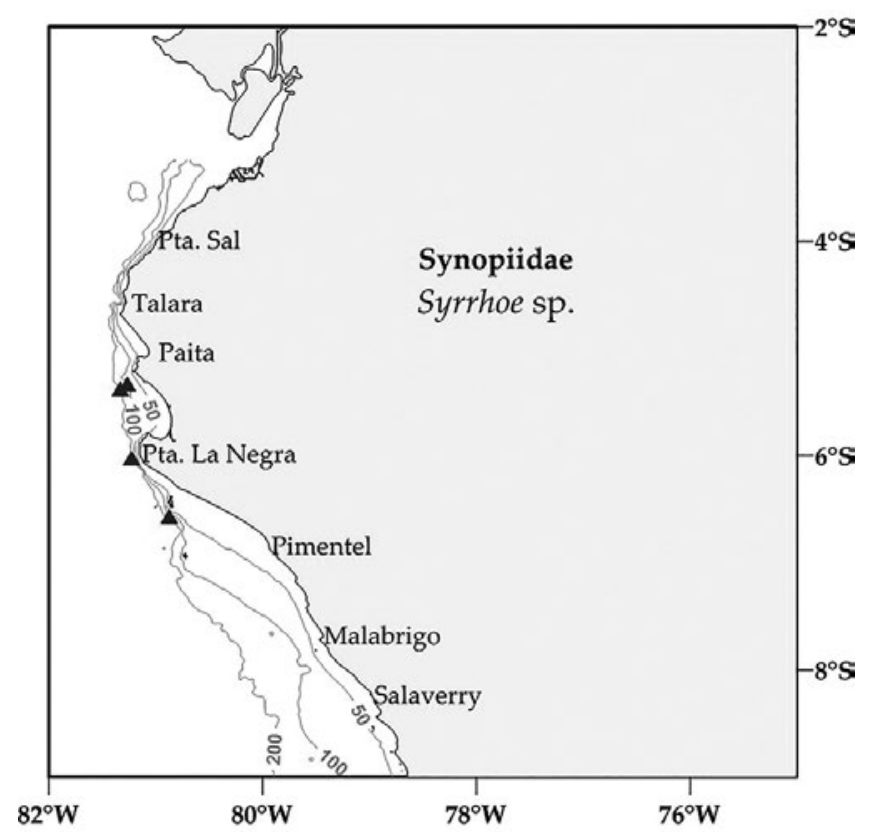

Figura 74. Distribución espacial de Syrrhoe sp. en la plataforma continental centro norte peruana. 
características resultan ser nuevas para el género, por lo que es necesario un mejor análisis futuro a los especímenes encontrados para describirlos como nueva especie.

Referencias: Barnard 1972 (Págs. 52 - 64).

SUBORDEN: SENTICAUDATA LOWRY \& MYERS, 2013 FAMILIA ERIOPISIDAE LOWRY \& MYERS, 2013

\section{Psammogammarus garthi (J.L. Barnard, 1952)}

$$
\text { Figura } 75-77
$$

Diagnosis: cuerpo delgado. Cabeza de igual tamaño igual que el segmento, con lóbulos laterales bien pronunciados y obtusos. Ojos no visibles. Gnatópodos subquelados. Gnatópodo 1, coxa 1 casi rectangular, con borde anterior redondeada; propodio tan largo como el carpo, palma oblicuo, convexo y con bordes de setas, con una espina; dáctilo) delgado, curvado, tan largo como la palma. Gnatópodo 2, carpo pronunciado con un lóbulo setoso basal; propodio largo y elongado, palma sinuosa con un diente medio subagudo, el borde sinuoso con espínulas; dáctilo fuerte, curvado y ajustado a la palma. Pereópodo 7, alargado y frágil por lo que es difícil la preservación de este apéndice, al igual que el urópodo 3 (birrámeo, elongado, con un pedúnculo muy corto, la rama interna mucho más corta que la rama externa). Telson hendido hasta la base, lóbulos anchos, con ápices oblicuos aserrados, cada lóbulo dos espinas y una seta (Figs. 75, 76).

Material examinado: 29 especímenes fueron examinados, de donde un ejemplar hembra fue diseccionado, de la estación C22 (07²8.8'S, 7951'W; 83m), Crucero de Otoño del ańo 2009.

Hábitat: sustrato blando y rocoso (grava).

Profundidad: 38 a $363 \mathrm{~m}$.

Localidades en la plataforma centro norte: $03^{\circ} 42^{\prime} \mathrm{S}$, $80^{\circ} 48^{\prime} \mathrm{W}$ a $07^{\circ} 30^{\prime} \mathrm{S}, 79^{\circ} 54^{\prime} \mathrm{W}$ (Fig. 77).

Distribución geográfica en el mundo: Baja California en ambiente intermareal.

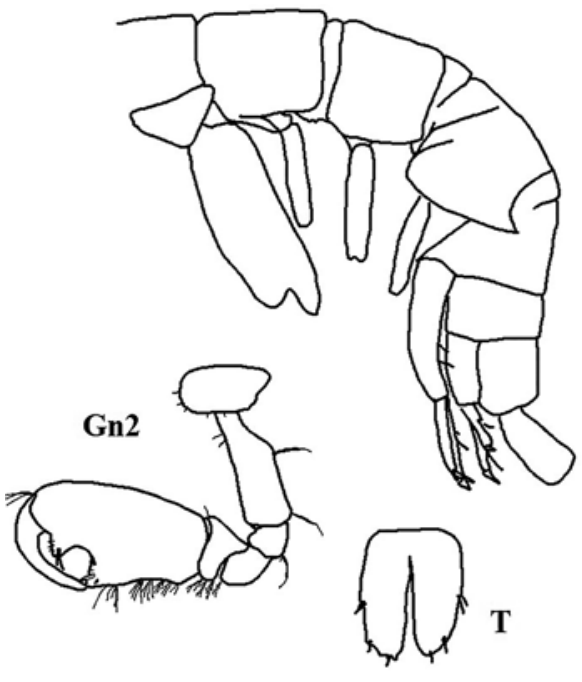

Figura 75. Características taxonómicas de Psammogammarus garthi J.L. Barnard, 1952: Parte posterior del cuerpo, gnatópodo 1 y 2 (Gn1 y 2) y telson (T), según Barnard (1952).
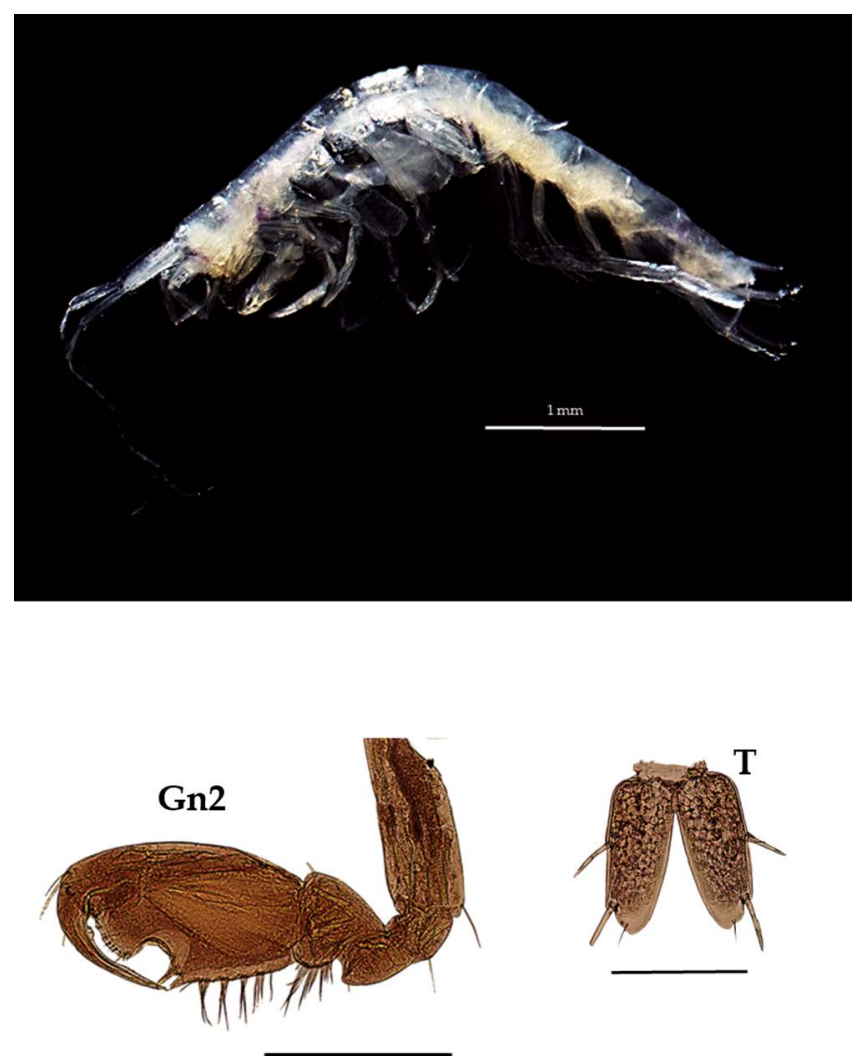

Figura 76. Psammogammarus garthi: gnatópodo $2(\mathrm{Gn} 2)$ y telson (T). Escala: Gn2; 0.5 mm; T: $200 \mu \mathrm{m}$.

Observaciones: Previamente descrita dentro del género taxonómicamente complejo Eriopisa Stebbing, 1890 y revisada por Karaman (1984), donde es introducida dentro del género Psammogammarus S. Karaman, 1955.

Referencias: Barnard 1952, Karaman 1984.

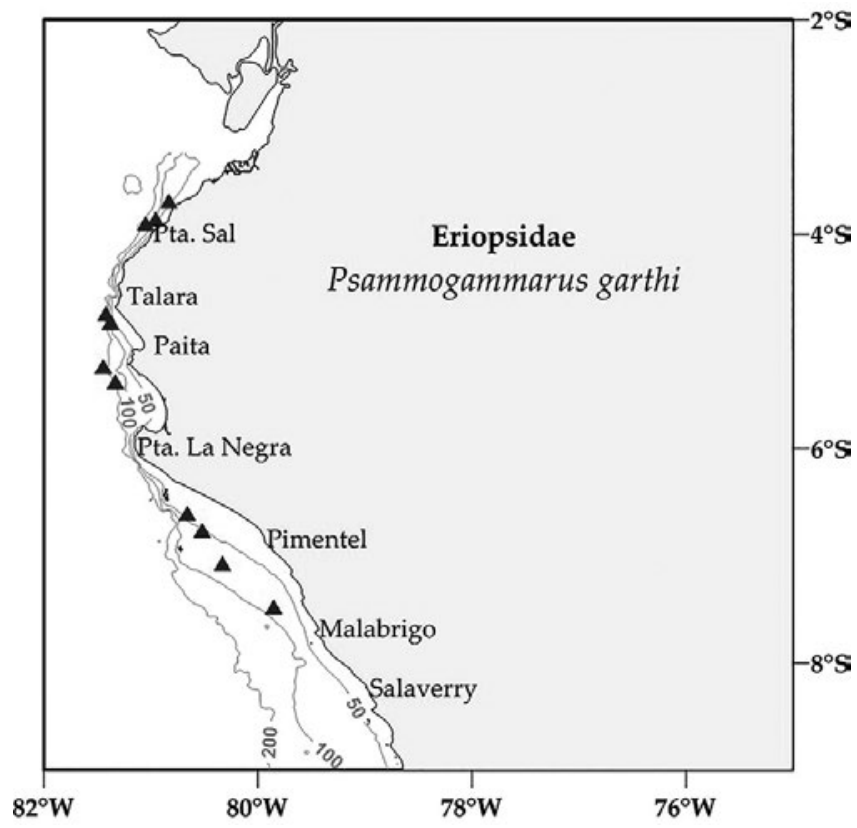

Figura 77. Distribución espacial de Psammogammarus garthi en la plataforma continental centro norte peruana. 


\section{Familia Photidae Boeck, 1871}

\section{Photis sp.}

Figura $78-80$

Diagnosis: Ojos pigmentados redondeados. Dimorfismo sexual observado en la forma de los gnatópodos. Gnatópodo 1 (macho) con artejo 2 ancho; artejo 5 más corto que el artejo 6, margen posterior estrecho y lobado; palma del artejo 6 cóncavo. Gnatópodo 2 (macho) presenta un artejo 6 robusto, transverso, con dientes agudos extendidos hacia el artejo 7 , sobre la palma; artejo 7 grueso. Gnatópodo 1 (hembra) simple, artejo 6 con palma expandida, con esquina poco definida. Gn2 (hembra), artejo 6 con palma débilmente escalonada o simple. Urópodo 3 birrámeo, con una de las ramas muy pequeña en relación a la otra. Telson entero, en forma triangular (Figs. 78, 79).

Material examinado: 31 especímenes fue examinados, de donde un ejemplar macho y una hembra (para Gnatópodo 2) fueron diseccionados de la estación C $48\left(05^{\circ} 30^{\prime} \mathrm{S}, 81^{\circ} 00^{\prime} \mathrm{W}, 44\right.$ $\mathrm{m})$, del Crucero de Otoño del año 2004.

Hábitat: fondo areno fangoso.

Profundidad: 37 a 309 m.

Localidades en la plataforma centro norte: $03^{\circ} 30^{\prime} \mathrm{S}$, $80^{\circ} 42^{\prime} \mathrm{W}$ a $06^{\circ} 54^{\prime} \mathrm{S}, 80^{\circ} 48^{\prime} \mathrm{W}$ (Fig. 80).

Distribución geográfica en el mundo: el género Photis es cosmopolita (Barnard 1962a). Conlan (1983) realizó una revisión de las especies para el Pacífico Norte.

Observaciones: este género es comúnmente encontrado en ambiente intermareal o asociado a comunidades de macroalgas marinas; pero también los podemos encontrar en fondos blandos, como en esta investigación. En cuanto a la determinación de las especies, esta se ve limitada por que son polimórficos a través de los diversos estados de desarrollo, tanto en hembras como machos, lo que hace compleja la identificación específica.

Referencias: Barnard 1962a, Conlan 1983.

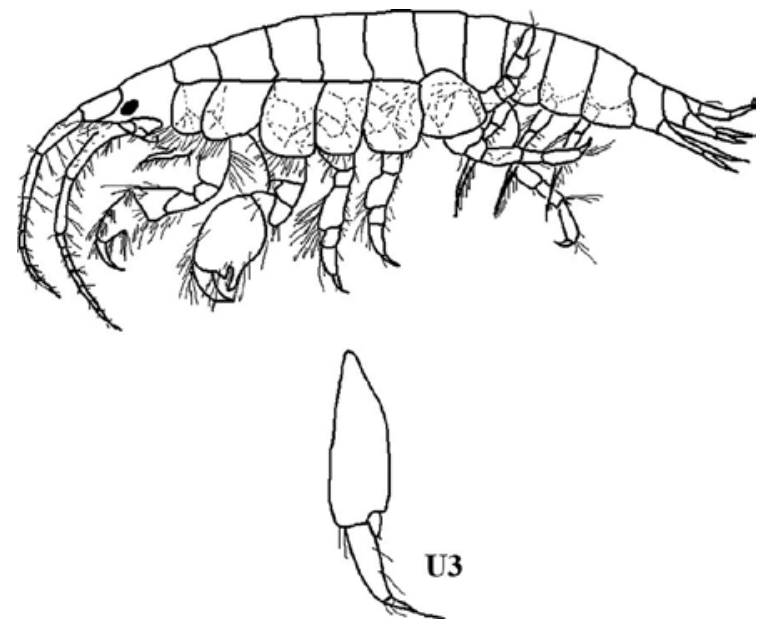

Figura 78. Características taxonómicas de Photis porvidons con semejanzas con los ejemplares de Photis sp.: Habitus, gnatópodo 1 y 2 ( $\mathrm{Gn} 1$ y 2 ) de hembra y macho, urópodo 3 (U3) y telson (T), según Conlan (1983).
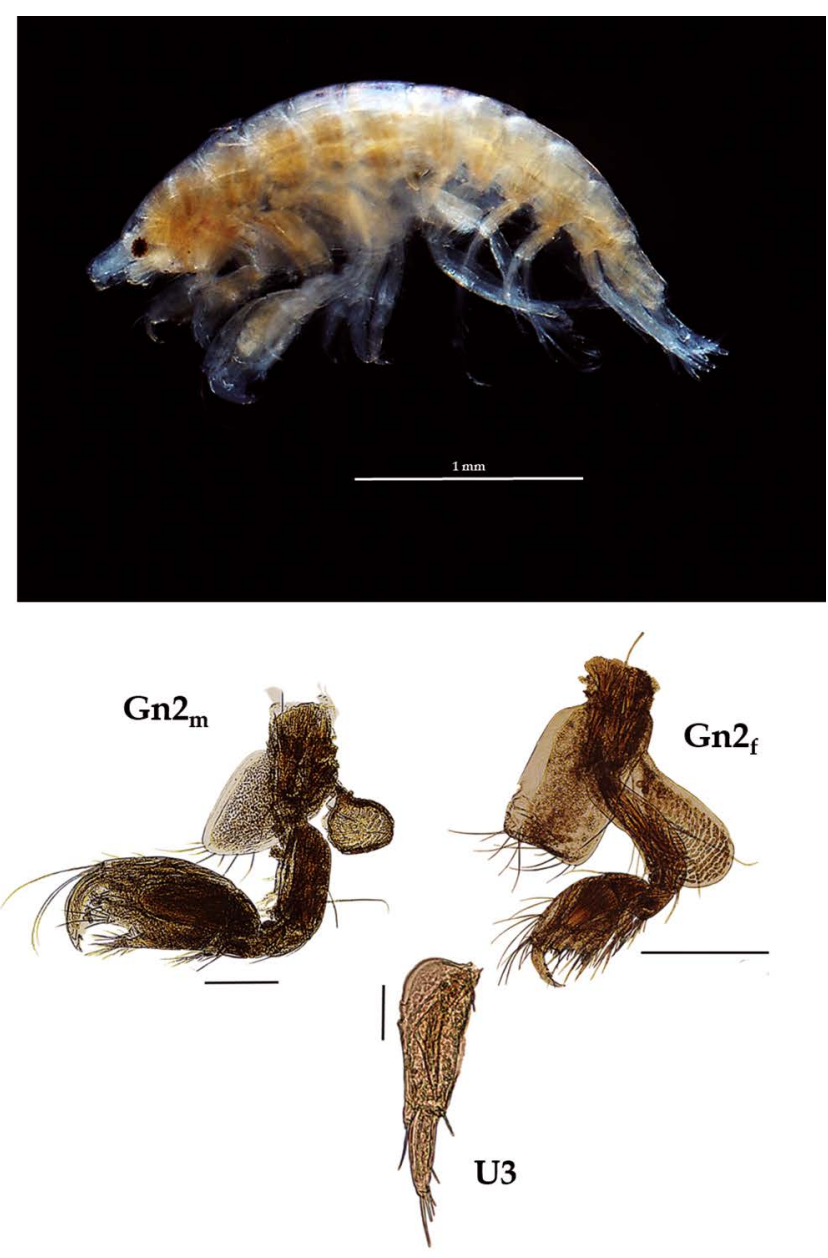

Figura 79. Photis sp.: gnatópodo 2 de macho y hembra $\left(\mathrm{Gn} 2_{\mathrm{m}}\right.$, $\mathrm{Gn} 2_{\mathrm{f}}$ ), urópodo 3 (U3). Escala: $\mathrm{Gn} 2: 0.5 \mathrm{~mm}$; U3: $25 \mu \mathrm{m}$.

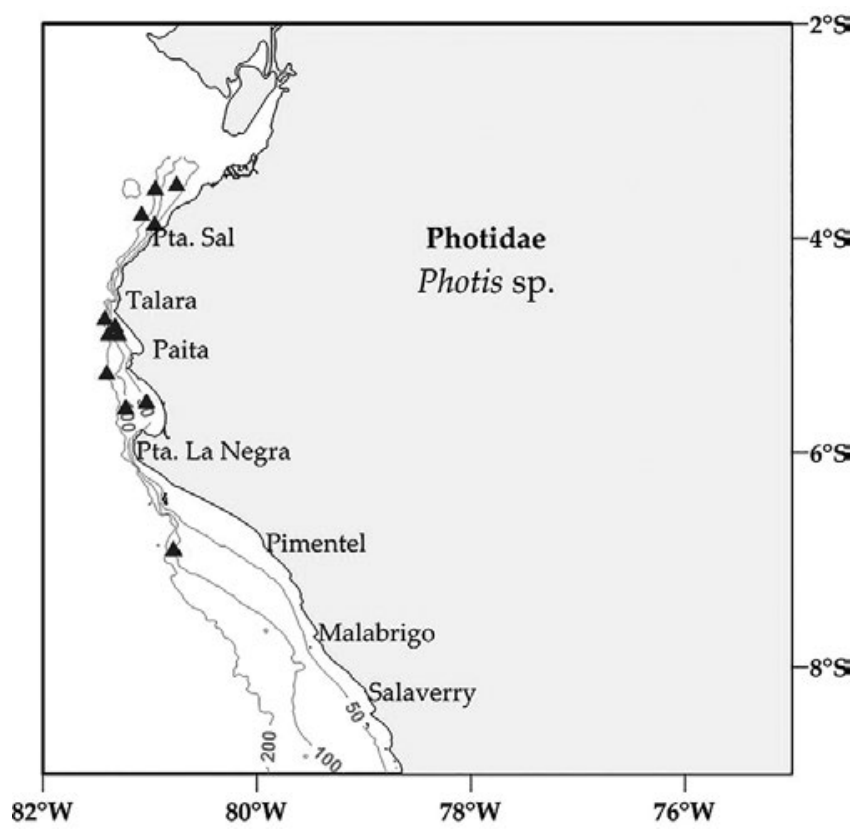

Figura 80. Distribución espacial de Photis sp. en la plataforma continental centro norte peruana. 


\section{Gammaropsis sp.}

Figura $81-83$

Diagnosis: Ojos pigmentados de forma reniforme. La cabeza presenta lóbulos pronunciados. Gnatópodos simples; gnatópodo 2 presenta el artejo 6 ovado y setoso (más largo que el artejo 5), palma oblicua, con un artejo 7 proyectado hacia el carpo. Urópodo 3 birrámeo con ramas subiguales. Placa epimeral 3 con borde posterior aserrado y con presencia de setas. Telson entero, truncado pero con dos esquinas prolongada, cada esquina con 2 setas (Figs. 81, 82).

Material examinado: 11 especímenes fueron examinados, de donde un ejemplar hembra fue diseccionado, de la estación C26 (04²'’ S, 81²4'W; 68 m.), del Crucero de Otońo del año 2005.

Hábitat: en diferentes, mayormente a profundidades someras.

Profundidad: 37 a $220 \mathrm{~m}$.

Localidades en la plataforma centro norte: $04^{\circ} 12^{\prime} \mathrm{S}$, $81^{\circ} 12^{\prime} \mathrm{W}$ a $04^{\circ} 48^{\prime} \mathrm{S}, 81^{\circ} 18^{\prime} \mathrm{W}$ (Fig. 83).

Distribución geográfica en el mundo: Cosmopolita, Conlan (1983) realizó una revisión de las especies para el Pacífico Norte (Baja California).

Observaciones: el género Gammaropsis es actualmente uno de los grupos más complejos en la identificación, debido a las variaciones morfológicas entre machos y hembras, y lo más importante que durante el crecimiento, ya que los juveniles pueden presentar diferentes características al llegar a la etapa adulta.

Referencias: Barnard 1962a, Conlan 1983.
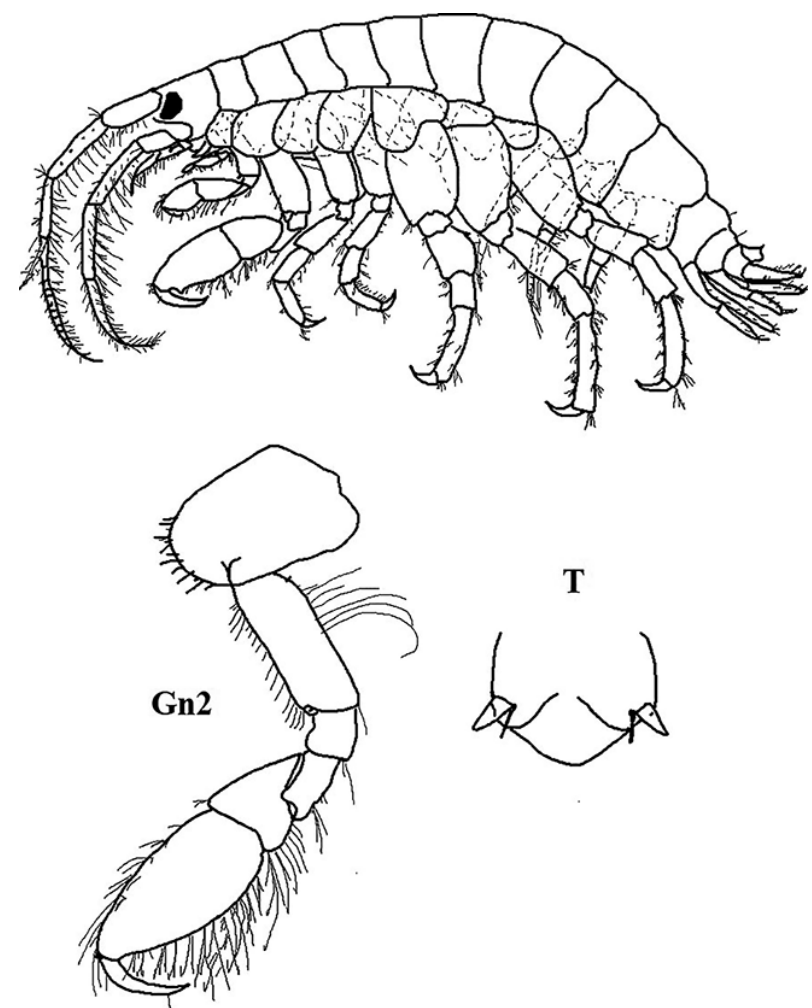

Figura 81. Características taxonómicas de Gammaropsis ellisi Colan, 1983, con similitudes con la especie Gammaropsis sp.: Habitus, Gnatópodo 2 (Gn2), telson (T), según Conlan (1983).
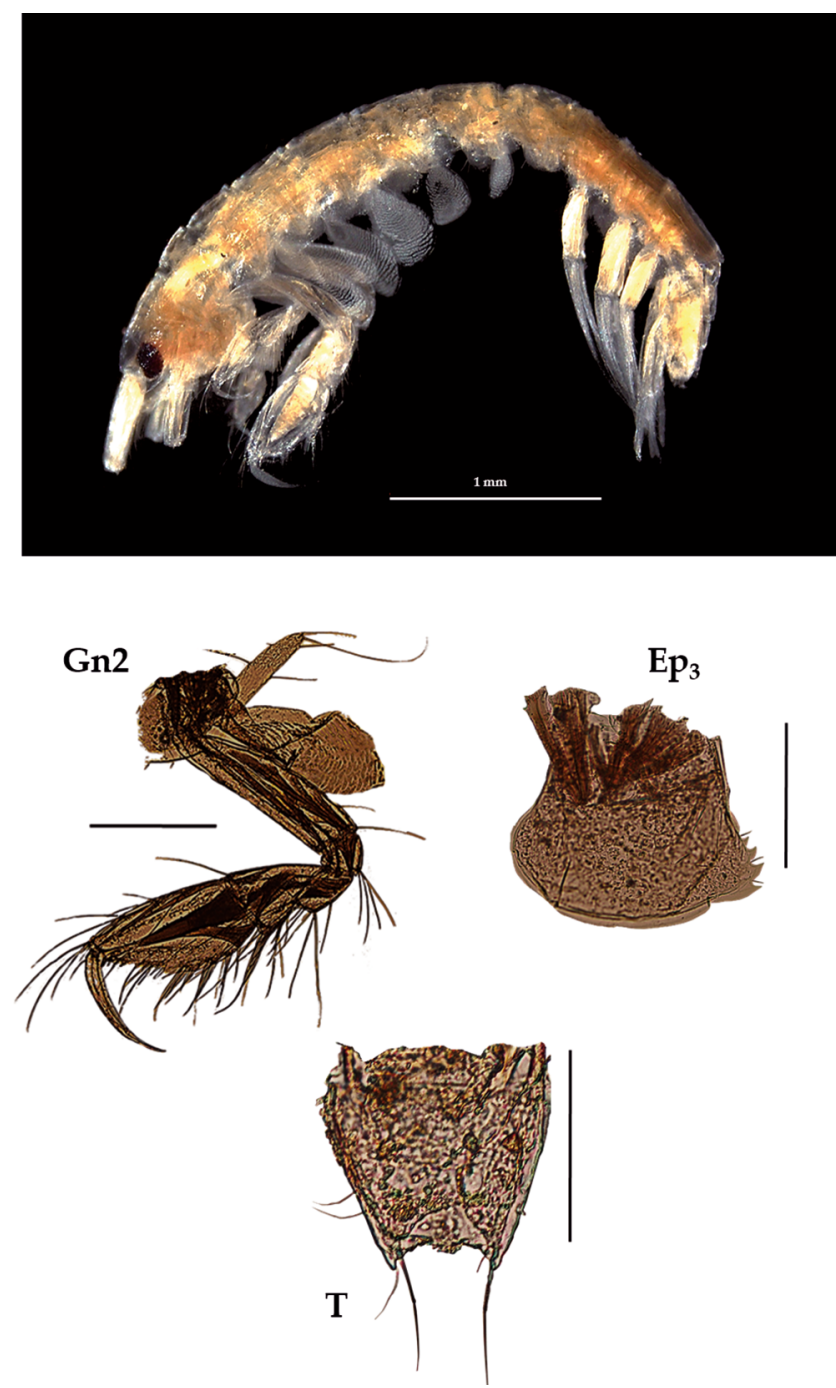

Figura 82. Gammaropsis sp. : Gnatópodo $2(\mathrm{Gn} 2)$, placa epimeral 3 (Ep3) y telson (T). Escala: Gn2: 0.5 mm; Ep3: 250 $\mu \mathrm{m} ; \mathrm{T}: 100 \mu \mathrm{m}$.

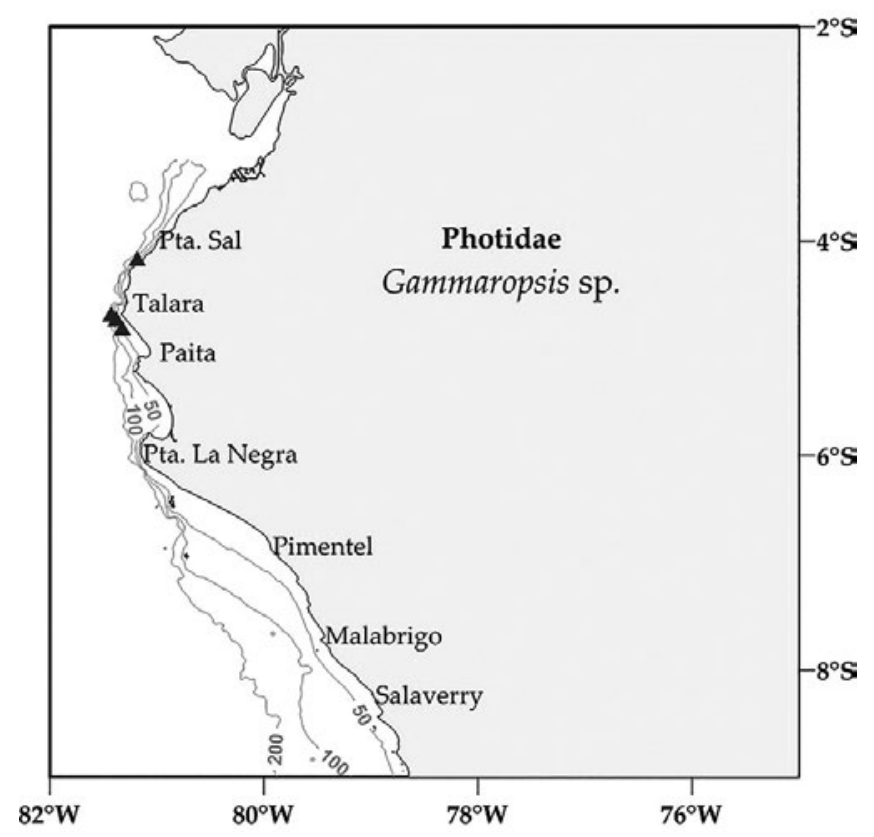

Figura 83. Distribución espacial de Gammaropsis sp. en la plataforma continental centro norte peruana. 


\section{FAMILIA CAPRELLIDAE LEACH, 1814}

\section{Caprella sp.}

Figura $84-86$

Diagnosis: Cabeza redondeada (sin rostro alargado), ojos bien desarrollados. Gnatópodo 1 con el artejo 2 alargado, más que la longitud del artejo 3 y 5; artejo 6 alargado de forma triangular, palma con setas alargadas y pequeñas; artejo 7 (dáctilo) alargado, curvado, margen ventral con setas. Gnatópodo 2, artejo 2 delgado y más largo que el artejo 3, 4 y 5; artejo 6 ovado, elongado, tan largo como el artejo 2; espina en el margen ventral inferior, seguida de una serie de setas pequeñas y grandes en la palma; artejo 7 curvado, con pequeńas setas ventrales. Branquias sobre los pereonitos III y IV. Ausencia de los pereópodo 3 y 4 (Figs. 84, 85).

Hábitat: sustrato fangoso.

Material examinado: cuatro (04) especímenes fueron examinados y un ejemplar hembra fue diseccionado, de la estación C39 (05 ${ }^{\circ} 10.2^{\prime}$ S, 81 $\left.1^{\circ} 14.4^{\prime} \mathrm{W} ; 90 \mathrm{~m}\right)$, Crucero de Otońo del año 2016.

Profundidad: 44 a $128 \mathrm{~m}$.

Localidades en la plataforma centro norte: $05^{\circ} 24^{\prime} \mathrm{S}$ $81^{\circ} 18^{\prime} \mathrm{W}$ a $05^{\circ} 42^{\prime} \mathrm{S} 81^{\circ} 06^{\prime} \mathrm{W}$ (Fig. 86).

Distribución geográfica en el mundo: Género cosmopolita, comúnmente reportado en ambientes someros y asociados a macroalgas.

Observaciones: Pocas especies de profundidad y fondo blando han sido descritas por la dificultad en la toma de muestra (Hendrickx \& Ayón-Parente 2014). Los especímenes encontrados no presentaron la parte anterior o ciertos apéndices necesarios para llegar a un nivel más específico.

Referencias: Arimoto 1976, Hendrickx \& Ayón-Parente 2014 .

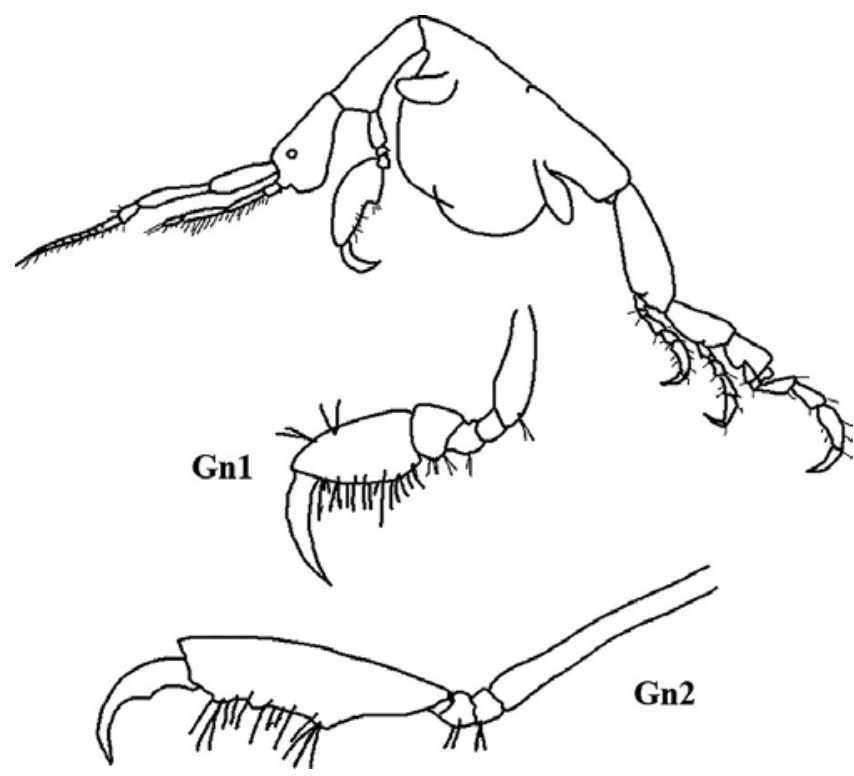

Figura 84. Anatomía de una especies de Caprellidae: Caprella decipiens Mayer, 1890, Habitus, Gnatópodo 1 y 2 (Gn1 y 2, Arimoto 1976).
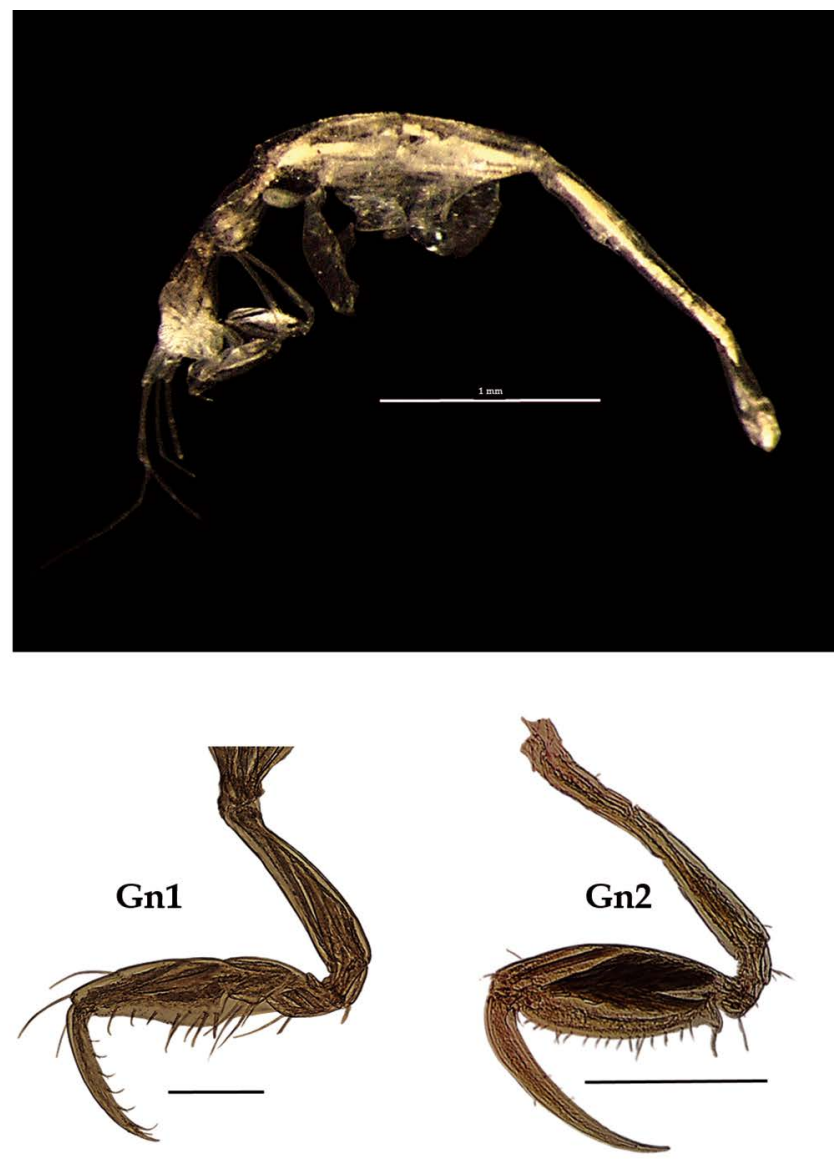

Figura 85. Caprella sp.: Gnatópodo 1 y 2 (Gn1 y Gn2). Escala: $100 \mu \mathrm{m}$

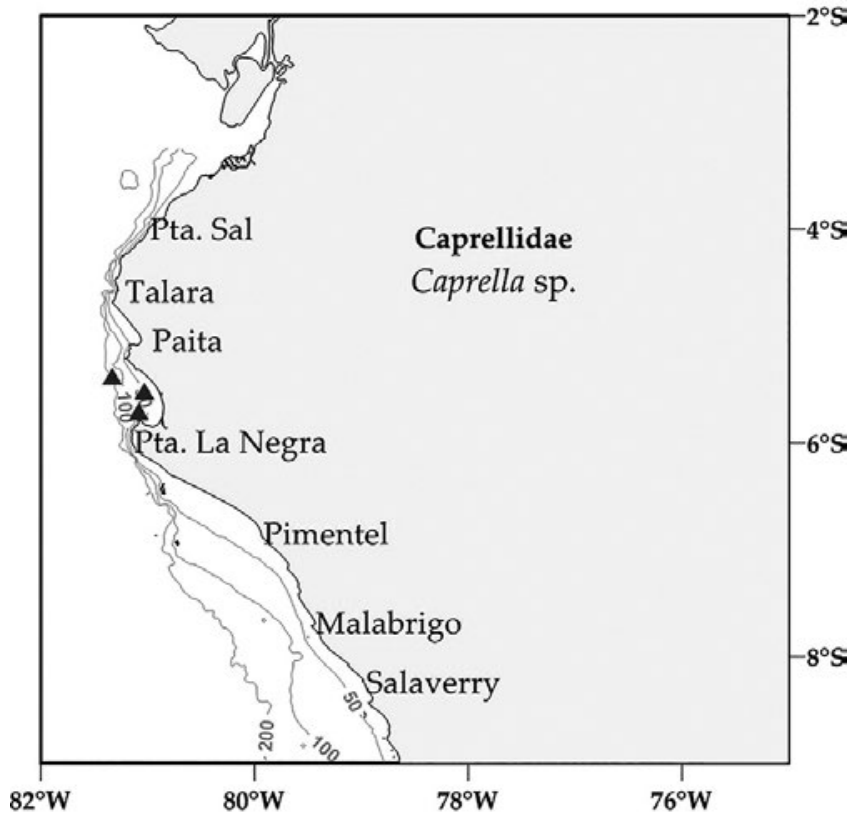

Figura 86. Distribución espacial de Caprella sp. en la plataforma continental centro norte peruana. 


\section{Discusión y conclusión}

Este estudio determinó 28 taxa de anfípodos bentónicos; con veinte (20) taxa a nivel de especie y ocho (8) a nivel de género (Tabla 1). Diversos estudios taxonómicos y ecológicosoceanográficos en la plataforma continental peruana, evidenciaron que del total de especies, ocho (8) han sido reportadas para esta zona del océano Pacífico (Frankenberg \& Menzeis 1968, Salzwedel et al. 1988, Gutiérrez 1989, Gutiérrez et al. 2008, García-Madrigal 2007).

Asimismo, en el Perú, la escasa información sobre la composición real de las especies de anfípodos bentónicos ha sido evidenciado en listados e inventarios generales de especies del invertebrados bentónicos (Del Solar et al. 1970, Paredes et al. 1988) y en estudios ecológicos, los cuales han sido poco difundidos. Unido a la falta de especialistas para describir adecuadamente las especies bentónicas del mar peruano. En la presente investigación, se reporta catorce (14) nuevos registros (Dickinson 1982, Barnard 1954, Jarrett \& Bousfield 1994, Hendrycks com. pers. 2017) (Tabla 2) y cinco (5) nuevas especies (Barnard 1960, Dickinson 1982, Bousfield \& Chevrier 1996) para descripciones taxonómicas futuras, distribuidos en todo el área de estudio; por lo que esta publicación aporta considerablemente al conocimiento sobre la taxonomía, hábitat y distribución de las especies de anfípodos bentónicos en el ecosistema de afloramiento costero peruano.

\section{Agradecimientos}

Este estudio es una contribución del grupo de investigadores del Laboratorio Bentos Marino del IMARPE. Agradecemos a los laboratorios de la Dirección General de investigaciones en Oceanografía y Cambio Climático del Instituto del Mar del Perú (Laboratorio Funcional de Producción Primaria y Laboratorio de Zooplancton y Producción Secundaria). Al Dr. Oliver Coleman por las enseńanzas y conocimiento transmitido a fin de mejorar este trabajo.

\section{Literatura citada}

Arimoto, I. 1976. Taxonomic studies of Caprellids (Crustacea, Amphipoda, Caprellidae) found in the Japanese and adjacent waters. Seto Marine Biological Laboratory, 1-229.

Barnard J.L. 1952. A new species of amphipod from Lower California (genus Eriopisa). Pacific Science, VI (4), 295-299.

Barnard J.L. 1954. Amphipoda of the Family Ampeliscidae Collected in the Eastern Pacific Ocean by the Velero III and Velero IV. Allan Hancock Pacific Expeditions, 18, 1-137.

Barnard J.L. 1959. Liljeborgiidae amphipods of Southern California Coastal Bottoms with a revision of the family. Pacific Naturalist, 1(3-4), 12-28.

Barnard J.L. 1960. The amphipod family Phoxocephalidae in the eastern Pacific Ocean with analyses of other species and notes for a revision of the family Allan Hancock Pacific Expeditions, 18(3): 175-368.

Barnard J.L. 1962a. Benthic Marine Amphipoda of southern California: families Aoridae, Photidae, Ischroceridae, Corophiidae, Podoceridae. Pacific Naturalist, 3, 1-72.

Barnard J.L. 1962b. Benthic marine Amphipoda of Southern California: families Amphilochidae, Leucothoidae, Stenothoidae, Argissidae, Hyalidae. Pacific Naturalist, 3, 116-163.

Barnard J.L. 1962c. Benthic Marine Amphipoda of Southern California: Family Oedicerotidae. Pacific Naturalist, 3, 351-371.

Barnard J.L. 1964. Marine Amphipoda of Bahia San Quintin, Baja California. Pacific Naturalist, 4(3), 58-77.

Barnard J.L. 1966. Benthic Amphipoda of Monterey Bay, California. Proceedings of the United States National Museum, 119(3541), 1-41.
Barnard J.L. 1972. A review of the family Synopiidae (=Tironidae), mainly distributed in the deep sea (Crustacea: Amphipoda). Smithsonian Contributions to Zoology, (124), 1-94. http://doi.org/10.5479/si.00810282.124

Karaman G.S. 1984. Revision of Eriopisa-complex of genera (Gammaridea) (Contribution to the knowledge of the Amphipoda 139). Poljoprivreda i Sumarstvo, 30, 39-72.

Barnard, J.L. \& G.S Karaman. 1991. The Families and Genera of Marine Gammaridean Amphipoda (Except Marine Gammaroids) Records of the Australian Museum, 13(1y2): 1-866. http://doi.org/10.3853/j.0812-7387.13.1991.91

Barnard, J. L. \& M. M. Drummond 1982. Gammaridean Amphipoda of Australia, Part V: Superfamily Haustorioidea. Smithsonian Contributions to Zoology, (360), 1-148. http://doi.org/10.5479/si.00810282.360

Barnard, J. L. \& R. R. Given. 1960. Common Pleustid Amphipods of Southern California with a Projected Revision of the Family. Pacific Naturalist, 1(17), 37-48.

Barnard, J.L. \& J.D. Thomas. 1983. The Platyischnopidae of the Americas (Crustacea: Amphipod). Smithsonian contributions to Zoology, 375: 1-33.

Bellan-Santini, D. 2006. Rhachotropis species (Crustacea: Amphipoda: Eusiridae) of hydrothermal vents and surroundings on the Mid-Atlantic Ridge, Azores Triple Junction zone. Journal of Natural History, 40(23-24), 1407-1424. http://doi.org/10.1080/00222930600956809

Bousfield E.L. 1970. Adaptive Radiation in Sand-Burrowing Amphipod Crustaceans. Chesapeake Science 11 (3): 143-54. https://doi.org/10.2307/1351237.

Bousfield E.L. 1973. Shallow-water Gammaridean Amphipoda of New England. Ithaca, Cornell University Press, 312p.

Bousfield, E. L. \& E. A. Hendrycks. 1994. A revision of family Pleustidae (Amphipoda: Gammaridea) Part I. Systematics and biogeography of component subfamilies. Amphipacifica, I (1), 17-57.

Bousfield, E. L. \& E. A. Hendrycks. 1995. The Amphipod Superfamily Eusiroidea in the North American Pacific Region. I. Family Eusiridae: Systematics and Distributional Ecology. Journal of Systematic Biology, 1(4).

Bousfield, E. L. \& A. Chevrier 1996. The amphipos family Oedicerotidae on the Pacific coast of North America. I. The Monoculodes \& Synchelidium generic complexes: Systematics and distributional ecology. Amphipacifica, II(2), 75-148.

Carrasco, F. \& D. Arcos. 1984. Life history and production of a cold-temperate population of the sublittoral amphipod Ampelisca araucana. Marine Ecology Progress Series, 14, 245-252. http://doi.org/10.3354/meps014245

Chapman J.W. 2007. Amphipoda. In Carlton JT (ed) The Light and Smith manual: intertidal invertebrates from Central California to Oregon, 4th edn. University of California Press, Berkeley, CA, pp. 545-618.

Conlan, K. E. 1983. The Amphipod Superfamily Corophioidea in the Northeastern Pacific Region. Canada National Museum of Natural Sciences Publications in Natural Sciences, (4), 1-75.

Corrigan L.J., T. Horton, H. Fotherby, T.A. White \& A.R. Hoelzel. 2014. Adaptive Evolution of Deep-Sea Amphipods from the Superfamily Lysiassanoidea in the North Atlantic. Evolutionary Biology 41 (1): 154-65. https://doi. org/10.1007/s11692-013-9255-2.

De Broyer, C. 1984. Evolution du Complexe Orchomene BOECK (Amphipoda, Lysianassidae). Annales de la Société Royale Zoologique de Belgique, 114(1), 197-198.

De Broyer C. 1985. Notes les Orchemene de l'Océan Austral. 3. Révision d'Orchomenella acanthura (Schellenberg) (Crustace Amphipoda: Lysianassoidea. Journal of Natural History, 19, 729-738.

Del Solar E., F. Blancas \& R. Mayta. 1970. Catálogo de Crustáceos del Perú. Miranda, Lima: 53 pp.

Dickinson J.J. 1982. The Systematics and Distributional Ecology of the family Ampeliscidae (Amphipoda: Gammaridea) in the Northeastern Pacific Region I. The genus Ampelisca. National Museum of Natural Sciences, Ottawa, Canada, 1-39. 
Dickinson J.J. 1983. The systematics and distributional ecology of the superfamily Ampeliscoidea (Amphipoda: Gammaridea) in the Northeastern Pacific region. II. The genera Byblis and Haploops. National Museum of Natural Sciences, (1), 1-38.

Frankenberg D. \& Menzies R.J. 1968. Some quantitative analyses of deep-sea benthos off Peru. Deep Sea Res Oceanogr Abstr. 15(226):623-6.

García-Madrigal S. 2007. Annotated checklist of the amphipods (Peracarida: Amphipoda) from the tropical eastern Pacific. Contributions to the study of East-Pacific crustaceans, 4(2), 63-195

Gallardo A. 1962. Descripción de una nueva especies de Ampelisca (Amphipoda). Gayana (Concepción), 7, 11.

Griffiths C.L. 1976. Guide to the Benthic marine amphipods of Southern Africa. (South African Museum, Ed.).

Gutiérrez D. 1989. Macrozoobentos de dos áreas de la Plataforma Continental del Norte Peruano en el verano de 1987. Tesis para optar el título de Biólogo en la Universidad Nacional Agraria La Molina. 116pp. Perú.

Gutiérrez D., K. Aronés, F. Chang, L. Quipúzcoa \& P. Villanueva. 2005. Impacto de la variación oceanográfica estacional e inter-anual sobre los ensambles de microfitoplancton, mesozooplancton, ictioplancton y macrozoobentos de dos áreas costeras del norte del Perú entre 1994 y 2002. Bol. Inst. Mar Perú 22(1-2).

Gutiérrez D., E. Enríquez, S. Purca, L. Quipúzcoa, R. Marquina, G. Flores \& M. Graco. 2008. Oxygenation episodes on the continental shelf of central Peru: Remote forcing and benthic ecosystem response. Progress in Oceanography, 79(2-4), 177-189. http://doi.org/10.1016/j. pocean.2008.10.025

Hendrycks E.A. \& E.L. Bousfield. 2004. The amphipod family Pleustidae (mainly subfamilies Mesopleustinae, Neopleustinae, Pleusymtinae and Stenopleustinae) from the Pacific coast of North America: systematics and distributional ecology. Amphipacifica, 3(4), 45-114.

Hendrickx M.E. \& M. Ayón-Parente. 2014. Two new species of deep-water Caprella (Peracarida, Amphipoda, Caprellidae) from the Pacific coast of Mexico collected during the talud XIV cruise, with a checklist of species of caprellidae recorded for the Eastern Pacific. Crustaceana, 87(1), 4163. http://doi.org/10.1163/15685403-00003277

Jansen T. 2002. A taxonomic revision of Westwoodilla Bate, 1862 (Crustacea: Amphipoda), including descriptions of two new species. Steenstrupia, 27, 83-136.

Jarrett N.E. \& E.L. Bousfield. 1994. The amphipod superfamily Phoxocephaloidea on the Pacific Coast of North America. Family Phoxocephalidae. Part II. Subfamilies Pontharpiniinae, Parharpiniinae, Brolginae, Phoxocephalinae, and Harpiniinae. Systematics and distributional ecology. Amphipacifica, I(2), 70-150. http://doi.org/10.1016/ S0022-0981(97)00036-1

Jiménez A. 2018. Variación espacial de la diversidad de anfípodos bentónicos en la plataforma continental centro-norte del Perú $\left(3.4^{\circ}-9^{\circ} \mathrm{S}\right)$, en los otońos de 2004 a 2010 . Tesis para optar el grado de Biólogo. Facultad de Ciencias Biológicas, Nacional Mayor de San Marcos. p.96. http://biblioimarpe.imarpe.gob.pe:8080/handle/123456789/3169

Karaman G. S. 1980. Revision of genus Idunella Sars with description of new species, I. sketi, n. sp. (Fam. Liljeborgiidae). Acta Adriatica, 21(2), 409-435.

Krapp-Schickel T. 2006. New Australian Stenothoids (Crustacea, Amphipoda) with key to all Stenothoe species. Bollettino del Museo Civico di Storia Naturale di Verona, 30 (august 1981), 39-56.

Lincoln R. 1979. British marine Amphipoda: Gammaridea. Natural History Museum Publications. 657pp.

Lorz A. 2010. Deep-sea Rhachotropis (Crustacea : Amphipoda : Eusiridae) from New Zealand and the Ross Sea with key to the Pacific, Indian Ocean and Antarctic species. Zootaxa, 48(May), 22-48. http://doi.org/10.11646/ zootaxa.3995.1.11
Lowry J.K. \& A.A. Myers. 2013. A Phylogeny and Classification of the Senticaudata subord. nov. Crustacea: Amphipoda). Zootaxa, 3610(1), 1-80. http://doi.org/10.11646/zootaxa.3610.1.1

Lowry J.K. \& A.A. Myers. 2017. A phylogeny and classification of the amphipoda with the establishment of the new order Ingolfiellida (Crustacea: Peracarida). Zootaxa, 4265(May), 1-89.DOI: http://doi.org/10.11646/zootaxa.4265.1.1

Lowry J.K. \& H E. Stoddart. 1994. Crustacea Amphipoda: Lysianassoids from the tropical western South Pacific Ocean. Memoires du Museum National d'Histoire Naturelle, 12(161), 127-223.

Macdonald III K.S., L. Yampolsky \& J.E. Duffy. 2005. Molecular and morphological evolution of the amphipod radiation of Lake Baikal. Molecular Phylogenetics and Evolution 35 (2): 323-43. https://doi.org/10.1016/j. ympev.2005.01.013.

Martin J.W. \& G.E. Davis. 2001. An update classification of the recent Crustacea. Natural History Museum of Los Angeles County. Science Series 39: 1-124.

Mayor S. 1996. Las comunidades bénticas entre los $03^{\circ} \mathrm{y} 09^{\circ} \mathrm{S}$ en mayo de 1995. (Cr. BIC SNP-1, 9505-06). Inf. Inst. Mar Perú, 117: 61-71. Perú.

Moore S. E., J. M. Grebmeier, \& J. R Davies. 2003. Gray whale distribution relative to forage habitat in the northern Bering Sea: current conditions and retrospective summary. Canadian Journal of Zoology, 81(4), 734-742. http:// doi.org/10.1139/z03-043

Myers A. A. \& J. K. Lowry. 2003. A Phylogeny and a New Classification of the Corophiidea Leach, 1814 (Amphipoda). Journal of Crustacean Biology, 23(2), 443-485.

Oliver J.S., P.N. Slattery, M. A. Silberstein \& E. F. O'Connor. 1984. Gray whale feeding on dense ampeliscid amphipod communities near Bamfield, British Columbia. Canadian Journal of Zoology, 62(1), 41-49. http://doi.org/10.1139/ z84-009

Paredes C., J. Tarazona, E. Canahuire, L. Romero \& O. Cornejo. 1988. Invertebrados macrobénticos del área de Pisco, Perú. Pp 121-132. Recursos y dinámica del ecosistema de afloramiento peruano, Boletín Inst. Mar Perú-Callao, Vol. Extraordinario: 121-132.

Quipúzcoa L., F. Velazco, H. Castañeda \& R. Marquina. 1998. Estudios de bentos y Sedimentología durante el crucero oceanográfico BIC Humboldt 9706-07. Inf. Prog. Inst. Mar Perú, 79: 17-29. Perú.

Salzwedel H, Flores LA, De Flores EC, Alina Z \& Carbajal G. 1988. Macrozoobentos del sublitoral peruano, antes, durante y después de El Niño 1982-83. Boletín del Inst del Mar del Perú. Volumen Ex:77-98.

Sars G.O. 1890-1895. Amphipoda. An account of the Crustacea of Norway with short descriptions and figures of all the species. Vol. I. Amphipoda.

Shoemaker C.R. 1930. The Amphipoda of the Cheticamp Expedition of 1917. Contributions to Canadian Biology and Fisheries, 5(1), 221-359. http://doi.org/https://doi. org/10.1139/f30-010

Stebbing T.R.R., 1906, Amphipoda I, Gammaridea, Das Tierreich, 21, 806 pp.

Roney J.D. 1990. A New Species of Marine Amphipod (Gammaridea: Ampeliscidae) from the Sublittoral of Southern California. Bull. Southern California Acad. Sci., 89(3), 124-129.

Tam J. 1992. Variación latitudinal del Macrozoobentos del Litoral frente al Norte de Perú, durante el verano de 1987. Tesis para optar el título de Biólogo en la Universidad Nacional Agraria La Molina. 114pp. Perú.

Tarazona J., H. Salzwedel \& W. Arntz. 1988. Oscillations of Macrobentos in shallow waters of the Peruvian central coast induced by El Niño 1982-83. Journal of Marine Research, 46: 593-611.

Thomas J.D. 1993. Biological monitoring and tropical biodiversity in marine environments: a critique with recommendations, and comments on the use of amphipods as bioindicators. Journal of Natural History, 27, 795-806. http:// doi.org/10.1080/00222939300770481 
Thomas J.D. \& J. L Barnard. 1986. New genera and species of the Megaluropus group (Amphipoda, megaluropus) from American Seas. Bulletin of Marine Science, 38(3), 442-476.

Thurston M.H. 1980. Abyssal benthic Amphipoda (Crustacea) from the East Iceland basin. 2. Lepechinella and an allied genus. Bulletin of British Musuem of Natural History, 38(1), 69-87.

Thomas J.D. \& J. L. Barnard. 1983. The Platyischnopidae of America (Crustacea: Amphipoda). Smithsonian Contributions to Zoology, (375), 1-33.
Walker O. 1910. Amphipoda of Marine Peru. Transactions of the Liverpool Biological Society, 25: 67-72.

Wellborn G.A. \& R.E. Broughton. 2008. Diversification on an Ecologically Constrained Adaptive Landscape. Molecular Ecology 17 (12): 2927-36. https://doi.org/10.1111/j.1365-294X.2008.03805.x.

Yupanqui W., L. Quipúzcoa, R. Marquina, F. Velazco \& D. Gutiérrez. 2007. Composición y distribución del macrobentos en la Ensenada de Sechura, Piura, Perú. Revista Peruana de Biología, 14(1), 75-85. 